Portland State University

PDXScholar

Spring 6-5-2017

\title{
African American Teacher Recruitment: a Case Study in Oregon
}

Deborah Miller Allen

Portland State University

Follow this and additional works at: https://pdxscholar.library.pdx.edu/open_access_etds

Part of the African American Studies Commons, and the Teacher Education and Professional Development Commons

Let us know how access to this document benefits you.

\section{Recommended Citation}

Allen, Deborah Miller, "African American Teacher Recruitment: a Case Study in Oregon" (2017).

Dissertations and Theses. Paper 3622.

https://doi.org/10.15760/etd.5514

This Dissertation is brought to you for free and open access. It has been accepted for inclusion in Dissertations and Theses by an authorized administrator of PDXScholar. Please contact us if we can make this document more accessible: pdxscholar@pdx.edu. 
African American Teacher Recruitment:

A Case Study in Oregon

by

Deborah Miller Allen

A dissertation submitted in partial fulfillment of the requirements for the degree of

\author{
Doctor of Education \\ in \\ Educational Leadership: Curriculum and Instruction
}

Dissertation Committee:

Micki M. Caskey, Chair

Dannelle D. Stevens

Samuel Henry

Lindsey Wilkinson

Portland State University

2017 
(C) 2017 Deborah Miller Allen 


\begin{abstract}
The public school teacher population of the United States is predominantly White, while the demographics of P-12 student population continue to grow increasingly diverse. Across the nation, there has been a call for the recruitment and retention of culturally and linguistically diverse teachers. The state of Oregon passed the Oregon Educator Equity Act, originally called the Oregon Minority Teacher Act, in 1991, and with recent renewed attention, the preparation of more culturally and linguistically diverse teachers in the state has gained prominence. Refocused consideration to the lack of diversity in the teaching workforce is overdue, as evidenced by the low numbers of African Americans found in Oregon's teacher workforce. Moreover, the experiences of African American teachers are underexplored. The purpose of this dissertation was to examine the factors that contributed to the successful recruitment of African American teachers, specifically graduates of a teacher pipeline program. Employing an assets-based framework, a qualitative multiple-case design was used; data analyses included open coding of interview data, a constant comparison analysis of individual cases, and cross-case analysis. The predominant themes that contributed to the success of participants in this study included, belonging, accountability, and commitment to equity. While these findings, consistent with much of the literature on achievement of students of color, are not new, this study adds African American teacher voices to the existing research on the diversification of the teacher workforce. Additionally, this dissertation highlights successful efforts made toward recruitment of teachers of color with an Oregon lens.
\end{abstract}




\section{Acknowledgements}

Throughout my years in the doctoral program, I received a lot of support and worked with many incredible people. First, I am eternally grateful to the participants in this study. They spent precious time, entrusting me to share their career journeys. I am ever changed by their stories, and I am confident that their experiences will inspire others, as they have inspired me. I am also indebted to the TPP director for taking time to help me with this study; her kindness and support were indispensable and her long-term advocacy work on behalf of future teachers of color in our region is unparalleled.

Second, I want to thank my committee members for their guidance and recommendations. A special thank you to Dr. Micki Caskey, for agreeing to chair my committee and for not giving up on me; her encouragement, dedication, and wisdom were invaluable. I also want to thank my doctoral student comrades, from my fellow cohort members, whom I spent two years learning with, to the students I met in classes and in the hallway next to my office—generous, intelligent, and passionate scholars. Those include Lisa Dion, Serap Emil, Donna Barrow Green, and many more.

Finally, I am grateful for my loving family and friends, who helped sustain me. My husband, Dave, who was encouraging, supportive, and who listened attentively, no matter whether I was seeking counsel or simply needed him to lend an ear. I am also appreciative of my son, Sawyer, who was patient throughout, even when I was preoccupied with my studies. This journey took much longer than I expected, and I appreciate all of the kindness, care, and patience I received along the way. 
Table of Contents

Abstract.............................................................

Acknowledgements.............................................. ii

List of Tables.......................................................

List of Figures.................................................. vi

Chapter 1: Problem Statement........................................ 1

Background of the Problem................................... 6

Statement of the Research Problem............................... 12

Significance of the Research Problem.............................. 13

Presentation of Methods and Research Questions.................. 15

Definitions of Key Concepts.................................. 16

Summary of Problem Statement.............................. 19

Chapter 2: Literature Review................................... 20

Theoretical and Conceptual Frameworks........................ 21

Review of the Research Literature............................ 32

The value of CLD teachers............................. 33

The educational pipeline.............................. 36

Pre-college socialization and readiness..................... 38

Baccalaureate college achievement..................... 50

Post-baccalaureate success and graduate educator preparation.........................59

Review of Methodological Literature.......................... 73

Summary of the Literature Review............................ 77

Chapter 3: Methods............................................... 80

Research Method: Qualitative Case Study...................... 81

Multiple-Case Design..................................... 85

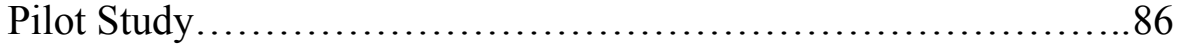

Participants................................................ 86

Procedures and Data Collection................................. 88

Recruitment........................................ 88

Informed consent.................................... 89

Maintaining confidentiality.............................8 89

Data collection instruments..............................90

Role of Researcher............................................ 96

Data and Analysis............................................. 98

Reliability and Validity................................ 100

Summary of Methods.........................................101 


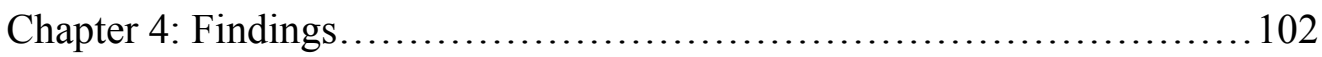

Analysis of Findings............................................ 103

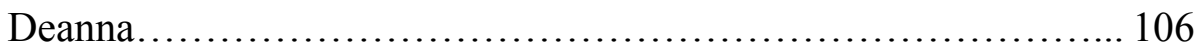

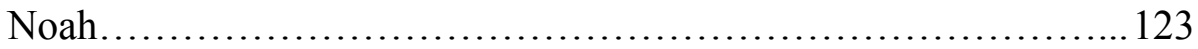

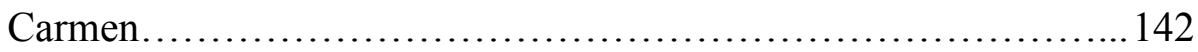

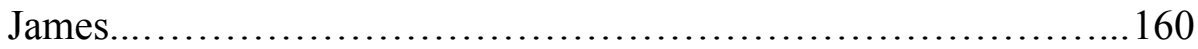

Findings Related to Research Questions..........................179

Research Question 1................................... 179

Research Question 2...................................182

Research Question 3................................. 188

Research Question 4.................................. 194

Limitations of Study ............................................. 200

Summary of Findings.......................................... 201

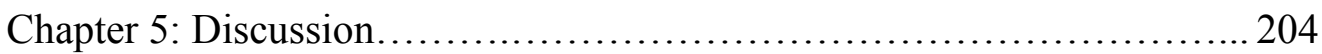

Major Themes Related to Success...............................205

Belonging..............................................206

Accountability.....................................211

Commitment to Equity.....................................215

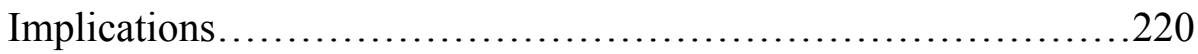

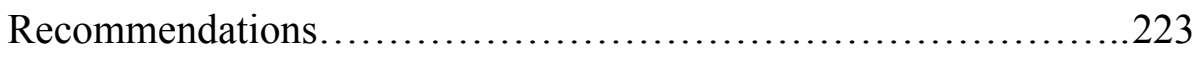

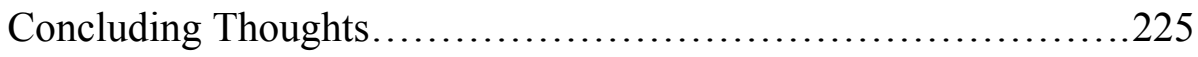

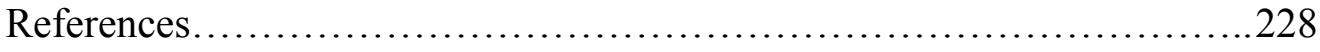

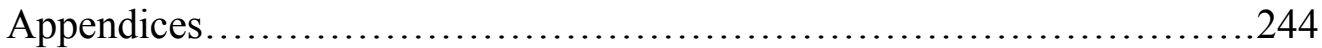

Appendix A Recruitment Documents.............................. 244

Appendix B Informed Consent Form............................... 246

Appendix C Pre-interview Questionnaire..........................247

Appendix D Interview Protocol....................................248

Appendix E Codes Families, Codes, and Subsets......................250 


\section{List of Tables}

Table 1 Percentages of Teachers by Race in the U.S............. 6

Table 2 The Loss of African American Teachers Following Brown v. Board of Education: A Snapshot.................62

Table 3 Alignment of Framework, Research Questions, and Interview Items............................92

Table 4 Sample Participant Responses to RQ4..................... 195 


\section{List of Figures}

Figure 1 Anti-Deficit Achievement Framework.................... 28

Figure 2 African American Teacher Pipeline.........................37 


\section{Chapter 1: Problem Statement}

Our nation's children need and deserve an education that not only maintains high academic standards, but is also welcoming, relevant, and responsive to all learners (Banks, 2004; Gay, 2010; Ladson-Billings, 2009; Villegas \& Lucas, 2004). The cultures and languages found in our U.S. public school classrooms have changed greatly over the past several decades (Achinstein, Ogawa, Sexton, \& Freitas, 2010; Banks, 2004; Clewell \& Villegas, 1998). Developing an educational system that is equitable, culturally responsive, and supportive is critical to ensuring our nations' children become well educated - a necessary foundation to a prosperous and democratic society (DarlingHammond, 2007; Sleeter, 2008; Villegas \& Irvine, 2010). To meet all students' needs, schools must have a critical mass of individuals from varying cultural perspectives included in the dialogue (Gay, 2010; Villegas \& Irvine, 2010). Cultural and linguistically diverse (CLD) teachers' involvement in the design and implementation of learning environments may help shape these environments with inclusion in mind. In our nation, the larger problem is an insufficient number of teachers of color in the workforce (Ingersoll \& May, 2011; National Collaborative on Diversity in the Teaching Force, 2004; Villegas, Strom, \& Lucas, 2012), and specifically in Oregon the number of African Americans choosing to become teachers is particularly low (U.S. Department of Education, 2015).

For several decades, the state of Oregon's governing members have shown awareness to the lack of diversity in the state's teacher workforce, initially evidenced by the state legislature passing the Minority Teacher Act in 1991 Chief Education Office, 2001), which was revised and renamed in 2015 to the Oregon Educator Equity Act (Chief 
Education Office, 2015, 2016). This legislation outlined accountability requirements with the goal of proportionately increasing the percentage of diverse teachers in Oregon to be more similar to the demographic makeup of the state's P-12 student body within a 10-year time frame. Coincidentally, in 1991, the same year that the Minority Teacher Act passed, I moved to Oregon. As a teacher prepared in another state, I applied and earned my Oregon teaching license. At that time it was a difficult economy to find a teaching position in Oregon due to the passage of Measure 5, which had a dramatic impact on the funding of public education (Mapes, 2011). Despite this challenge, I managed to find a position teaching in a progressive school.

As a novice teacher, in my second year of teaching, I was also fortunate to have a mentor. My mentor teacher, Grace (pseudonym), was a veteran in the field with a strong grounding in child development and pedagogical knowledge and a natural ability to provide guided practice and critical feedback in a variety of domains; she was instrumental in helping shape my own teaching philosophies and practices, in-and outside of the classroom. Grace grew up in the metropolitan area and she had been teaching in the profession for many years. She had two young children, one of whom attended the school where we worked. Grace and I co-taught together for four years, and I cannot think of an experience in my 23 -year career as an educator that was more impactful to my personal and professional life.

Grace introduced me to the anti-bias curriculum, she encouraged me to join the Diversity-Equity committee as part of a regional professional association, and she taught me about cultural competence (i.e., the ability to identify and understand students' cultural/ethnic customs and behaviors shaped by their family and social affiliations). The 
students in our school were racially, linguistically, and culturally diverse - a rich teaching and learning environment. Grace was also raising two bi-racial children of her own, and we often spoke about parenting, which provided me with a different point of view, the parent perspective. During those four years, I learned a lot about being a teacher, as is expected of a beginning experience, after all teaching is a profession learned over time, but I also learned about racism, White privilege, and intercultural communication. The more formalized elements of my learning (e.g., curricular texts, conferences, committee work) were key to my foundational understanding and development, but it was the candid conversations, the interruptions of bias, and Grace's willingness to work collaboratively that led to my high quality rigorous induction into the profession of teaching that has stayed with me over the years.

Our first year of teaching together was not without struggles and challenges. I was a single, childless, young White woman who was raised in an upper-middle class home on the other side of the country, and I was still learning about my profession, a new community, and grappling with identity issues. Needless to say, it took some time for us to learn to work together. During that first year, I began to recognize and reflect on the complex configurations embedded in our social system, especially issues around access and oppression; it was often messy, awkward, and emotionally draining work. Our daily interactions, both personal and professional, led me on a journey that I continue to this day. Without those years of careful listening and in-depth communication with a person of color who graciously provided teaching and learning opportunities beyond the classroom curriculum, I might not have gained awareness about my own privilege; I most 
certainly would not have learned as much or as quickly about the challenges faced by people of color.

My early teaching experience shaped my belief in the importance of the interactions we have with others, especially those who bring differing perspectives from our own, in our teaching environment. Our fellow teaching colleagues play an important role in our understandings about formal and informal teaching techniques and strategies. I believe that it is critical to employ a diverse teaching staff for every school, as this can lead to a richer teaching environment for all educators - not to mention the innumerable positive impact on the curriculum and the students and their families in the school. Importantly, I envision an environment where many teachers of color who are not isolated, tokenized, or made to feel as though they speak for an entire race or culture. Further, state Departments of Education, licensing agencies, and school districts in U.S. talk about the importance of induction, and I argue that with this mentorship also comes the critical element of informal social experiences with all of our workplace colleagues. If the nation's educational system does not authentically include CLD teachers, our teachers pay the price of not living and working in a community that mirrors the world outside of our school buildings — or even the demographic makeup of the student body in our classrooms.

Despite state legislators monitoring of the Oregon Educator Equity Report (Chief Education Office, 2016; OEIB, 2014) —which has routinely called attention to the problem of our state's lack of diversity in the teacher workforce in Oregon over the past two decades - the workforce has failed to keep pace with the exponential growth in diversity of our P-12 schools. In addition to Oregon's legislation, national reports 
include data about the diversity in Oregon's teacher pipeline with evidence that illustrates this reality, specifically about educator preparation program enrollment (American Association of Colleges for Teacher Education, 2013; Boser, 2014; U.S. Department of Education, 2015). In the federal data collected from preparation institutions, as part of Title II of the Higher Education Act, the teacher candidate enrollment reported for Oregon showed that the percentage of African Americans in the teacher pipeline was 1\% of all teacher candidates (U.S. Department of Education, 2015). Though there has been some headway made at recruiting and preparing more CLD teachers (Chief Education Office, 2016; Ingersoll \& May, 2011) the dearth of African Americans as teachers in our schools negatively impacts the state of Oregon and the public education system. More can and needs to be done, especially to recruit specific populations where percentages and regional needs warrant a greater and more focused effort.

The purpose of my study was to examine factors that contribute to the successful recruitment of African American teachers in Oregon. I based my findings on the experiences of four African Americans in Oregon who chose a career in teaching while enrolled in a Teacher Pipeline Program (pseudonym, TPP). Success stories, such as these, shed light on strategies that educational leaders and policy makers can apply in future endeavors to recruit and support more African Americans who seek teaching as a career. Ultimately, the study was about four unique individuals - discovering what inspired them and how and why they persisted. A cross-case analysis of their experiences in the pipeline to become teachers provided insight into motivations, supports, networking strategies, and optimal pathways. 


\section{Background of the Problem}

CLD teachers are a rarity in our nation. According to the National Center for Educational Statistics (NCES), $81.9 \%$ of teachers are White; juxtaposed to the data for African Americans that documents that only $6.8 \%$ of our nation's teachers are Black or African American (2015). As shown in Table 1, the percentage distribution of teachers for selected years shows that the percentage of White teachers has declined slightly over the past two decades, $86.5 \%$ in 1991 to $84.3 \%$ in 2000 to $81.9 \%$ in 2012 . Unfortunately, the same is true for African Americans teachers, $8.3 \%$ in 1991 to $7.6 \%$ in 2000 to $6.8 \%$ in 2012. During this time, teachers of color from some other races and/or ethnicities have increased, more true for the Hispanic/Latino population, thus making the decrease of African Americans teachers more notable. As mentioned, the state of Oregon has been well aware of the lack of CLD teachers in the state's workforce and has made attempts to rectify the problem by passing legislation (Chief Education Office, 2016; Governor's Office of Education and Workforce Policy, 2001).

Table 1

Percentages of Teachers by Race in the U.S.

\begin{tabular}{llll}
\hline & 1991 & 2000 & 2012 \\
\hline White & 86.5 & 84.3 & 81.9 \\
Black/African American & 8.3 & 7.6 & 6.8 \\
Hispanic/Latino & 3.4 & 5.6 & 7.8 \\
Asian & 1.0 & 1.6 & 1.8 \\
Pacific Islander & Not Available & Not Available & 0.1 \\
American Indian/Alaska Native & 0.8 & 0.9 & 0.5 \\
Two or more races & Not Available & Not Available & 1.0 \\
\hline
\end{tabular}


The state, however, failed to meet the goal of achieving a diverse teaching workforce in 2001 as outlined in the 1991 legislation. Though the state collected data continually for more than 20 years, it was not until 2013 that the state legislature amended the Minority Teacher Act. The legislature called for specific incremental and time sensitive goals within a short time frame. Since 2013, educational stakeholders in the state have shown continued attention to the issue as evidenced in the 2014 Oregon Minority Teacher Act Status Report (OEIB, 2014), the 2015 Educator Equity Report (Chief Education Office, 2015), and the 2016 Educator Equity Report (Chief Education Office, 2016). The 2016 document also included data on diversity in Oregon's educator workforce which highlighted a slight increase in the numbers of racially diverse teachers candidates enrolled in preparation programs in the state, and reported an anticipated, “...increase in racially diverse candidates enrolling and completing educator preparation programs within the next one to three years" (Chief Education Office, 2016, p. 5).

Oregon is not the only state in our nation that is and has been calling for a more diverse teaching force. In fact, the teacher education community has been making claims about population statistics and rationales for diversifying the profession since the $1980 \mathrm{~s}$ (Case, Shive, Ingebretson, \& Spiegal, 1988; Dilworth, 1990; King, 1993; Spellman, 1988). "The demographic imperative" (Cochran-Smith \& Fries, 2005, p. 41; Dilworth, 1990; McDonald, 2007) or “demographic urgency" (Sleeter \& Milner, 2011, p. 81) was how some referenced the need for teacher workforce diversification. In explaining the essence of the demographic imperative, McDonald (2007) stated:

The demographic imperative characterizes three interlocking challenges that converge on teacher education: 1) the increasing diversity of the students enrolled in U.S. public education; 2) the gap between such students and their teachers in 
terms of their lived experiences; and 3) the disparity in educational outcomes between students of color, low-income students, and their White middle-class peers. (p. 2049)

No matter how it is termed or packaged in national reports, published research, or texts from notable scholars, the issues have remained the same for several decades. As with McDonald's (2007) research, much of what is written about these issues, seems to be stemming from (or pointing to) teacher education preparation programs; the need for preparation programs to deal with the problems of our pervasively White teaching workforce in our growing multicultural and multilingual nation.

In Oregon, as with other states across the nation, the numbers of students of color is increasing. Students of color in Oregon make up over one-third (36.6\%) of the student population, while teachers of color make up less than one-tenth (9.2\%) of Oregon's educator workforce (Oregon Department of Education, 2016). In other words, Oregon's teaching workforce is overwhelmingly White. The population of Black/African American students is relatively small in comparison to other students of color, making up only $2.4 \%$ of the total student population, while the breakdown of teachers who identify as Black/African American is only $0.6 \%$ of the total teacher population in Oregon (ODE, 2016). I find it illuminating to look at teacher data with actual numbers, instead of by percentages. These data indicated that approximately 180 Black/African American worked as teachers throughout Oregon in 2015-2016. One caveat to that number is with consideration to the relatively new "multi-race" descriptor added to the options of racial categories, some African Americans who identify with more than one race may have been counted in that new category, and thus lowering the number self-reported as (solely) African Americans. However, even if all the teachers who identify as multi-race are 
included with those identified as African American, the total number of teachers in Oregon in these two categories combined is approximately 700 , or only $2.3 \%$ of the total Oregon teacher population of over 30,500 (ODE, 2016). In fact, the 2016 Educator Equity Report mentioned that national trends of decreased numbers of African Americans choosing to become teachers is the reality for Oregon as well (Chief Education Office, 2016), potentially lowering those numbers in the coming years.

Recruitment of CLD teacher candidates in university-based teacher preparation programs is an ongoing challenge for many colleges and universities in the U.S. (Achinstein et al., 2010; Lewis, 2006), as well as in Oregon (Chief Education Office, 2016). Many reports have been published by national organizations and associationsincluding reports from the National Education Association (Dilworth \& Coleman, 2014; NEA, 2009), the Center for American Progress (Boser, 2011, 2014; Bireda \& Chait, 2011), the National Association for the Advancement of Colored People (Glenn, 2012) all highlighted the lack of diversity in our nation's teacher workforce and the persistent challenge of recruiting and preparing more teachers of color. While the challenge to recruit more teachers of color is a national concern, recruitment methods have been defined through a regionally (or culturally) specific lens. As noted in a report by the Education Commission of the States (Allen, 2005), “...teacher recruitment and retention are local problems that require locally appropriate solutions" (p. 8). To this end, one of the "model programs" in the state of Oregon recruiting teachers of color to the Oregon workforce is the Teacher Pipeline Program (TPP, pseudonym) (Chief Education Office, 2016). 
The model for the Teacher Pipeline Program (TPP) is not unlike other pathway programs found in Oregon and throughout the nation—all of which typically provide some combination of financial, academic, testing, and personal support structures throughout teacher candidates experiences in their journey (before and during) to earn a teaching license. In a review of successful programs aimed at diversification, Sleeter and Milner (2011) found that some programs “...do not attempt to change teacher education programs but rather to build support systems into, around, and through them" (p. 85). They went on to say that, "Programs to support university students of color typically offer financial and academic support as well as social and cultural support to combat alienation on predominantly White campuses" (p. 85). There is, of course, variation with program design and supports, for example some programs focus recruitment efforts on middle or high school students interested in teaching as a career, while others recruit paraprofessionals or classroom aides who are adults already working in the local school district (Sleeter \& Milner, 2011). Whether a Grow Your Own (GYO) program, where the focus of recruitment is localized and/or an "early recruit" program (e.g., recruitment of middle and high school students), many programs involve partnerships or collaborations with community colleges, other higher education institutions, as well as local school districts. Beyond financial assistance, such as scholarships, many programs include elements that involve mentoring, culturally relevant pedagogy, curriculum that addresses racial identity development, assistance with the navigating college environment, and support with testing requirements (Sleeter \& Milner, 2011).

In the case of the pipeline program in this study, the TPP recruits the majority of students before beginning college or while attending community college. However, there 
are exceptions, such as with some career changers or individuals who have completed some college. The program places an emphasis on retention throughout the student experience, including the undergraduate years at community college and university to completion of the graduate educator program. TPP strives to assist with the development of a multicultural workforce, recruiting and supporting students from historically underrepresented populations, including African Americans, but the student population of TPP is racially, ethnically and culturally diverse. The TPP has a long-standing reputation in the community with established articulation agreements between the community college and the university. The program maintains partnerships with school districts in the region, and has sustained connections in the community with local and state-level educational stakeholders for many years. My decision to limit information regarding the background and history of the TPP was made to protect the identities of the participants.

The process of recruiting potential students into teacher education is not a shortterm endeavor; it can be years from initial inquiry or interest into a career in teaching to admission to a teacher program. Teacher preparation programs in Oregon are often at the graduate level, which adds more years to the timeline of earning a teaching license and beginning a career. Graduate preparation programs may also be disconnected from the undergraduate program experience. Students may not necessarily be made aware of teaching as a career option while pursuing their bachelor degrees, because Education may not be listed as a major available to choose from to earn their bachelor's degree and/or the pursuit of a post-bachelor or graduate degree might not be a consideration. Given the graduate preparation program design, teacher pipeline programs become all the more critical in providing information and support to potential recruits in 2- and 4-year 
institution. According to American Association of Colleges for Teacher Education (AACTE) many teachers are prepared at the post-baccalaureate or master's level; AACTE reported that in 2011 of the 150, 913 initial teachers prepared at AACTEaffiliated institutions, 63,711 (42.2\%) were in post-baccalaureate- or master's-level programs (AACTE, 2013).

In national reports, many associations said the diversification of the teacher workforce is necessary and helpful for policy-makers and for setting state-level agendas and legislative acts. What is lacking from these national reports are descriptions of the actual experiences of teachers of color and their pathway to a career; understanding the stories of teachers of color may inform preparation programs and teacher educators in practical ways. As McCray, Sindelar, Kilgore, and Neal (2002) pointed out, “A first step to improving African-American teacher recruitment, retention, and preparation is improving our understanding of their experiences and purposes for teaching” (p. 270). Thus, my initial interest in conducting this study was to ascertain, by way of personal interviews with African American teachers in Oregon, the reasons individual African Americans considered teaching as a career, and explore their personal experiences in navigating recruitment resources and the landscape of teacher education. In the following sections of this paper, I further define this problem in practice, describe the potential contribution this study may make to the field, provide an initial overview of the methods used to conduct this research and note my specific research questions.

\section{Statement of the Research Problem}

The public school teacher population of the United States is predominantly White, while the demographics of P-12 student population continue to grow increasingly diverse. 
As the demographics of Oregon's P-12 student population continue to shift and with the state's renewed attention on CLD teacher data, an urgency to recruit and prepare more CLD teachers persists in Oregon. The purpose of this dissertation was to examine the factors that have contributed to the successful recruitment of African American teachers. While more teachers of color have begun to join the teaching profession in the U.S. (Ingersoll, 2011) and in Oregon (Chief Education Office, 2016), not all racial and ethnic groups have made gains (Boser, 2014; Chief Education Office, 2016). I chose to limit the focus of this research on African Americans due to the scant number found in Oregon schools and classrooms. My study was designed to shed light on one specific population - and although some lessons learned might be transferrable to other populations - the goal was to learn more about the experiences a small group of individual African Americans teachers in Oregon and their journeys into the profession as they navigated their way into and through the TPP. The intent of the study was to discover what inspired them to become teachers and how and why they persisted, including effective strategies, powerful social networks and/or resources, and more specifically, to gain an understanding of what a pathway to success looked like for a few African American teachers who achieved their goals.

\section{Significance of the Research Problem}

Recruitment of CLD teacher candidates is of importance due to the scant numbers of students from culturally and linguistically diverse backgrounds, in particular African Americans, who are choosing and succeeding to become licensed educators in Oregon. While scholars argued that CLD teachers are critical to the nation's P-12 school system (Gay, 2010; King, 1993; Ladson-Billings, 2009), and leaders and policymakers in Oregon 
adopted and recently amended legislation with relatively robust goals and timelines to increase minority teacher enrollments in preparation programs (OEIB, 2014), there has been a lack of research to inform this legislation. Not surprisingly, the legislature has not funded these mandates and the enrollments into teacher education programs across the nation have dropped (Sawchuk, 2014). Oregon's enrollment data collected as part of the Title II Higher Education Act showed that enrollments decreased more than $22 \%$ from 2012 to 2013, and more than 44\% from 2013 to 2014 (U.S. Department of Education, 2015). In the 2015 report by the Chief Education Office, Oregon's public educator preparation programs was reported as being drastically short of the goals set forth by legislation. The target goal was 217 diverse students enrolled in public preparation programs, while the actual number of diverse students enrolled in programs was 116 , more than 80 fewer. Additionally, it was noted, "total teacher enrollments for both public and private education preparation programs declined as well" (Chief Education Office, 2015, p.5). Though many state and national reports exist explaining the problem, and data highlighting numbers, percentages, and statistics are plentiful; few studies have focused on the students in the graduate educator preparation programs in Oregon.

Many researchers examined the college experiences, persistence and academic success of minority students (Hurtado, Milem, Clayton-Pedersen, \& Allen, 1998; Pascarella \& Terenzini, 2005; Stewart, 2015); yet, few researchers focused specifically on graduate preparation programs. In addition, even fewer researchers followed up with CLD teachers about their experiences in teaching. Scholars have called for further research focused on learning about CLD teacher candidate experiences (McCray, Sindelar, Kilgore, \& Neal, 2002; Villegas \& Irvine, 2010), especially as it relates to 
programs that have been deemed to provide supportive student services (Sleeter \& Milner, 2011). As Sleeter and Milner (2011) stated in their review of diversification programs and recruitment efforts, "Programs designed to recruit and prepare teachers of color have been in existence for a long time but are not well researched and consequently are not well known" (p. 92). Sleeter and Milner also suggested a need for more contextualized external evaluations, “ $\ldots$ in order to provide insight into the successful and unsuccessful practices of those participating and facilitating the programs" (p. 96). Research in this vein has shed light on what elements of teacher pipeline programs are supportive and influential for students who are interested in becoming teachers.

\section{Presentation of Methods and Research Questions}

Using a qualitative case study methodology (Merriam, 2009; Yin, 2014), I explored the aspirations and experiences of African Americans pursuing careers in teaching in Oregon. I grounded my study in an anti-deficit approach, focusing on individuals who have successfully achieved the professional status as teachers. In addition, all participants selected for this study were graduates of an teacher pipeline program - a program which recruited them, supported their efforts at completing an undergraduate degree, with some initially starting at the community college level- as well as helping with their admissions, enrollment, and completion of a graduate educator preparation program.

The following research questions guided my research efforts:

1. What do African American teachers report as reasons for choosing to become a teacher in Oregon?

2. How do African Americans teachers in Oregon describe their journey into teaching? 
3. How might the lived experiences of African American teachers' success stories help others in Oregon?

4. What recommendations do African American teachers in Oregon offer to improve recruitment efforts and African American representation in the teaching profession?

To explore my research questions, I used qualitative case study methodology because case study methodology was well suited to investigate the experiences of a set group of teachers, a bounded system (Creswell, 2005; Merriam, 2009). The bounded system may be a single entity, or a group, around which there are boundaries (Merriam, 2009). Thus, in this study, the bounded system is an African American teacher who participated in a specific teacher pipeline program. Because I was interested in "insight, discovery, and interpretation rather than hypothesis testing" (Merriam, 2009, p.42), my study was a good fit for case study design. As Yin (2014) defined, "A case study is an empirical inquiry that, investigates a contemporary phenomenon (the 'case') in depth and within its realworld context, especially when the boundaries between phenomenon and context may not be clearly evident" (p. 16). I designed my case, or multi-case, study, to gain a richer and deeper understanding of the experiences of a small set of African American teachers in Oregon who successfully navigated their pathway into teaching and who all participated in a teacher pipeline program. To collect data for this case, I conducted semi-structured interviews with teachers, which I transcribed, coded, and used member checking for accuracy.

\section{Definitions of Key Concepts}

For my research study, I selected and identified key concepts. In this section, I provide definitions for these concepts. 
African-American. The U.S. Census Bureau defined African American and Black with one definition: "A person having origins in any of the Black racial groups of Africa. It includes people who indicate their race as 'Black, African Am., or Negro'...” (Humes, Jones, \& Ramirez, 2011, p. 3). Along those same lines, the terms African American and Black are often used interchangeably in research (e.g., Howard, 2013; Villegas et al., 2012; Wood \& Turner, 2011). Hall, Phillips, and Townsend (2015) conducted research to ascertain the perceptions of using different ethnic-labels to describe Americans of African descent, specifically the terms: African American and Black. Hall et al. (2015) concluded that people perceived the terms differently, and more specifically, participants viewed the individuals described as African Americans more positively than individuals described as being Black. Hall et al. stated, "Although the terms African-American and Black are used synonymously, our work indicates that the label used to identify an American of African decent can have material consequences for that person" (p. 190). Given the results of Hall et al.'s (2015) research, and the effects ethnic labeling may have on perceptions and potential prejudice, I selected the term African American for this dissertation.

Educational pipeline. In the context of my study, the pipeline metaphor was used to illustrate the educational trajectories of students, from their early educational experiences (P-12) through their years in higher education. The progression along the continuum includes critical stages or phases along the pathway to a career, highlighting key transition points, culminating in this study to a teaching license. Achievement is dependent upon students flowing through each stage of the pipeline successfully. 
Teacher pipeline programs. Teacher pipeline programs come in a variety of models; they can be in the form of local, regional, state, and even national initiatives encouraging individuals to pursue careers in teaching. Programs offer a range of support services for prospective educators, typically beginning with recruitment and possibly including incentives (e.g., financial support). Also referred to as "pipeline programs" (Sleeter \& Milner, 2011, p. 85), recruitment of participants in these programs may begin as early as middle or high school and typically offer students opportunities to develop academic skills, practical experiences working with youth, and activities to help them navigate college. The specific Teacher Pipeline Program (TPP) referenced in this case study, like other programs offered throughout the nation, is in a partnership with a community college, a 4-year baccalaureate higher education institution, and local school districts.

Recruitment. The term recruitment, in this dissertation, refers to recruiting individuals into the career of teaching, as well as recruiting students into various educational institutions involved in preparing people for that profession. The focus is primarily on the pathway to the career, up through earning the teaching license and prior to employment, and thus, specific recruitment activities mentioned herein are mostly related to the various pipeline points along the pathway to teaching. Various factors such as enrollment, admissions, and licensure requirements are an emphasis, but the broader themes associated with recruitment into the profession are also important to acknowledge. As Lortie (2002) noted, “To draw in new members, an occupation must possess certain recruitment resources" (p. 26). He further categorized the recruitment resources into two types: attractors, or appealing traits of the profession (e.g., type of 
work, pay, schedule) and facilitators, or mechanisms to aid in entrance to the profession (e.g., financial incentives, support services, admissions criteria). In seeking to understand more about the factors that contribute to recruitment, I explore both attractors and facilitators.

\section{Conclusions}

In this chapter, I introduced my problem in practice, provided an overview of the significance of the problem, and identified the purpose of the study. My study addressed gaps in the literature by focusing on the experiences of African Americans teachers in Oregon, to learn about their successful journeys, with careful attention paid to how their experiences can help with recruitment of more African Americans into the teaching profession. In Chapter 2, I present an overview of theoretical and conceptual frameworks that guided my study and provide a review of the literature. 


\section{Chapter 2: Literature Review}

The purpose of my study was to examine the factors that contribute to the successful recruitment of African Americans into an educator preparation program in Oregon. African Americans have historically not selected teaching as a career in the state of Oregon. The number of culturally and linguistically diverse (CLD) teacher candidates in the state, and in particular the numbers of African Americans enrolled in preparation programs, is very low (Chief Education Office, 2015, 2016; ODE, 2016; OEIB, 2014). Some researchers found that the U.S. no longer has a recruitment problem associated with CLD teachers, but rather, a retention problem (Ingersoll \& May, 2011). Nationally, retention of CLD teachers may be more significant; in Oregon, however, the issue of recruitment remains a critical concern.

To pursue the circumstances that led to the successful recruitment of African American teachers in Oregon, I used four research questions: (a) What do African American teachers report as reasons for choosing to become a teacher in Oregon?, (b) How do some African Americans teachers in Oregon describe their journey into teaching?, (c) How might the lived experiences of African American teachers' success stories help others in Oregon?, (d) What recommendations do African American teachers make to improve recruitment efforts and African American representation in the teaching profession? In addition, I applied a multiple case study design to examine my problem in practice by gaining deeper understanding about the experiences of African American teachers in Oregon as they pursued their careers while participating in a teacher pipeline program. 


\section{Theoretical and Conceptual Frameworks}

To begin this chapter of recruitment efforts of African American teachers in Oregon, I situated my study within a theoretical framework (i.e., Bandura's theory of self-efficacy) and a conceptual framework (Harper's Anti-Deficit Achievement Framework). I used these frameworks to guide my research. I explored what researchers have found about the success of students of color, specifically African Americans, during their transitions from pre-college socialization and readiness to undergraduate college achievement and finally, to professional licensure and post-college success (Harper, 2012). Using Harper's (2012) “eight researchable dimensions of achievement” (p. 5) (i.e., familial factors, P-12 school forces, out-of-school college prep resources, classroom experiences, out-of-class engagement, enriching educational experiences, graduate school enrollment, and career readiness), or subcategories within each pipeline point, I discussed relevant research — drawing connections from these scholarly works to these subcategories - paying particular attention to how they relate to African American teachers in Oregon.

\section{Theoretical Framework: Self-Efficacy}

Data indicate that the vast majority of individuals pursuing and ultimately becoming teachers are White and female (Ahmad \& Boser, 2014; Chief Education Office, 2016; Zumwalt and Craig, 2005); however, in my professional life, I witnessed many CLD college students succeeding and achieving in educational careers despite the odds. Although the numbers are not large, some African Americans choose to pursue teaching and succeed at becoming teachers in Oregon. Supportive teacher pipeline programs — ones that provide financial, academic, and personal support structures — may 
account for a large portion of these students' success. Not everyone, however, who has access to these resources takes advantage of them; that may be a conscious decision or more related to issues of circumstance. My point was to articulate that some resources remain untapped. I designed this study to learn more about the factors that contribute to African Americans who selected the pathway (i.e., tapping into the resources) and succeeded at becoming teachers in Oregon; this was an investigation about individuals who embarked upon the journey to become a teacher and found success. In other words, this was a study about career aspirations, resiliency, and self-efficacy.

Social cognitive learning theorist, Albert Bandura, introduced the concept and wrote extensively about self-efficacy (Bandura, 1977, 1986, 1997a, 2012). Bandura (1997a) stated, "Self-referent thought activates cognitive, motivational, and affective processes that govern the translation of knowledge and abilities into proficient action" (p. 37). He added, "Efficacy beliefs operate as a key factor in a generative system of human competence" (Bandura, 1997a, p. 37). A strong sense of self-efficacy influences behavior and has a positive effect on motivation and performance; efficacy beliefs impact critical functions such as decision making, innovation, and communication, which all influence one's course of action, persistence, and resiliency (Bandura, 1997a). Furthermore, avoidance behaviors may be developed in individuals with low self-efficacy expectations; on the other end of the continuum, an individual with high self-efficacy expectations is more likely to exhibit behavior that leads to success, such as demonstrating persistence (Bandura, 1997a). In relation to students' academic pursuits, Bandura's (2001) stance on having a strong sense of coping efficacy may affect a student's "vulnerability to stress and depression in taxing situations and strengthen 
resiliency to adversity" (Bandura, 2001, p.10). As students pursue career options, such as teaching, multiple obstacles need to be overcome along the way; efficacy beliefs inform the ways a student may or may not choose or remain on a given path.

Although my study was not deeply embedded within the field of career psychology, nor does it use instruments for measurement of psychological constructs such as the Career Decision Self-Efficacy Scale to analyze career decisions of participants, social cognitive theory, and specifically self-efficacy, are commonly used as theoretical frameworks in the research and practice of career psychology and career development (Bandura, 2001, 2012; Gushue, Scanlan, Pantzer, \& Clarke, 2006; Lent, Brown, \& Hackett, 1994; Lindley, 2006). Not only have there been studies about selfefficacy in career development research, but self-efficacy has also been found to be relevant across and within different racial and cultural groups (Bandura, 1997a; Earley, 1994). In a comprehensive review of the vocational literature, Lindley (2006) found that concepts of self-efficacy had a history of applicability and merit with helping to understand career pursuits in relation to diverse populations. As Lindley noted, Bandura's notion of "collective efficacy" (Bandura, 1997a) helps extend the theory to group ideology, or group performance, which may give it more credibility or applicability with populations or cultures less focused on individualism.

In her review of the literature on self-efficacy and diverse populations, Lindley (2006) cited several studies that found self-efficacy impacting career choices for people of color. For example, she described Luzzo and McWhirter'study (2001), which indicated that students of color had a lower self-efficacy than Whites in terms of coping with career barriers. Lindley pointed out that these Luzzo and McWhirter's findings are 
troubling given that students of color "may have lower self-efficacy for certain occupational fields leading them to restrict their career options at the same time that they perceive greater barriers to their career pursuits, with which they feel less capable of coping” (Lindley, 2006, p. 149). Results of this nature may provide career counselors, academic advisors, and others involved with helping students navigate career decisions with a better understanding of the populations they serve, keeping in mind the importance of efficacious beliefs. In sum, efficacy beliefs may significantly influence student success in general, and career pursuits more specifically. Thus, self-efficacy, as a theoretical framework, may augment what is known about motivation and persistence in career decision-making, and in supporting students along the career trajectory.

Investigating what helps shape efficacious beliefs was paramount to my study. How students found success while they navigated the various educational transitions to their career, especially related to the focused efforts generated by the TPP, was critical to understand. As Bandura (1997a) stated, “...the different modes of building a sense of personal efficacy can be used to eliminate self-limiting barriers that have become ingrained over time through institutional practices and to create the means for exercising proactive control over one's occupational future" (p. 438). Furthermore, Earley (1994) suggested, "Verbal coaching and information that a person receives about performance norms, future expectations, and past performance all influence self-efficacy by persuading him or her that a given performance level is attainable" (pp. 89-90). Efficacy beliefs inform career aspirations and decisions, and they play a role not only in selfperception, but also in how people respond to others' behaviors. As Bandura (1997b) wrote, "People with high self-efficacy... attract support from others, which reinforces 
their ability to cope”; and in turn, “...others supply incentives and resources, provide good examples to model, and demonstrate the value of perseverance" (p. 4).

The potential role self-efficacy plays in affecting the kinds of support services and information someone may (or may not) receive in their pursuit to a career, is a key factor. Understanding the role of support services is also directly related to Harper's conceptual framework, the Anti-Deficit Achievement Framework (Harper, 2010, 2012), which I discuss in a subsequent section. Efficacious beliefs clearly affect student choices throughout their academic and career journeys, and thus, factors embedded within academic experiences that aid in student achievement are critical to understanding success.

Learning more about the teacher pipeline program components, specifically the perception by former students on what worked, might provide useful data to the program and for other student's navigating the same terrain. According to Bandura (1997a, 2012), one way individuals can develop beliefs in their capabilities is by vicarious experiences, which he also refers to as social modeling. "Seeing people similar to oneself succeed by perseverant effort raises observers' aspirations and beliefs in their own capabilities" (Bandura, 2012, p. 13). Focusing on achievers is critical for the sake of social modeling. Prior to discussing the Anti-Deficit Achievement Framework (Harper, 2010, 2012), which provides rationale and effective methods for uncovering insights into the experiences and educational realities of achievers, it is important to highlight factors about learning and motivation that are not addressed in Bandura's theory of self-efficacy. Given the effect of self-efficacy on career aspirations, motivation, and resiliency, understanding what most influences a person's sense of self-efficacy is key. There is a 
need to frame the discussion in operational terms and Carol Dweck's (2006) research on mindsets provides this framework, specifically her work on fixed-versus growthmindsets, which has enhanced what is known about the applicability of learning and motivation in real world settings. Dweck $(2006,2008)$ posited that individuals with a growth mindset, who are able to see intelligence as changeable or something that can be developed over time, are more successful than individuals with a fixed mindset, who see intelligence as something they either have or do not have, typically take fewer risks, and are "challenge-avoidant and vulnerable" (Dweck, 2008, p. 392). She emphasized the importance of malleability when it comes to personality characteristics, as it relates to belief systems and learning. Dweck (2008) stated, "Self-theories play an important (and casual) role in challenge seeking, self-regulation, and resilience, and changing selftheories appears to result in important real-world changes in how people function" ( $\mathrm{p}$. 392). Thus, focusing on developing strong self-efficacious beliefs, as Bandura (1986, 1997a) suggested, is important for student achievement, but helping students develop a growth mindset (e.g., focusing on the process of learning, giving praise for effort, and teaching that intelligence can be acquired) applicable to real life circumstances will ultimately lead to success with wide ranging endeavors (Dweck, 2006, 2008). Research related to mindsets is not contrary to self-efficacy theory, but rather it builds upon it, illuminating the importance of success and furthering the development of interventions to make success a reality and a lifelong pursuit for many.

Dweck, Walton and Cohen (2011) have taken these notions about self-efficacy and mindsets and have termed them as academic tenacity. "More specifically, academic tenacity is about the mindsets and skills that allow students to: 
1) Look beyond short-term concerns to longer-term or higher-order goals, and

2) Withstand challenges and setbacks to persevere toward these goals. (Dweck, et al., 2011, p. 4)

Some students already have skills and/or have developed growth mindsets before they come to school, but Dweck and her colleagues have contended that these traits can be learned about, encouraged and mastered while in school as well (Dweck et al., 2011). Academic tenacious students often display characteristics and behaviors including a sense of belonging, an understanding of the importance of school, hard work ethic, seeking out challenges, and a general sense of perseverance and resiliency (Dweck et al., 2011). In his study on African American male success in higher education, Harper's (2012) described the participants as having similar tenacious traits. On a much smaller scale, my study focused on African American teachers in Oregon who also have demonstrated academic tenacity, and to learn what strategies, interventions, supports helped shape their experiences on their path to becoming teachers. In sum, my goal was to learn how African American teachers in Oregon turned self-efficacy into academic tenacity.

\section{Conceptual Framework: Anti-Deficit Achievement Framework}

Harper (2012) developed the Anti-Deficit Achievement Framework (Figure 1) for a large-scale qualitative study on Black male success in higher education. Using a framework with an anti-deficit lens, Harper's findings identified the positive school experiences of high achieving African American males. Harper based this framework on his review of decades of literature about African American men in education and society as well as theories from education, gender studies, sociology, and psychology. By inversely viewing foundational theories, which Harper described as race-oriented deficit theories of research that frame the discourse through a lens of under-achievement; the 
Anti-Deficit Achievement Framework focuses the researchers' attention on persistence, grit, and achievement. Harper maintained, “Asking those who have been successful to talk about what helped them succeed is the most powerful recommendation I have for anyone who endeavors to improve the status of Black male students" (p. 19). With the focus on achievement, this framework places the spotlight on positive attributes and stories, crafting a less commonly documented narrative about the successes of African Americans.

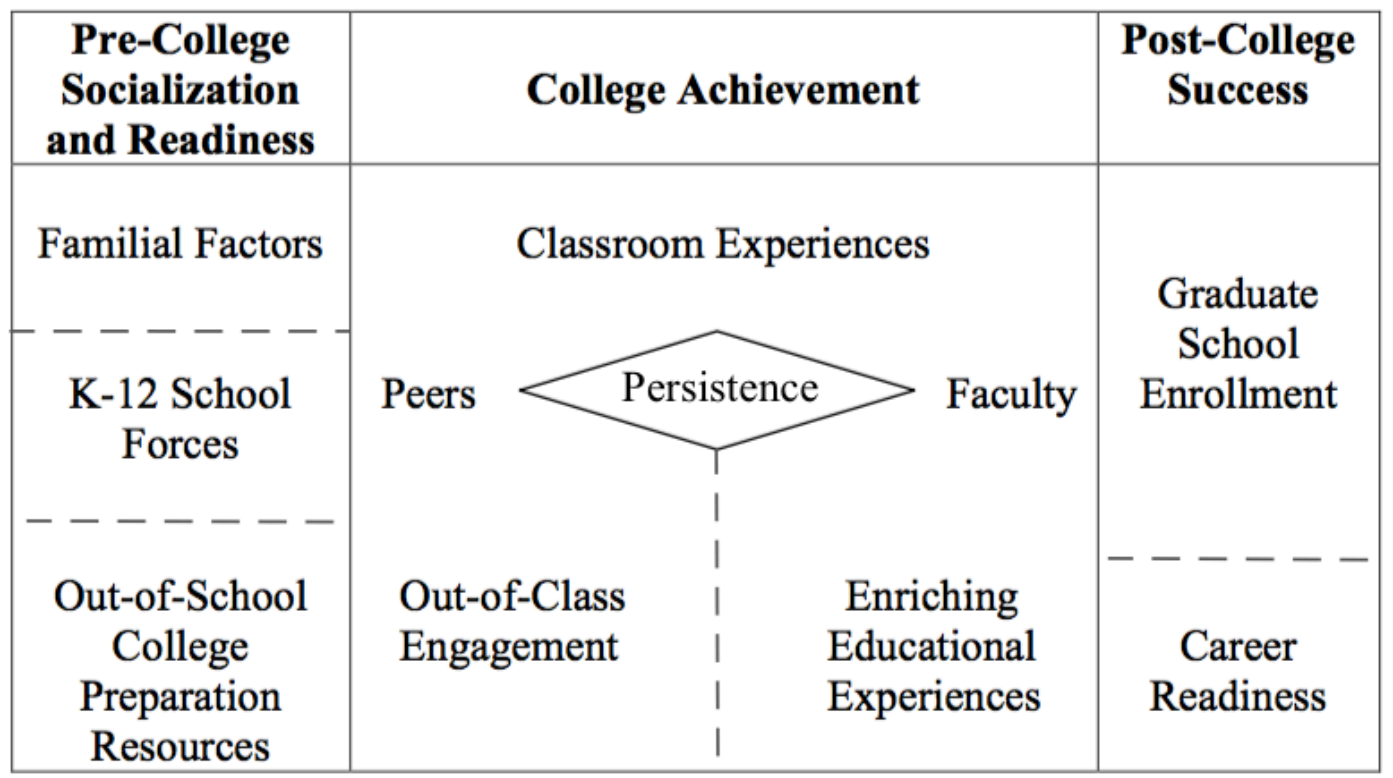

Figure 1. Anti-deficit achievement framework. Adapted from Harper, S.R. (2012). Black male student success in higher education: A report from the National Black Male College Achievement Study. Philadelphia: University of Pennsylvania, Center for the Study of Race and Equity in Education.

Fundamental to the Anti-Deficit Achievement Framework is an emphasis on the social and cultural elements of a participant's life, such as family, peers, faculty, which are critical for the researcher to investigate or attempt to inquire about, to aid in illuminating the mechanisms and supports that ultimately lead an individual to success. 
Socio-cultural factors are part of the eight dimensions of achievement and are embedded within each of the "three pipeline points (pre-college socialization and readiness, college achievement, and post-college success)" (Harper, 2012, p. 5). Similarly, in a report about post-secondary student success, Perna and Thomas (2006) reviewed studies from multiple disciplines (e.g., education, economics, sociology, and psychology) to inform a conceptual model including "the role of multiple layers of context" (p. 11). Perna and Thomas concluded, "The path to student success is not universal but may vary across racial/ethnic, socioeconomic, and other groups based on differences in culture, family resources, local school and community structures and supports, economic and social conditions, and public policies (p. 11). As with the Anti-Deficit Achievement Framework (Harper, 2010, 2012), the conceptual model proposed by Perna and Thomas (2006) to understand student success "is a longitudinal process that is marked by the four key transitions," (p. 9) including college readiness, college enrollment, college achievement, and post-college achievement. In addition to these transitions, Perna and Thomas's (2006) model focused on individual student identity, familial factors, school environment, and lastly, social, economic and policy context. Both of these models, Harper's $(2010,2012)$ Anti-Deficit Achievement framework and Perna and Thomas's (2006) Student Success Framework, bare striking resemblance to one another; an important emphasis to both conceptual frameworks is the "...ways in which the broader structure of social and educational opportunities shapes the range of options..." (Perna \& Thomas, 2006, p. 22). In other words, various environmental, cultural, and personal factors influence (e.g., parents, schools, teachers, and peers) influence student achievement. 
The Anti-Deficit Achievement Framework is an operational model; as Harper (2010) noted, "This framework is mostly about the questions researchers ask" (p. 71). Deficit theorists tended to place an emphasis on failure, and although Harper developed the Anti-Deficit Achievement Framework to counter foundational theoretical frameworks with a different (inverted) approach to research, the framework is not necessarily antithetical to these foundational theories' underpinnings. What makes this framework unique is the process and approach. Given that former research employing deficitoriented approaches did not necessarily lead to solutions or significant improvements within the larger context of the achievement gap, employing a research framework with a fresh approach was a worthy of consideration for my study. Research that aligns with what worked with less emphasis on what did not work helps shape the discourse in such a way that it allows, perhaps encourages, for different outcomes not previously considered. As Howard (2013) contended, "A move toward a more asset-based approach, which recognizes the strengths, promise, and potential of students and can lead to opening up research approaches that delve into a more comprehensive, nuanced, complex, and authentic account of them" (p. 62). In his review of the research on successful Black males, Howard (2013) reported a large increase in research studies sharing this paradigm shift in the past 15 years. I contend that applying the Anti-Deficit Achievement Framework (Harper, 2010, 2012) for my study on African American teachers may add to this well-deserved growing body of assets-based research.

Harper's (2012) framework is particularly well suited to help answer the research questions of my study. In fact, my study is very similar to Harper's initial research when he first designed the framework. There are some subtle differences with my study's 
application of the model, such as, I am not exclusively studying one gender, and my focus is on a specific discipline/profession. Prior to publication of the report on African American male achievement, Harper applied his framework to a study on students of color who had succeeded in postsecondary science, technology, engineering and mathematics (STEM) fields (Harper, 2010), which substantiates its applicability across genders and for population and discipline variances.

Given the focus of this research study is on recruitment, I placed an emphasis on the first two pipeline points (e.g., pre-college socialization and readiness college achievement). Although all three points are relevant to the career trajectory of a teacher, the third point, post-college success, relates to graduate school enrollment and employment. I did not consider employment for this case; this study was limited to the point when the teacher earns the license, and not beyond. Although research on employment and retention in the profession, albeit are both very important and worthy of further study, they exceed the scope of this study.

In the following section, I further elaborate on some of the findings of Harper's (2012) study, which he used to develop the Anti-Deficit Achievement Framework. Harper's results relate to my study and the various points along the educational pipeline, and specifically to the recruitment of African American teachers. Harper's findings and framework offer a compelling rationale for why this approach has merit. When reflecting on his research approach, Harper (2012) noted:

Most surprising and most disappointing is that nearly every student interviewed said it was the first time someone had sat him down to ask how he successfully navigated his way to and through higher education, what compelled him to be engaged in student organizations and college classrooms, and what he learned that could help improve achievement and 
engagement among Black male collegians. (p. 15)

I concur, as Harper reported, that a dialogue of this nature is beneficial; seeking the insights of successful African American teachers in Oregon is warranted.

\section{Review of the Research Literature}

In this review of the research literature, I provide an overview of scholarly works, including research studies and theoretical reviews, focused on teachers of color, specifically African Americans, and their pursuit of a career in teaching. As framed earlier in this chapter, career endeavors in the context of teaching typically involve all stages/points along the academic pipeline. In this study, I used the points along the pipeline that Harper (2012) defined as pre-college socialization and readiness, college achievement, and post-college success (including professional licensure for teaching). I began this review by initially discussing the rationale for, and value of, CLD educators in the P-12 teacher workforce, and concluded by presenting relevant and current research in relation to the three pipeline points, as well as the pertinent researchable dimensions therein (Harper, 2012). Given the use of the assets-based framework, I used literature that focused on the success and achievement of teachers of color in pursuit of a career. I intentionally selected research studies that emphasized assets and persistence in their description of the research purpose; I steered away from research grounded in deficit thinking and research that largely reported drawbacks (e.g., obstacles, shortcomings). In addition, as discussed, recruitment of teachers into the profession is of primary concern; I did not include studies that concerned teacher employment or teacher attrition. 
The Value of CLD Teachers

Indeed many researchers support the notion that diversification of our teacher workforce is an important and worthwhile pursuit (Achinstein et al., 2010; Brown, 2014; Clewell \& Villegas, 1999; Haberman, 1988; King, 1993; Torres, Santos, Peck \& Cortes, 2004; Villegas et al., 2012). A variety of thoughts and opinions, or root rationales, existed about why our nation's public schools need more CLD teachers. Villegas et al., (2012) recently reviewed minority teacher recruitment policies and programs over the past 20 years. In framing the rationale for creating a more diverse workforce, Villegas et al. (2012) suggested two main arguments. Those two arguments can be roughly summarized as a need for more diverse role models in U.S. schools and a need for more teachers who can relate in culturally similar ways more successfully to the growing diverse population in the school system (Villegas et al., 2012). Researchers theorized that students sharing characteristics with teachers, or who are more similar to them, may be more likely to develop bonds and therefore succeed in school (e.g., "cultural synchronicity") (Villegas \& Irvine, 2010, p. 178). Dee (2004) reported that a teacher of color as a role model would lead to a student of color's improved self-esteem and desire to learn. In fact, studies indicated increased achievements in students of color when taught by race-similar teachers (Dee, 2004; Grissom, Kern, \& Rodriguez, 2015), or what Eddy and Easton-Brooks (2011) have termed "ethnic matching" (p. 1280).

As a part of the second rationale, Villegas et al. (2012) mentioned a critical point, and one of the main reasons that led me to my problem in practice. “...The teaching profession, as a whole, stands to gain from the diverse experiences and perspectives people of color can bring to it" (Villegas et al., 2012, p. 288). It is my position that a 
more diverse teacher workforce, as with any profession, would enhance the work environment for all professionals. As with my own experience, working in a diverse setting has an impact for all practitioners. Citizens of the United States live in a pluralistic society and our P-12 public school faculty should reflect that environment. Researchers have framed this third rationale related to the profession as "the workforce rationale" (Villegas \& Irvine, 2010). This rationale is grounded in a personnel management or human resources lens; our schools need to have a critical mass of CLD teachers to support one another as well as contribute and inform the conversations and daily work of all teachers.

Whatever the rationale it is clear that researchers, policy makers, and educational theorists have a united goal of recruiting and retaining CLD teachers into the profession (Achinstein et al., 2010; Brown, 2014; Clewell \& Villegas, 1999; Haberman, 1988; King, 1993; Torres et al., 2004; Villegas et al., 2012), and though rationales may have slight deviations, researchers are aligned when it comes to desired outcomes. Sleeter (2008) asserted, “.... diverse teaching force is more likely than a homogeneous one to bring knowledge of diverse students' backgrounds, families, and communities, and commitment to serving diverse students" (Sleeter, 2008, p. 1949). Policy makers and practitioners, however, may have varying approaches to solving the problem.

Much of the literature on teacher workforce diversification has stemmed from policy makers and educational theorists. An emphasis in the reports and scholarly writings focus on increasing the numbers of teachers recruited, prepared, and retained (Chung \& Harrison, 2015); numbers have a way of influencing policy decisions, and ultimately funding to support efforts. However, some researchers have voiced concern 
and pointed to issues with using a numbers-only focus to the problem (Brown, 2014; Chung \& Harrison, 2015; Dillard, 1994). Chung and Harrison (2015) described the oftused numbers approach to the problem as "dehumanizing" (p. 4) and suggested reframing the problem — instead of conducting research using the student as the unit of analysis, research should be looking more closely at the institution — focusing on "How might teacher education programs be transformed to make space for students of color" (p. 5). Dillard's (1994) research has been cited (Brown, 2015; Chung \& Harrison, 2015) as a good example of viewing the problem from the human (not numbers) perspective. Dillard (1994), conducting research on a summer intensive program for prospective graduate teacher education students, found importance in focusing on the whole student and the entire student experience. Importantly, for the students of color in Dillard's summer program, she found that her courses, “...had to be more than information and materials about graduate study and careers as teachers: they had to be the curriculum, with a full acknowledgment of their humanity as the place from which they might ultimately see themselves as teachers" (Dillard, 1994, p. 12). As Dillard posited:

We must share the responsibility of moving the active recruitment of future teachers of color beyond the discussion of numbers to one which listens to and values the tremendous potential and energy which people of color represent for all of our nations' students and schools. (p. 17)

In the 20 years since Dillard's research, there has been more emphasis in the research placed on the people and the life experiences, as opposed to the policy perspective and the numbers approach to the problem. I elaborate on this research, which focuses on individuals' experiences navigating the educational pipeline in more detail as the discussion focuses on pathways into teaching. 


\section{The Educational Pipeline}

Research on diversifying the teacher workforce, given the non-linear and multiple pathways into teaching, is complex. Research addressing this complicated problem is commonly illustrated in the context of a pipeline metaphor, described as an education or academic pipeline. That is, education trajectories - the entrance into academia and the persistence and continuing success during educational pursuits - are described in relation to a pipeline often times leading up to a profession/career or graduate studies. In short, an educational pipeline consists of a series of transitions or points along a career path, usually from high school through college.

The pipeline metaphor helps illustrate that students are moving forward and navigating critical transition points along a track to a career, and although I prefer a different metaphor, the pipeline is helpful in thinking about educational journeys. That is, factors within the educational environment that provide support throughout the twists and turns in any given educational journey, or to take a less positive spin on outcomes, the pipeline may include weaknesses which "leak," describing unfulfilled journeys. I dislike the metaphor because I do not like to reduce learning and education, or in particular the learners themselves, to a metaphor which conjure images of things that move through pipes or equating their lack of success to "leakage." Nevertheless, it is a metaphor used pervasively and works well in this context. Thus, I maintain the use of the pipeline metaphor throughout my paper (as seen in Figure 2), while at the same time, recognize its limitations. 


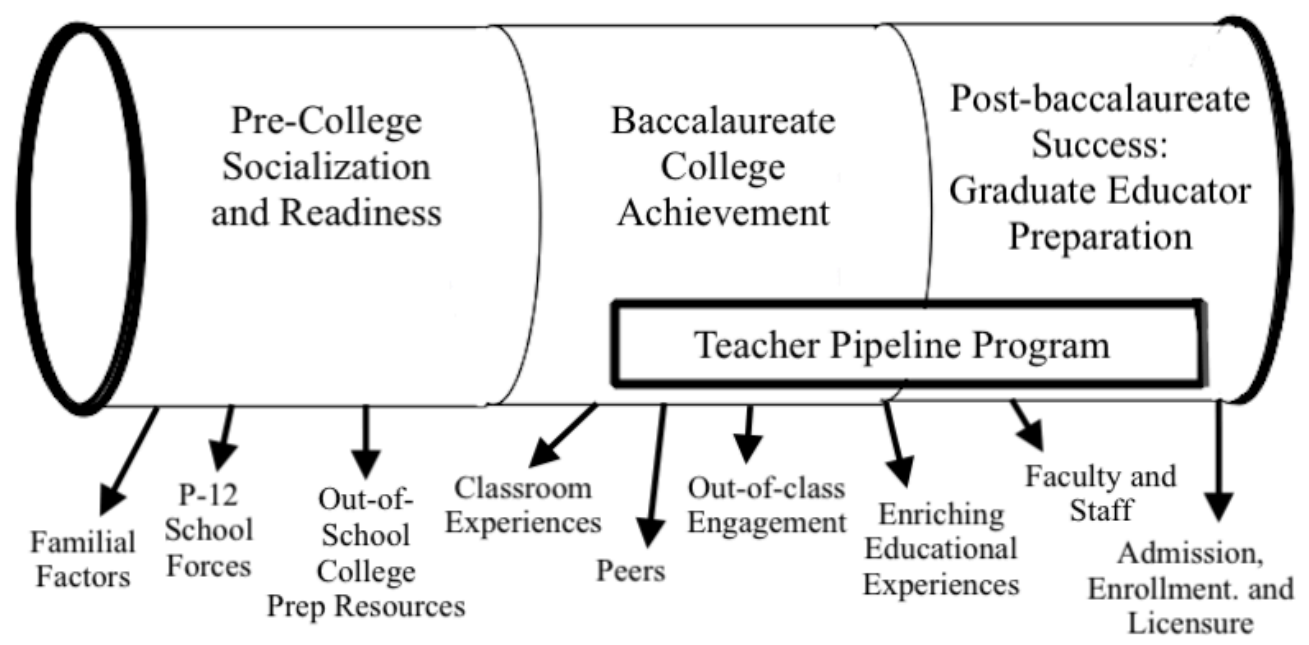

Figure 2. African American Teacher Pipeline. Adapted from Harper's $(2010,2012)$ AntiDeficit Achievement Framework

The pipeline metaphor is somewhat misleading in that the transition or points along the pathway to a career might be viewed as progressive or having an accumulative effect on a given students' perceived self-efficacy. The assumption that one's success leads to another success along the pipeline does not match with Bandura's theory of selfefficacy $(1977,1997 a)$. Unlike self-esteem, which is a general personality trait about self-worth (Bandura, 2012); self-efficacy is situational and task specific, not generalizable (Bandura, 1997a). For example, a student may feel highly efficacious taking subject-specific courses at the community college, but not so confident taking a different subject matter course in a 4-year college or university setting. In other words, efficacious beliefs are most useful in influencing the completion of specific task, not necessarily applied to an entire career journey. Thus, the individual pipeline subcategories, or the situational tasks embedded within each subcategory, are more 
consequential in relation to self-efficacy; each segment of the pipeline needs separate and focused consideration, and even though the segments are visually adjacent to one another they may be disassociated in critical ways. This notion of a student's journey being nonlinear, complex, and influenced by a myriad of factors, is summed up well by Rendón (2006), who stated:

Each student brings strengths as well as deficits, all of which affect student success. For example, prior life experiences such as schooling, validating and invalidating experiences, language development, and support and encouragement from significant others ultimately shape access and success in diverse forms of postsecondary institutions. In essence, the student is a human being moving in and out of different systems (e.g., family, community, postsecondary institutions) and not simply an unnamed entity flowing through a system in a neat, linear fashion. (p. 20)

In other words, educational journeys may not be sequential, or timely for that matter. Various tasks may be completed in random order with several months, or more likely years, in between accomplishments; students are not in a lock-step progression to a career as one might infer in viewing the simple one-way cylinder. Despite the limitations with using this metaphor, but as stated above, given that these limitations are recognized the metaphor remains a convenient and commonly used image, which I have developed to frame my study using Harper's $(2010,2012)$ Anti-Deficit Achievement Framework (see Figure 2). I referred to this frame as the African American Teacher Pipeline. Next, I address the first point along the pipeline to a career in teaching, pre-college socialization and readiness.

\section{Pre-college Socialization and Readiness}

Most states in the U.S., including Oregon, require a minimum of a bachelor's degree to become a teacher (Chief Education Office, 2016; Wilson \& Youngs, 2005). 
Therefore, the pathway into teaching, whether traditionally structured (e.g., 4-year undergraduate, graduate degree or post-bac certificate program) or through an alternative route (e.g., school-district sponsored, Teach For America), typically requires that an individual complete an undergraduate degree program prior to receiving non-provisional professional teaching license. Thus, pathways into teaching must include the first point on the academic pipeline of pre-college socialization and readiness, including graduation from high school (or equivalent) and factors leading up to being prepared for an undergraduate college experience. Researchers have found that access to a college education, specifically student success at the undergraduate level, relates to a variety of factors (Perna \& Thomas, 2006). Harper $(2010,2012)$ described the pre-college socialization and readiness point along the educational pipeline as one that is impacted by familial factors, P-12 school forces, and out-of-school college preparation resources. Klopfenstein (2005) stated, "The academic underachievement of black students relative to white students is often attributed to differences in family background characteristics, such as income, family structure, and parents' education" (p. 416), and while this may seem similar to the areas mentioned herein, it is with an eye toward achievement that this review will be focused. In this section, I review the literature related to success for African Americans specific to familial factors, P-12 school forces, and out-of-school college preparation resources, and I begin by defining what it means to be ready for college.

Conley (2011) defined college readiness as "the level of preparation a student needs to enroll and succeed — without remediation — in a credit-bearing general education course at a postsecondary institution that offers a baccalaureate degree or transfer to a 
baccalaureate program" (p. 1). In addition to this operational definition, Conley added that for optimal success, readiness also includes an “...understanding of the culture and structure of postsecondary education and the ways of knowing and intellectual norms that prevail in this academic and social environment" (p. 2). This is a critical point regarding context specific elements (i.e., culture, social contexts, and norms) involved in college preparedness, especially for someone who may be the first person in their family to attend college. If gaining access and an understanding about these elements to the college environment are critical to success, then it is important that individuals develop a literacy about these key sociocultural components; success may be dependent on a strong self-efficacy about the all-encompassing college experience—various nuanced factors included.

Familial factors. The value of family support in a student's educational journey may have tremendous impact. The role of family or parental involvement is often cited as a factor that contributes to success for students trying to access higher education (Perna \& Titus, 2005). That does not necessarily mean that a student without strong family support system would be unsuccessful, but that those who receive support from their families are better equipped to be successful. Family support is multifaceted and is evidenced in a variety of behaviors, overt and subtle, including moral encouragement (Perna \& Thomas, 2006), initiating educational activities outside of formal schooling (Harper, 2012), financial support (Elliot, Destin, \& Friedline, 2011; Zhan \& Lanesskog, 2014), as well as serving as role models. In the next section, I highlight the salient literature related to these supports. 
Finances for college cannot be overlooked as a factor related to college achievement. Although it is important to note is that not all African Americans have financial needs; in fact, "approximately one third of African American families live in suburban communities and send their children to middle-class schools" (Howard, 2013, p. 62) - however, given the cost of college these days, many middle-class students seek support. Economic researchers have found that household assets (e.g., home ownership) have a significant effect on enrollment and degree completion" (Elliot et al., 2011; Zhan \& Lanesskog, 2014). In studying financial implications, researchers have found it important to distinguish between household assets, income, and in some cases specific types of college saving plans (i.e., child-owned savings accounts), using these variables they have developed theories related to college-bound identity and motivation to attend and attain a degree (Elliot et al., 2011). In their review of the research on assets affecting educational outcomes, Elliot, Destin, and Friedline (2011) found that "when children have savings of their own, future identities may be particularly salient, as children are actively involved in the process that is linked to their college goals" (p. 2325). Economic theory aside, I believe it is important to simply recognize the potential impact of family financial assets have on influencing educational outcomes; with the increasing costs of a college education and concerns about incurring debt, financial factors associated with the educational pipeline are critical to the conversation about student success. Further discussion about financial aid and scholarships is in the following sections on college achievement and obtaining professional licensure.

In his study of 219 African American male high achieving students from 42 different colleges and universities across the United States, Harper (2012) found that 
parents and family members had a strong positive influence in the lives of these students. For example, parents of the students in this study focused on ensuring that their children would attend college, “...characterized as non-negotiable expectations that they would pursue postsecondary education" (p. 9). The students in Harper's study came from various socioeconomic and structurally different home environments, including nearly half came from homes where neither parent had earned an undergraduate degree. For the successful students in Harper's study, these data counter the notion that a child's parental educational attainment is a predictor of future student success, although parental encouragement may be the key distinguishing factor. Moreover, data from studies such as Harper's add to the growing literature that counters theoretical frameworks emphasizing anti-education ideologies in non-dominant majority cultures and dispels presumptions about a disinvestment in schooling from African American communities (Harper \& Davis, 2012). In other words, African Americans clearly care about education and the education of their children.

McCray et al. (2002) conducted a study that investigated "factors that influenced African-American women's perceptions of teaching and decisions to teach" (p. 269), and one of the main themes that emerged was the role of their mothers or "othermothers" ( $p$. 275) in their decision to become teachers. The participants in their study attributed their mothers with "shaping their views of the world beyond and within their community," also teaching them about their "responsibilities as educated African-American women to themselves, their family, and the community" (p. 277). The results of McCray et al.'s (2002) study indicated a change in the role of parent on college readiness, as not only in providing emotional and financial support, but in this instance on helping to shape 
occupational choice. Based on their data about the significant role of mothers' perceptions, McCray et al. recommended that "teacher educators should develop initiatives aimed at informing parents of the viable opportunities in the field today" (p. 288).

The role family members play in helping to shape career pursuits is also discussed in a study by Gordon (2000). In one of her studies, Gordon (2000) interviewed African American teachers about why they pursued teaching as a career. She reported that many African American teachers "did not consider teaching a viable or attractive career choice" (p. 23), with rationales that stem from, (a) economic conditions (e.g., low pay, other more lucrative career options), (b) educational experiences (e.g., negative experiences in school, lack of support for college), and (c) social/cultural reasons (e.g., racism, lack of encouragement). Overall, the majority (75\%) of the African American teachers in Gordon's study, did not recommend a career in teaching to their students, in fact, they discouraged it. According to Gordon (2000), teachers were not the only ones discouraging teaching as a career option; she found "significant discouragement coming from counselors and middle-class parents" (p. 33). Thus, family influence may be one of the reasons so few students of color are not choosing teaching as a career. No matter whether a negative or positive influence on choosing a career in teaching, it could be argued that family, and teachers - which I discuss further in a subsequent section of this chapter, play a vital role in shaping occupational decisions.

P-12 school forces. In addition to children being encouraged (or not) by family and friends to pursue careers as teachers, African American students who have negative experiences in their public school classrooms may want to consider career options outside 
of teaching to distance themselves from the inequitable and oppressive system they experienced while in school (Gordon, 2000; Wilder, 2000). Students of color, in general, entering into the public school system bring their own cultural identities, norms, and understandings, which may not always be acknowledged or understood by White teachers (Howard, 2013). Consensus exists on the need to prepare all educators about culturally responsive pedagogy (Gay, 2010; Sleeter, 2001, 2008); whether or not teachers are learning and applying this knowledge is not clear, but disparities in academic achievement continue to persist between White students and students of color (Elias, White, \& Stepney, 2014; Howard, 2013).

Given the emphasis of success and achievement on this study, it is important to consider support in the literature for what works. Villegas and Irvine (2010) identified five practices of successful teachers of color:

(a) Having high expectations of students;

(b) Using culturally relevant teaching;

(c) Developing caring and trusting relationships with students;

(d) Confronting issues of racism through teaching; and

(e) Serving as advocates and cultural brokers. (p. 180)

These practices play an important role in helping students of color in U.S. schools find success, and in turn, potentially play a part in impacting the number of students of color who are interested in joining the cycle of success by becoming teachers of color themselves. In their study about African American boys' perceptions of teaching as a career, Graham and Erwin (2011) pointed out, "With a smaller number of Black males entering college, the pool of potential future classroom teachers dwindles substantially" (p. 399). Consistent with Gordon (2000) and Wilder's (2000) findings, Graham and 
Erwin (2011) found that African American males' negative and stressful experiences in school impacted their decision to choose careers outside of education.

Research has shown that not all experiences in P-12 schools are negative for African Americans, as in Harper's (2012) study of African American male high achieving students. Harper found African American males who had positive school experiences, including some students who developed relationships with notable teachers. Harper reported that, "early schooling experiences almost always included at least one influential teacher who helped solidify their interest in going to college" (p. 9). Consistent with this finding, Ferguson (2002), based on surveys from seventh to eleventh graders, found that non-White students indicated that teacher encouragement was one of the most influential reasons for working hard in school, this was especially true for African Americans, more so than for Whites. Sadly, Harper (2012) found that the African American students he interviewed, “...considered themselves among the lucky few to have had teachers who, for some reason, thought they were worth the investment" (p. 10). High quality teachers, as perceived by African American adolescent males, motivate students by getting to know them, caring about them, and demonstrating concern for their academic achievement (Noguera, 2003). Again, the impact of teachers is clearly significant, and it seems likely that teachers of color might be more cognizant of this truth, in fact, teachers of color claim "humanistic" (Achinstein et al., 2010, p. 82) reasons for joining the profession. In a review of the research on teachers of color, Achinstein et al. (2010) found "some teachers of color are drawn to the profession to act on their commitments to serve students from non-dominant racial and cultural communities by enhancing opportunities to achieve academic success" (p. 86). Clearly 
one teacher can make a big difference in a given student's school experience, but school culture and climate have influence.

Teachers, counselors, school administrators, and other school personnel (e.g., social workers, nurses, administrative support, volunteers) all have the potential to influence the school culture as well as individual students. The literature supports the notion that school community must work together to enhance and create a climate of empowerment, respect, and achievement in schools, as one teacher can only affect so many students. There are other elements in school environments that bare significance in student achievement. School counselors are often responsible for providing information and resources to students about higher education options. In his study of African American male achievers, Harper (2012) found that "the overwhelming majority of participants explained that their counselors were more harmful than helpful" (p. 10). Given that the participants in Harper's (2012) study were all achievers, perhaps the "harm" caused by these counselors was not too great, as they all found success; conversely, one might also wonder how many students were not helped and could have been success stories had they received effective counseling. Teacher quality and effectiveness is often framed as the leading influence on student achievement (DarlingHammond, 2007; Rivkin, Hanushek, \& Kain, 2005), but there are a range of P-12 school environmental factors influencing non-cognitive skills (e.g., perseverance, coping, selfperceptions) that can have a significant impact on success (Dweck et al., 2011). More research is warranted in understanding how school climate and personnel effect success of students of color. Howard (2013) contended, in regard to African American males in particular, "There is a need to investigate the relationships that Black males have with 
school personnel to determine how they are formed, sustained, and how they contribute to better academic success" (p. 78). Research that explores relationships of school personnel with all students of color, that goes beyond academics, and investigates the impacts on various non-cognitive skills, is also needed.

In their study of how socioeconomic status (SES) and racial make-up influenced academic outcomes, Elias, White, and Stepney (2014) reviewed achievement test score data from 144 middle schools in New Jersey. Elias et al. (2014) found test scores were significantly related to SES and race/ethnicity; more specifically, they reported that, "High poverty, high minority population schools face a particular constellation of factors that when combined, make showing progress in substantial academic test score performance extremely difficult” (p. 19). Elias et al. (2014) hypothesized that these factors include racial microaggressions, oppressive school climates, safety (mental and physical) concerns, and general efficacious beliefs held by students; more specifically, "...there is the internalized oppression that results when children are in an environment in which they feel devalued and inferior and perceive little or no likelihood of their status changing" (p. 20). Moreover, they reported that students in such school environments are more likely to have negative thoughts about their abilities, leading to less tenacious attitudes, and potentially resulting in poor academic performance. Elias et al. (2014) posited, "Schools attempting a turnaround, or otherwise seeking to better their students' academic performance, must realize that academic development cannot be fostered unless students' social-emotional and character development is also fostered" (p. 21). Thus, providing a nurturing school climate, one that focuses on strengthening students' sense that they belong, is key to improving academic outcomes for all students. 
Out-of-school college preparation resources. In Harper's (2012) study of high achieving African American males, he found that "most of the achievers' parents and family members more aggressively sought out educational resources to ensure their success — tutoring and academic support programs, college preparatory initiatives, and summer academies and camps, to name a few (p. 9). Harper (2012) added, "Many of the educational resources parents accessed on their behalf were available at no cost” (p. 9), and moreover, "Without these programs, some achievers insisted that they would not have been prepared to compete for admission to college" (p. 10). Opportunities to learn outside of the school, both in informal and formal educational environments, are key to student achievement. As Ferguson (2002) recommended, from an analysis of a large scale survey of seventh to eleventh graders, "In response to differences in family background advantages, schools could supply more educational resources and learning experiences outside of the home, by providing access to books and computers and extracurricular opportunities for intellectual advancement” (p. 17). Given schools do not necessarily have additional, or an excess of, resources, it may be necessary for other nonprofit and community organizations, such as career pathways recruitment programs, to provide out-of-school educational experiences as suggested by Harper (2012) and Ferguson (2002).

In addition to providing students with extracurricular opportunities, early exposure to higher education may lead to academic achievement by raising expectations about degree attainment (Conley \& McGaughy, 2012; Harper, 2012). Creating opportunities for middle and high school students to visit colleges and university campuses, as well as providing "bridge" programs that address issues related to 
application and matriculation support (Harper, 2012), may help better equip students with an understanding about the bureaucratic nature of higher education institutions (Robinson, Paccione, \& Rodriguez, 2003). “Transition programs help more students prepare gradually for post-secondary expectations by conceiving of college readiness as a continuum, not a cut score" (Conley \& McGaughy, 2012, p. 33). Not only is early exposure to higher education settings valuable in itself, but given that African American students do not often encounter African American teachers in their P-12 school experiences (Wilder, 2000), it is important to provide opportunities where students can see individuals who look like them achieving academically oriented settings. Early experiences in higher education might also help to counter ideas and images of African American youth as portrayed in the popular culture, as Nasir, McLaughlin and Jones (2009) claimed, “The media has consistently offered a relatively narrow set of identity choices for non-dominant people" (p. 78). Nasir et al. (2009) added, "For African American youth, media images reinforce stereotypes of these groups as potentially dangerous, anti-intellectual, and downtrodden (p. 78). Dweck et al. (2011) noted that a general sense of belonging plays an important role in student achievement; experiences that foster positive self-concepts about acceptance and fitting-in have been shown to support success.

As a final note on out-of-school experiences, I would be remiss not to mention sports. At the same time, I hesitate to add examples including sports and athletic experiences when referring to the African American population given the disproportionate number of African American males represented in such extracurricular activities (Howard, 2013). I do not want to portray African American culture in a 
monolithic or stereotypical way, as often found in popular culture. Involvement in athletic activities, however, can lead to many positive experiences that build on noncognitive skills and ultimately lead to academic achievement. Howard contended, "What is often lost from [achievement] dialogue is the hard work, determination, sacrifice, countless hours, discipline, and mental focus that many [African American males] display to excel in the athletic domain" (p. 79). Unfortunately, sports are viewed by students of color, particularly African American males in the U.S., as defining what it means to be successful, rather than the preparation for success in college and career endeavors, which they can be considered, as endorsed by Howard.

\section{Baccalaureate College Achievement}

In this section, I address the second stage of the African American Teacher Pipeline (Figure 2). Obtaining a bachelor's degree is often the first step to a career, and access to higher education can vary greatly for many Americans in the U.S. Access into a 4-year college is also only the beginning of the journey to obtaining a baccalaureate degree. Students admitted to college must also enroll or register for their classes, pay for their tuition, and satisfactorily complete class requirements. It may seem obvious and perhaps simplistic, but in my experience working in a higher education setting, these tasks can be considered challenging for some students. In fact, in their review of the literature on student success, Kuh, Kinzie, Buckley, Bridges, and Hayek (2006) noted:

More recently, it has become clear that too many students, especially those from historically underserved backgrounds, lack accurate information about postsecondary options. They are confused about expectations for academic work, actual tuition costs and the content of college entrance and placement tests. (p. 25) 
Most importantly, the rising costs of higher education present a significant barrier for many students (Kuh, Kinzie, Buckley, Bridges, \& Hayek, 2006). In their review of the literature on factors critical to the access and success of African American males in postsecondary education, Palmer, Wood, Dancy, and Strayhorn (2014) concluded, "Research has identified TRIO programs, affirmative action, and college readiness programs as serving as important gateways to higher education for Black students" (p. 60). Palmer et al. (2014) highlighted the similarities of postsecondary encouragement programs and student services to the teacher pipeline programs available to prospective teachers. In this section, I discuss the literature related to African Americans pursuit of a bachelor's degree, and although this study focuses on graduate educator preparation, I address the elements of education pathway program within this and the next stage of the pipeline as illustrated in Figure 2. I discuss the literature on success and achievement in route to a baccalaureate degree as it relates to classroom experiences and out-of-class engagement including the relationship to peers, faculty and program personnel, as well as relationships to the research on teacher pipeline programs.

Classroom experiences. Many students begin their undergraduate careers in community college classrooms. In a report on the U.S. teacher of color "leaky pipeline," Ahmad and Boser (2014) claimed, "In 2011, 44 percent of students enrolled in a community college were students of color, a significantly higher proportion than at fouryear public universities, where they make up 38 percent of the student body" (p. 11). They added that was truer for African American students with a larger percentage at community colleges than at four-year public universities (e.g., 16\% vs. $12.7 \%$ ), where the reverse was true for their White peers (e.g., 55.5\% vs. 62.3\%). Community colleges 
are an important step for many students of color, particularly African American and Hispanic/Latino students, as they navigate their pathway to a baccalaureate degree (Ahmad \& Boser, 2014; Palmer et al. 2014). Likewise, "transfer rates from community colleges to four-year colleges and universities are lower for students of color than for Whites" (Ahmad \& Boser, 2014, p. 11); there is also less likelihood that community college students have career aspirations (Palmer et al. 2014). Palmer et al. (2014) emphasized that "a large number of Black men who begin their postsecondary education through community college do not persist to graduation or transfer to four-year institutions" (p. 65). Consequently, community colleges, while being a viable option for many students of color, clearly play a role with student retention, completion and transfer to baccalaureate granting institutions.

As mentioned in a previous section of my paper, college readiness literature highlights the value of, "bridge" or transition programs, typically offered the summer before the freshman year, where students are brought to campus for several weeks, ideally helping them get acclimated and giving them insights into their future college experiences (Harper, 2012). Kuh et al. (2006) summarized, "Programs with a strong residential component are among the more effective, allowing students to become familiar with the physical, social, and cultural environments of the campus where they will matriculate" (p. 26). In addition, support services geared toward adjustment and belonging also strengthen student achievement in coursework and academics. Conley and McGaughy (2012) asserted the importance of developing students' cognitive skills to increase achievement, including the teaching of, "cognitive strategies; key learning skills and techniques, such as goal setting and progress monitoring, test-taking and note-taking 
methods, and persistence with challenging tasks" (p. 33). Students that develop such skills early on in their academic journeys may be better equipped to find success.

As Wood and Palmer (2014) found in their study of African American male community college students, learning to focus was found to be a key strategy, and they defined focus as "the degree of attention students placed on academic tasks" (p. 148). Wood and Palmer (2014) reported, "Helping students cultivate the ability to focus would impact cognitive maturation, which may facilitate better decision making relating to academic or social issues" (p. 149). While they corroborated the notion that social interaction and a sense of belonging fosters success, Wood and Palmer found this perspective to be "overly simplistic" (p. 149). Moreover, they argued that participants "indicated that excessive social interactions can lead to a minimalized focus on school, resulting in lower academic levels of academic achievement” (Wood \& Palmer, 2014, p. 149). Harper's (2012) study on male achievers affirmed Wood and Palmer's (2014) findings and framed social interactions (e.g., out-of-class time playing video games and sports, pursuing romantic relationships) as being disengaged; "Achievers believed disengagement was a major factor in explaining poor academic performance and high rates of attrition among Black undergraduate men at their institutions" (Harper, 2012, p. 12). In the following section, I discuss student engagement on out-of-class experiences. In discussing classroom experiences, it is important to mention the role of faculty on achievement. Wood and Turner (2011) noted that faculty in community colleges, like their P-12 colleagues, need to employ culturally relevant pedagogical practices; “ ... teaching practices used in community college are devoid of content which is connected to the sociocultural experiences of African American males" (p. 139). In their review of the 
literature, Wood and Turner (2011) pointed out that, "positive faculty-student interactions are integral to student achievement and success" (p. 139), which was consistent with their own findings. Stressing the importance of relationships, Wood and Turner (2011) summarized:

Faculty serve as integral actors is determining student academic success. Students who received personal attention from faculty members benefited from the establishment of positive relationships that led to greater engagement (e.g., attentiveness during class, attending office hours) in the course. (p. 147)

So too, Bensimon (2007) pointed out the significance of faculty on student achievement, but in contrast to the scholarship on student success that focuses almost entirely on the student as a unit of analysis, Bensimon framed "student success as a learning problem of practitioners and institutions" (p. 446). In other words, Bensimon (2007) argued that faculty and institutions should be the unit of analysis of future scholarly work on student success and that practitioners are the true "catalyst of change" (p. 464) in creating equitable educational outcomes.

Education pathway programs, supporting prospective teachers of color, have attempted to create classroom experiences and learning environments with similar strategies previously outlined in this section. In their case study of one program that created a Teacher Education Advocacy Center (TEAC), which aimed to provide more support for students of color interested in teacher education. Robinson, Paccione, and Rodriguez (2003) described some of the programs and services which were developed to create a "culture of support, encouragement, community building and goal attainment" for their students (p. 205). Of those program and services outlined in Robinson et al.'s study, some specifically addressed classroom experiences in baccalaureate programs, for 
example, TEAC staff designed a Freshman Cohort Learning Community where freshman considering becoming teachers are recruited and selected to "enroll in the same sections of General Psychology, English Composition, and Freshman Experience” (p. 206) together to complete prerequisite courses with like-minded individuals while also getting mentor support from faculty invested in social justice issues. The TEAC program staff and faculty also designed the Teacher Recruitment for Urban Schools of Tomorrow (TRUST) program, which recruited $77 \%$ ethnic minority students in the inaugural cohort, all of whom focused on teaching mathematics and science in high-need districts (Robinson et al., 2003). Furthermore, the TRUST program, with an emphasis on culturally responsive pedagogy, provided "academic, moral, and teaching support, unique field-based experiences in social service agencies, and a teaching position upon successful completion of the program" (p. 206). In their case study, Robinson et al. (2003) highlighted the work of one center at one teacher preparation institution; the programs and services provided are not necessarily unique. As discussed, many programs include elements that involve mentoring, culturally relevant pedagogy, curriculum that addresses racial identity development, assistance with the navigating college environment and support with testing requirements (Sleeter \& Milner, 2011). One of the criticisms of teacher education programs, with regard to recruiting and supporting students of color, is the lack of willingness to change the program; preparation programs do not make changes within but rather, "build support systems into, around, and through them" (Sleeter \& Milner, 2011,,p. 85). As discussed, the course content and the practitioners that teach those courses clearly have an effect on student success; teacher preparation in tandem with the baccalaureate programs leading to them must 
include a comprehensive approach and a visible commitment to recruiting, teaching and supporting students of color throughout the college experience.

Out-of-class engagement. Student participation in out-of-class activities on college campuses strongly influences non-cognitive factors, (e.g., perseverance, coping, self-perceptions) which affect student achievement (Good, Halpin, \& Halpin, 2007; Kuh et al., 2006; Schwartz \& Washington, 2007). Strategies, attitudes, and behaviors students bring to, or develop during, college influence decisions about the participation in campus life activities. Early exposure to higher education settings and first-year support programs may assist with adjustment to academic settings, as Schwartz and Washington (2007) affirmed in their study of first year, African American female college students. Schwartz and Washington asserted, "In addition to high school rank and grades, adjustment variables like social adaption are important considerations" (p. 39). Adjustment variables, as well as other non-cognitive skills, play an important role in student success. Good et al. (2007) emphasized in their study that looked at the retention of African American engineering students; acknowledging that "non-cognitive factors provided through involvement in a minority engineering program appear to be as essential to understanding retention as are the cognitive factors of student achievement" (p. 56). Hence, understanding more about what strategies, attitudes, and behaviors lead to positive student engagement, and ultimately success, is critical.

Much of what is written about participation in college life is termed student engagement (Kuh et al., 2006), and although student engagement may include in-class experiences, the focus of much of the research on student engagement refers to activities outside of the classroom. Student engagement includes two central elements: students' 
behaviors (e.g., time and effort studying, faculty interaction, peer involvement) and institutional conditions (e.g., educational polices, programs and practices, structural features, supports/resources) (Kuh et al., 2006). As Kuh et al. (2016) stated:

Student engagement represents two critical features. The first is the amount of time and effort students put into their studies and other educationally purposeful activities. The second component of student engagement is how the institution deploys its resources and organizes the curriculum, other learning opportunities, and support services to induce students to participate in activities that lead to the experiences and desired outcomes such as persistence, satisfaction, learning, and graduation. (p. 31)

Many examples of activities on college campuses can be considered educationally purposeful, such as active involvement in student government and participation in other student organizations. Some other activities have been deemed "high-impact" in this regard, such as service-learning opportunities, internships, and study abroad programs (Kuh, 2008). By extension, "While these and other educational purposeful activities are positively linked to desired outcomes for all types of students, historically underserved students and those who are less well prepared tend to benefit even more" (Kuh, 2007, p. 4). Unsurprising, in Harper's (2012) study on African American male achievers, high levels of student engagement are well documented in the college life of high achieving students. Harper (2012) noted that student engagement had positive consequences for almost all the participants in his study, in fact, "the men believed they earned higher grades because they had less time to waste, interacted frequently with academically driven others, and had reputations to uphold" (p. 12). Moreover, peer relationships are an integral part to student engagement activities. Harper reported, "Black male student leaders played an important role in helping the achievers transition smoothly to their 
colleges and universities" (p. 11). As with in-class experiences, the achievers in Harper's (2012) study benefited from working with faculty outside of the classroom, which greatly impacted their future opportunities in a variety of ways. In fact, "Student leadership positions gave these men access to campus officials on whom they could rely for advice, recommendation letters, advocacy, and insider knowledge about institutional policies and procedural loopholes (Harper, 2012, p. 16). Indeed, positive relationships - whether with other students, faculty or program and university personnel—often coincide with engagement activities and provide support for individuals in the path to and beyond a baccalaureate degree.

In framing the discussion on student engagement around teacher pipeline program options, examples in the literature are consistent with the aforementioned evidence, including links to educational gains, cognitive and intellectual skill development, adjustment, positive self-image, and persistence. Given the focus of many of the teacher pipeline program options on recruiting students of color, it is worth mentioning what Harper (2009) coined as, race-conscious student engagement (p. 38). Harper (2009) called attention to the need for institutions to adjust practices in ways that better support students of color; he pointed out that institutions should not assume that minority undergraduates will "comfortably initiate interactions with faculty, seek out engagement opportunities with the same ease as their White peers, or visit campus offices staffed by people who lack cultural competence" (p. 43). He went on to say that maintaining the status quo "unfairly puts the onus entirely on the students" (p. 43), and that raceconscious practices "attribute the presence of engagement inequities to institutional dysfunction" (p. 41). Harper noted: 
Effective educators avoid asking, what's wrong with these students, why aren't they getting engaged? Instead, they aggressively explore the institution's shortcomings and ponder how faculty members and administrators could alter their practices to distribute the benefits of engagement more equitably. (p. 41)

Harper is not alone in criticizing research, policies, and programs that put the burden on the student, as Reddick (2013) wrote:

We need to call to question research that frames Black students, or any demographic of students, as deficient or troubled, when in fact the blame and responsibility lies primarily, if not exclusively, in a structure that persists in penalizing youth for their race, ethnicity, and the absence of the transfer of intergenerational wealth. (p. 173)

Ultimately, personnel in educator preparation programs that want to recruit and prepare more teachers of color must embrace race-conscious student engagement practices, and faculty and administrators should question policies and practices if they are falling short in meeting their desired goals. In the next section of my paper, as part of the discussion on the last stage of the African American Teacher Pipeline (Figure 2), I provide more detail about race-conscious student engagement practices.

\section{Post-baccalaureate Success and Graduate Educator Preparation}

In attempting to analyze the differences and similarities between readiness to pursue a baccalaureate degree and career readiness, the Educational Policy Improvement Center, headed up by David Conley, conducted many studies about college and career readiness (Conley \& McGaughy, 2012). Conley and McGaughy (2012) suggested, "That college readiness and career readiness share many important elements, but they're not exactly the same" (p. 31). As Conley and McGaughy (2012) reported in a review of the literature: 
A lack of proficiency in [study skills, time management skills, persistence, and ownership of learning] probably affects career-oriented students more adversely than it does students entering bachelor's degree programs - in part because career-oriented programs tend to offer fewer supports to help students develop these skills if they lack them on entry and in part because students in such programs are more likely to be discouraged by problems early in their program. (p. 31)

In this section, I address the last stage on the African American teacher pipeline on post-baccalaureate success and graduate educator preparation (Figure 2). I shed light on how both issues suggested by Conley and McGaughy (2012), that is, fewer supports and sense of discouragement, are less likely to be found within graduate level and/or professional programs when students are offered "a comprehensive network of academic and support services" (Villegas \& Davis, 2007, p. 146). Such comprehensive services include, but are not limited to, consistent advising, support to develop cognitive skills, educationally purposeful out-of-class experiences, test-prep workshops, and admissions, and enrollment support.

Next, I reference barriers and obstacles that some students of color face in pursuing careers in teaching. I acknowledge that including research with a bent toward deficit-thinking is a deviation from the majority of the research reviewed herein, but I argue that in the case of the African American teacher pipeline, some specific issues warrant consideration as they cause a large portion of the "leaks" in the African American teacher pipeline in Oregon. This is not to say that I waiver from the premise that learning, for the most part, from past successes is most beneficial. It is also my intention to ground achievements in the socio-political context, learning from the past 
and using that knowledge to inform the present and future. I heed the advice of Allen (1992), who in talking about African American college student achievement, wrote:

Any attempt to address the problems faced by African-American college students without considering the broader context of issues confronting Blacks as a discriminated minority in America is doomed to fail, for the experiences of Black students in higher education are in part products of larger systemic problems. (p. 42)

Hence, to understand the larger systematic problems and to frame my problem in practice in a historical context, I begin with information about the history of African American teachers in the U.S. and follow with a description of the Oregon context.

A brief historical perspective of African Americans teachers in the U.S. I set the discussion about diversification of the teacher workforce in context of the history of African Americans as teachers in the U.S. In the years following the landmark U.S. Supreme Court decision, Brown v. Board of Education of Topeka, Kansas, the teaching workforce experienced dramatic changes in demographic makeup, specifically for African American teachers (Hudson \& Holmes, 1994; Lewis, 2006; Tillman, 2004). In 1954, the U.S. Supreme Court mandated that P-12 schools be integrated; meaning that all students be permitted to attend the same schools, share classrooms and materials, and participate in all school activities together. In practical terms, this decision also meant that African American students would begin enrolling in White schools, as opposed to White students enrolling in schools in African American neighborhoods. In a report about the condition of minority teachers in the U.S., Torres, Santos, Peck, and Cortes (2004) described, "While minority students were transferred in some numbers into majority-White schools, African American teachers were transferred with far less frequency. Apparently, no provisions were made to integrate school faculties, 
administrations, and staff' (p. 9). Consequently, as the schools consolidated in the White neighborhoods, African American teachers began to lose their teaching positions (Hudson \& Holmes, 1994; Lewis, 2006; Tillman, 2004). As represented in a timeline in Table 2, before the Brown v. Board of Education of Topeka (1954) was rendered, there were over 82,000 African American teachers in the U.S., but after the decision was rendered, within approximately 10 years, almost half $(38,000)$ of African American teachers lost their jobs (Hudson \& Holmes, 1994). Moreover, within 20 years of the landmark decision, the numbers of Africans choosing to major in education also declined drastically.

Table 2

The Loss of African American Teachers Following Brown v. Board of Education of Topeka: A Snapshot.

Pre-1954 Approximately 82,000 AfricanAmerican teachers were responsible for the education of 2 million African American children.

1954 The Brown v. Board of Education of Topeka decision was handed down.

1954-1965 More than 38,000 African American teachers and administrators in 17 southern and border states lost their jobs.

1975-1985 The number of African American students majoring in education declined by $66 \%$.

Note. Adapted from Missing teachers, impaired communities: The unanticipated consequences of Brown v. Board of Education on the African American teaching force at the precollegiate level, (Hudson \& Holmes, 1994, p. 389).

Researchers have deemed the loss of the African American teachers and 
administrators as both unanticipated (Hudson \& Holmes, 1994) and (un)intended (Tillman, 2004) consequences of the Brown v. Board of Education of Topeka decision. Moreover, as described by Torres et al. (2004):

The reduction in the numbers of African American teachers immediately following desegregation resulted in the loss of specific pedagogical skills that had been effective in educating prior generations of African American. When African American schools closed, the quality of teaching and the degree of concern for students' welfare appears to have diminished. (p. 14)

Likewise, Tillman (2004) highlighted the significance of African American educators in the pre-Brown era and defined this work as "a historical and cultural artifact" (p. 282). In addition, Tillman (2004) wrote, "The work of Black teachers in the pre-Brown era represented distinguished contributions to the long history of Black education" (p. 283); she added, "Black principals [of that era] served as connections to and liaisons between the school and the community, they encouraged parents to donate resources to the schools, helped to raise funds for schools, were models of servant leadership" (p. 283). It has been reported that African American educators lost their jobs as a result of many factors including, dominant culture perceptions of their inferiority, lack of support by the courts, demotions, and salary disputes (Hudson \& Holmes, 1994; Lewis, 2006; Tillman, 2004, Torres et al., 2004). Hudson and Holmes (1994) pointed out, "Because conditions will never again be the same, many of the positive features of the all-Black school systems of the pre-Brown era, and of the African American educators who worked within them, will be difficult to reproduce" (p. 392). Hudson and Holmes also suggested that the African American communities must look forward, "charting a new course" (1994, p. 392), for the education of their children. Unfortunately, since the publication of Hudson and Holmes' study, the percentages of African American teachers in the U.S. has grown 
very little, and sadly, in the six decades since the promise of the Brown v. Board of Education, of an opportunity to an education on equal terms, has yet to be fulfilled. The state of Oregon is no exception, but as evidenced by recent legislative acts (Chief Education Office, 2015, 2016; OEIB, 2014), it would appear there is some impetus for change.

Oregon historical context. The state of Oregon, and the largest metropolitan city in the state, Portland, historically has never had large percentages of African Americans as residents (Johnson \& Williams, 2010). Admittedly, since 1859, when Oregon officially became a state in the U.S. and throughout the late $19^{\text {th }}$ century, Oregon was considered "the most formidable and dangerous place outside the South for an AfricanAmerican person to call home" (Johnson \& Williams, 2010, p. 7). In fact, racist laws remained in the state's constitution until the mid-1920s (Johnson \& Williams, 2010). In part, because the population of African American students was so small, segregated schools were abolished in Portland in 1867 (Johnson \& Williams, 2010). The state's population of African Americans expanded to some degree in the 1940s (from approximately 1,900 in 1940 to approximately 23,000 in 1945), "resulting in a profound impact on the relationship between Portland Public Schools and the city's AfricanAmerican population" (Johnson \& Williams, 2010, p. 11). The population of teachers, however, remained predominantly Euro-American/White, and the loss of African American teachers, as noted in the Southern states, was not an issue in Oregon-after all, you cannot lose what you never had. Following the Brown v. Board of Education decision, many racially motivated, contentious, public debates in the Portland Public School district with community members focused on the inequities in education for 
students of color. Johnson and Williams (2010) noted that the African-American community, in particular, has been for decades "fighting for a quality education for its children" (p. 33), including a history of struggle for "implementation of policies that never fully addressed the concerns and needs of the African American community"(p. 33), which Johnson and Williams insisted "continue to exist today" (p. 33). The state is by no means fulfilling the promise of the Brown decision, as mentioned above, but there is some effort to do so, as evidenced in the Oregon Educator Equity Act, what was formerly called the Oregon Minority Teacher Act (Chief Education Office, 2016, 2016; Governor's Office of Education and Workforce Policy, 2001). As outlined in reports from 2015 and 2016, the state continues to struggle with meeting goals mandated by the legislature for increasing the number of diverse teacher candidates in our state's preparations programs. Noted in the 2016 Oregon Educator Equity Report:

If educator preparation programs were able to graduate candidates who mirrored the demographics of Oregon's graduating high school students, the pool of candidates for hire should be over 31 percent racially and linguistically diverse. However, the percent of 2014-15 teacher candidates completing a public, private non-profit or for-profit educator preparation programs is 10.34 percent, approximately one third of that goal. (p. 5)

To meet the goals mandated by the Oregon legislature, efforts must be made to eliminate barriers to admission and enrollment in public teacher education programs, as well as obstacles to licensure and employment. One strongly recommended recruitment strategy highlighted in the literature, which taps into pools of employees already in the school district, encourages focusing recruitment initiatives on P-12 paraprofessionals or educational assistants (Clewell \& Villegas, 2001). Likewise, recruitment of educational assistants has been identified as a key strategy to diversify the Oregon teacher workforce 
(OEIB, 2014a). Promising practices in Oregon were highlighted in the 2015 and 2015 reports, which included, early recruitment strategies, such as cadet programs in middle and high schools; collaborative efforts that emphasize university and school district partnerships; and programs beginning in community college and providing a seamless bridge to university preparation. Other approaches included such ideas as financial assistance, increasing student support services, hiring diverse faculty, and helping with retention efforts for students of color of campuses. In addition, model Oregon programs employ strategies described in more detail below, but even model programs face challenges and seek out strategies to improve upon their recruitment practices. In the following section, I summarize key recommendations from a variety of model programs, which are recognized practices for recruiting teachers of color.

Key recommendations from model programs. In addition to the models described by Oregon policymakers and stakeholders (Chief Education Office, 2015, 2016; OEIB, 2014), many reports and studies published by national organizations and associations (Boser, 2011, 2014; Bireda \& Chait, 2011; Dilworth \& Coleman, 2014) and program evaluators and researchers (Clewell \& Villegas, 1999, 2001; Robinson, Paccione \& Rodriguez, 2003) have highlighted key findings for recruiting and preparing more teachers of color in the U.S. In an attempt to move the agenda of diversifying the U.S. teaching force forward, reports and studies have provided recommendations. Of the bounty of recommendations, to recruit more teachers of color available in the extant literature, I selected suggestions that relate closely to my study. While this is not an exhaustive or comprehensive list, it is a discerning list most applicable to my research and the Oregon context. 
Prior to citing specific teacher recruitment strategies, I preface key recommendations with context about what influences people to teach. In his seminal work, Schoolteacher, Lortie (1975), identified five themes, which draw individuals into the teaching profession. Although the initial research was conducted in 1975, Lortie's themes still resonate with recent literature; themes included: (a) the interpersonal theme, working with people, especially young people; (b) the service theme, service to the community and making a difference in peoples' lives; (c) the continuation theme, based on having had positive experiences in school and the desire for school/education associated employment pursuits; (d) the market/material benefits theme, a desire for a stable and secure income; and, (e) the time compatibility theme, having a profession that is compatible with family needs and/or personal desires (e.g., having summer breaks and a schedule more suited for parent responsibilities) (Lortie, 2002). In terms of the present day, Ramirez (2010) — who conducted a study with 76 students of color from institutions in Southern California—reported similar findings. The students' in Ramirez's (2010) study perceptions of teaching, which I have framed using Lortie's (2002) themes, included the service theme (e.g., giving back to the community), the material benefit theme (e.g., summer breaks, time off) and the material benefits theme (e.g., retirement and health insurance benefits). Whether researchers have taken these themes into consideration when developing recommendations for recruitment is unknown, but as Lortie (2002) emphasized in his original text, they bare significance as "recruitment resources" (p. 26).

The following are key recommendations found in the literature on recruitment of teachers of color. Each recommendation can stand by itself as a single strategy that 
stakeholders may want to employ. However, given that teachers enter the profession through a variety of non-linear and multivariate pathways, and there are many factors which may influence decision-making, a multilayered recruitment effort that utilizes more than one strategy is advised and highlighted within the literature (Burbank \& Diaz, 2012).

Specialized cohort models. Researchers called for specialized cohort-based programs focusing on the needs of students of color as they navigate the educator preparation program together (AACTE, 1989; Burbank \& Diaz, 2012; Clewell \& Villegas, 2001; Hollins \& Guzman, 2005; Ramirez, 2010; Robinson, Paccione \& Rodriguez, 2003). In a review of the literature on preparing teachers for diverse populations, Hollins and Guzman (2005) reported, "In special programs or cohorts for candidates of color, the intention is to build the camaraderie that supports candidates' learning that is missing in many programs where candidates of color are in the minority" (p. 505). Cohort models offered opportunities of both formal and informal peer support systems, mentoring and alumni involvement.

Financial incentives and support. College is expensive, and teacher preparation programs are not an exception. National reports and research studies call for the need for more funding streams for prospective teacher candidates, especially for historically underrepresented students (Boser, 2011, 2014; Clewell \& Villegas, 2001; DarlingHammond, 2007; NEA, 2009). Unfortunately many teacher pipeline programs that support students of color begin with short-term funding streams (e.g., grants with timelines), and may not be sustainable; establishing sustainable financial support is a must (Bireda \& Chait, 2011; Clewell \& Villegas, 1999). Financial support comes from a 
variety of sources (e.g., federal, state, educational institution, school district) and may be dispersed in different ways (e.g., tuition, scholarship), and some programs have a postprogram employment commitments for recipients (e.g., working with specific populations or locations). The literature on financial support does not outline a silver bullet or recipe for success, but funding sources are universally agreed upon as a key recommendation for program success.

Comprehensive advising systems. To assist teacher preparation programs with recruiting more students of color the American Association of Colleges for Teacher Education (1989) published a guide and described, "The four Cs of recruitmentconcern, commitment, collaboration, and creativity..." (p. 8). The strategies for success focused on program characteristics that lead to a comprehensive approach, not only to recruitment, but also to a multi-faceted, institutionally supported commitment to students of color pursuing careers in teaching. An example in the literature of this type of comprehensive approach was a case study (Robinson, Paccione \& Rodriguez, 2003) about the Teacher Education Advocacy Center (TEAC) at one institution, which intentionally sought to offer students multi-level support with an emphasis on persistence and retention. "The variety of programs sponsored by TEAC supports students in finding their own place within the structure, recognizing that pre-admission, undergraduate, postbachelor, or career change students may have different needs" (Robinson et al., 2003, p. 210). Described as "not just a bag of tricks" (Robinson et al., 2003, p. 210), but rather as a well-organized coordinated effort to intentionally support students of color from a variety of programs; TEAC provides multiple examples of what the researchers support 
(AACTE, 1989; Clewell \& Villegas, 2001; Wong, Murai, Berta-Avila et al., 2007) as a need for comprehensive advising.

Partnerships and community involvement. Collaborations and partnerships across and within the teacher education community are highlighted throughout the literature about recruiting more teachers of color (Burbank \& Diaz, 2012; Clewell \& Villegas, 2001; Lewis, 2006; Villegas and Irvine, 2010). Partnerships associated with teacher pipeline programs are typically found between community colleges and baccalaureate granting institutions, but researchers have pointed out the need for more collaborations with P-12 settings (Clewell \& Villegas, 2001). Granted, partnerships and collaborations need to be about more than student teaching field placements and hires for hard-to-staff schools, they need to focus on the needs of the prospective teachers and the needs of the P-12 students. Burbank and Diaz (2012) pointed out the need for "honest conversations within collaborative partnerships" (p. 1024); as collaborations between educational entities can be challenging as noted by the NAACP (Glenn, 2012):

When preparation programs do seek to establish close partnerships with local schools, they often encounter barriers such as misaligned cultures and schedules. These disconnects represent a real loss of expertise among educators on both sides of the PK-12/higher education divide and to the profession as a whole and contribute to ineffective teaching contexts. (p. 20)

In my estimation, community extends beyond the P-12 school buildings and higher education institutions - partnerships could potentially exist between and among different organizations/agencies (e.g., school districts, four-year colleges, two-year colleges, teachers' unions, community organizations) and as suggested by Lewis (2006) the community role in the recruitment of teachers of color is worthy of further consideration. 
First, the majority of traditional teacher preparation programs in the state of Oregon are at the graduate level. As with teacher preparation programs in the neighboring state of California-where undergraduate college students are required to add a fifth year of study to complete preliminary state credentialing requirementsOregon prospective teachers are often faced with post-baccalaureate requirements. Ramirez (2010) reported that participants had negative thoughts about California's state requirements and perceived fewer students of color pursued careers in teaching because they "knew that they would likely have to put in five years of schooling before receiving a teaching credential, with the fifth year adding additional expense after earning their [bachelor's] degree" (Ramirez, 2010, p. 34). One of the recommendations Ramirez (2010) called for as a method to increase the recruitment of more teachers of color was "Creation of 4-year teacher credential programs" (p. 35). I did not list baccalaureate program as a recommendation, because there is some debate as whether this strategy would increase recruitment of teachers of color. Zumwalt and Craig (2005) noted in their review of the literature on the characteristics of teachers going into the profession, that master's level (and alternative) programs are attracting a higher proportion of teachers of color into the profession.

Second, issues and concerns raised about recruiting teachers of color across the U.S., for the most part, are also evident in the Oregon landscape. An example of a common challenge found in Oregon and throughout the nation is teacher testing, that is, the battery of teacher licensure exams that include basic skills tests (e.g., reading, writing, mathematics), content/subject matter tests, and pedagogical knowledge tests (Wilson \& Youngs, 2005). Researchers and stakeholders have raised concerns about high-stakes 
standardized tests, regulated by state licensing agencies, being barriers to certification for teachers of color (Bennett, McWhorter, \& Kuykendall, 2006; Dilworth \& Coleman, 2014; Sleeter, 2008). Having spent more than 10 years serving as the liaison to the state licensing office for a public university, I am well acquainted with Oregon's rules and requirements for educators - I am aware that there have been many changes to the rules and procedures related teacher testing over the past several decades. The most recent change to teacher testing in Oregon is the adoption of a pedagogical knowledge test that will be administered during the teacher preparation program, prior to licensure. Oregon has offered "alternative assessment" options in the past, but with accountability concerns, these options have all been eliminated. The research on teacher testing provides mixed, if any, results; Wilson and Youngs (2005) pointed out, researchers in the U.S. “...know next to nothing about certification tests' predictive validity" (p. 610). Nevertheless, Oregon is one of the many states maintaining testing requirements for teachers. The third, and last consideration to the Oregon context, is related most intimately with my topic; that is, in Oregon, a vast majority of the students enrolled in higher education institutions (as well as in the teaching workforce) are predominantly White, which may be a concern for some students of color when considering options for graduate study and a future career. The key recommendations help to address concerns of this nature, but obviously they can only do so much. As Oregon and the U.S. move closer to becoming a "majority-minority" state and nation, which may be within the next 25-50 years, this issue will become less significant, as most of higher education will no longer be made up of predominantly White institutions (PWIs). 
Review of the Methodological Literature

In this section, I offer a brief introduction of the methodology and the application to my research. In Chapter 3, I discuss the methodological design for my study in more detail. Given my desire to explore the varied and unique life and educational experiences of a select group of African American teachers in Oregon, the qualitative approach was the most fitting approach. The discovery-oriented and rich descriptive nature of both my research questions and the evidence necessary to answer them is most certainly characteristic of this approach to research. Qualitative research is an appropriate choice when the emphasis of the inquiry is on understanding unique situations and when the researcher plays an active role in both collection of data and analysis (Merriam, 2009). In addition, qualitative research requires an inductive process, in that "the framework is informed by what we inductively learn in the field" (Merriam, 2009, p. 16), and the evidence collected is in words rather than numbers (Maxwell, 2005).

To gain a better understanding of the unique experiences of African Americans teachers as they pursued their careers in Oregon, qualitative case study design was chosen. Case study methodology shares qualities of other forms of qualitative research (Merriam, 2009), but in addition, the focus of the inquiry and investigation of case study design is of a specific "bounded" system (Merriam, 2009; Yin, 2014). Additionally, case study provides an in-depth description of a contemporary phenomenon studied in a realworld context, as Yin (2014) described, "The boundaries between the phenomenon and context may not be clearly evident" (p. 16). In my research, the phenomena I studied were African Americans teachers in Oregon as they navigate the academic pipeline to their desired career. The boundary of the case study is the specific Teacher Pipeline 
Program (TPP), which all of the participants completed as part of their pathway to teaching. I applied a cross case analysis in my research study; thus, further defined my research methodology as a multiple case study; exploring the experiences of more than one case allowed me to discover more robust findings.

One of the main strengths of qualitative multiple case study design is that "case study offers a means of investigating complex social units consisting of multiple variables of potential importance in understanding the phenomenon" (Merriam, 2009, p. 50). For my particular interests, this research methodology offered an opportunity to explore insights into the lives of African American teachers, through rich, thick description, specific to their pursuits of a career in teaching; focusing on a limited number of participants, or what can be described as a small sample size. However, one of the main limitations noted with case study design is the issue of generalizability (Merriam, 2009). What compelled me to choose this specific research topic was my interest in recruiting more African American teachers in Oregon; though findings of my research may not be generalizable, through a cross-case analysis I was able to discern critical lessons learned. Yin (2014) described such lessons learned from case study research, as "analytic generalizations" (p. 41). Yin wrote, "The analytic generalization may be based on either, (a) corroborating, modifying, rejecting, or otherwise advancing theoretical concepts that you referenced in designing your case study, or (b) new concepts that arose upon completion of your case study" (p. 41). Flyvbjerg (2006) stated, "Formal generalization is overvalued as a source of scientific development, whereas the force of one example is underestimated" (p. 228). Hence, the limitation of generalizability is a factor of consideration, but the ability to provide a detailed account(s) and rich 
description of my phenomenon of interest was of upmost importance to me as a researcher, and I found the process to be a very worthy endeavor.

In addition to the lack of generalizability, other limitations of case study design include: (a) time and resource intensive data collection and analysis, (b) potential researcher bias, (c) perceived lack of rigor, (d) reliance on self-reported evidence from interviews, and (e) concerns about accessibility for stakeholders outside of academia due to the in-depth narrative results, as opposed to numeric findings reported in quantitative research (Flyvbjerg, 2006; Merriam, 2009, Yin, 2014). In the next paragraphs, I describe qualitative case studies conducted on related phenomena in similar contexts as further justification of the applicability of a case study design for my research.

First, Achinstein and Ogawa (2011) conducted a multiple-case study of 17 novice teachers of color, and although they reported on the retention of teachers of color in relation to the school accountability movement; they did not begin their study with the intention of focusing on school accountability. Instead, Achinstein and Ogawa's (2011) addressed issues associated with the diversification of the teacher workforce, and the overall purpose of their research was to "study how the interplay between teacher's personal/professional histories and the school contexts in which they work affects how they teach and the meaning they attach to that experience" (p. 8). Achinstein and Ogawa (2011) described using case study approach for the "opportunity to describe teachers' conceptions and the classroom practice" (p. 8), also "to obtain an in-depth understanding of processes contexts and their meanings for those involved" (p. 8); their decision to use case study approach echoed my own intentions. Achinstein and Ogawa (2011) also described the benefits of using case study to "build theory about relationships that may 
otherwise remain hidden" (p. 8). In my study, for example, structured program supports were more visible, but other elements (e.g., personal relationships, cultural connections, and supplemental supports) were less obvious or transparent.

Second, Robinson, Paccione and Rodriquez (2003), focused on a center (Teacher Education Advocacy Center (TEAC) within one university that supported programs and practices to recruit and retain students of color in teacher preparation. Robinson et al.'s (2003) case study was bounded by the center (TEAC), and not one individual program, thus the research included multiple sources of evidence (e.g., research reports, structured and informal interviews, observations) and three researchers. Robinson et al. (2003) used comprehensive single case study design — bounded by one center, "the setting's efforts toward recruitment and retention of preservice teachers of color were the focus of the case study" (p. 203). In the next chapter, I discuss single case versus multiple case design, as well as my rationale for doing a multiple case design.

In a third case study, Bryan and Browder (2013) explored the experiences of one African American male teacher focusing on the problem of why so few African American males choose teaching as a profession. The rationale for choosing case study methodology was "to capture the unique voice of an African American male kindergarten teacher, while also capturing the authenticity of his pre-service and in-service teaching experience" (p. 147). Bryan and Browder (2013) added, "The voices of African American male teachers have been excluded from extant literature, privileging the voices of individuals from dominant culture groups in pre-service and in-service teaching" (p. 147). Additionally, and similar to my own study, this study included semi-structured interviews and prior to analysis the interview transcripts were member checked by the 
participant to ensure accuracy. Bryan and Browder (2013) disclosed, "Structural and institutional barriers that hinder the academic and professional plight of African American males extends beyond the P-12 educational contexts (i.e. higher education and professional spaces)" (p. 153). They reported that their findings added to the knowledge base by naming the barriers in the spaces (i.e., racial and gender microaggressions and hyper-visibility).

For my case study, I conducted semi-structured interviews, and as with the limitations related to any research methodology, there are concerns with sources of evidence and data collection techniques. One limitation of interviewing, whether structure, semi-structured, or non-structured, is the self-reported nature of the collected data, which is at risk for including inaccuracies. That is not to imply that participants intentionally provide false information, yet there is the possibility that individuals may have issues associated with misperception, memory, or they may simply misspeak. As discussed in relation to the case study by Bryan and Browder (2013), member checking is one way of combating some of the inaccuracies, which I also applied. I discuss the interview procedures in Chapter 3.

\section{Summary of Literature Review}

In this chapter, I put forth a rationale for studying factors that contribute to the recruitment of African American teachers in the profession of teaching, and situated within the theoretical frame of self-efficacy and the conceptual framework of an assetsbased model, research questions for this study are embedded within the essential arguments and current scholarly work. Underlining my study was the idea that despite obstacles, some African Americans in Oregon have chosen to be, and have succeeded in 
becoming, teachers; to that end, the review of literature highlights the stages of the academic pipeline, and the various motivators and factors within each, that drive some students toward success. Within this chapter, I described relevant literature using African American Teacher Pipeline model, adapted from Harper's (2010, 2012) Anti-Deficit Achievement Framework.

The African American Teacher Pipeline model includes three major pipeline points/stages, including pre-college socialization and readiness, baccalaureate college achievement, and graduate educator preparation program success - embedded within the last two stages of the pipeline is the TPP. Discussed within the first stage of the pipeline are familial factors, P-12 school forces, and college prep resources. As Perna and Thomas (2006) acknowledged, "Student behavior cannot be fully understood without attention to the context in which the student lives" (p. 10), thus, literature related to context of African American students was reviewed. For example, extracurricular activities and early exposure to college raised expectations about degree attainment (Conley \& McGaughy, 2012, Harper, 2012). Villegas and Irvine (2010) identified practices of successful teacher of color in a review of the literature on increasing achievement of students of color which included, "having high expectations...; using culturally relevant teaching; [and] ... developing caring and trusting relationships with students" (p. 180).

Literature related to the college experience was also discussed; specifically the role of community college experiences for students of color was explored (Ahmad \& Boser, 2014; Palmer et al., 2014; Wood \& Palmer, 2014; Wood \& Turner, 2011). The notion of student engagement was highlighted as a mechanism to enhance and increase 
achievement for students of color (Kuh, 2007, 2008; Kuh et al., 2006). In reference to the last stage of the pipeline and with regard to educator preparation, literature about key recommendations from model program on the recruitment of teachers of color was discussed. Recommendations included specialized cohort models (Burbank \& Diaz, 2012; Clewell \& Villegas, 2001; Hollins \& Guzman, 2005), financial incentives (Boser, 2011, 2014; Darling-Hammond, 2007), comprehensive advising systems (Robinson et al., 2003; Wong et al., 2007), and partnerships (Burbank \& Diaz, 2012; Lewis, 2006; Villegas and Irvine, 2010). High-stakes standardized tests, regulated by state licensing agencies, were also discussed as being barriers to certification for teachers of color (Bennett, McWhorter, \& Kuykendall, 2006; Dilworth \& Coleman, 2014; Sleeter, 2008; Wilson \& Youngs, 2005).

I concluded this chapter on the review of literature with a brief rationale about my choice to conduct a qualitative case study to explore the successes of African American teachers in Oregon, and examples of methodological literature that justified my selection of research method (Achinstein \& Ogawa, 2011; Bryan \& Browder, 2013; Robinson et al., 2003). In the next chapter, I describe the methods, procedures, and data analysis used in my study. 


\section{Chapter 3: Methods}

As the United States' P-12 school student population has grown increasingly diverse over the past several decades, concerns about employing an overwhelmingly White population of public school teachers have heightened across the nation. As of 2016 , the number of teachers of color in Oregon had increased to $10 \%$ of the total Oregon teacher population; however, African American teachers make up less than one percent of that population (ODE, 2016). The purpose of this dissertation was to examine the factors that contribute to the recruitment of African Americans into an educator preparation program in Oregon. Success stories of African Americans may shed light on motivations, supports, networking strategies, and optimal pathways for prospective teachers; to that end, this study used the following research questions to guide the inquiry:

1. What do African American teachers report as reasons for choosing to become a teacher in Oregon?

2. How do some African Americans teachers in Oregon describe their journey into teaching?

3. How might the lived experiences of African American teachers' success stories help others in Oregon?

4. What recommendations do African American teachers make to improve recruitment efforts and African American representation in the teaching profession?

Scholars interested in African American teacher recruitment have considered similar lines of research, but this study addressed a gap in the literature: the absence of African American teachers' voices and perspectives specifically related to the Oregon context. I used qualitative case study research methods, interviewing multiple participants, because 
I wanted to gain an in-depth understanding of a select group of African Americans' journeys to their professional careers in teaching.

\section{Research Method: Qualitative Case Study}

For this dissertation, I used qualitative case study methodology (Merriam, 2009;

Yin, 2014) with semi-structured interviews to explore the aspirations and experiences of African Americans who pursued careers in teaching in Oregon. My research was aligned with the strengths of qualitative research, derived “...primarily from its inductive approach, its focus on specific situations or people, and its emphasis on words rather than numbers (Maxwell, 2005, p. 22). Most importantly, qualitative research, as opposed to quantitative, was a suitable choice given my focus on an interpreted study of a real-world, contemporary issue (Maxwell, 2005; Yin, 2014). According to Merriam (2009) the overall purposes of qualitative research is to "achieve understanding of how people make sense out of their lives, delineate the process (rather than the outcome or product) of meaning-making, and describe how people interpret what they experience" (p. 14). I investigated the perspectives and experiences of African American teachers and their journeys into teaching within the Oregon context. Because I sought to understand the experiences of African American teachers, a qualitative case study was most appropriate.

Furthermore, qualitative case study methodology was well suited to investigate the experiences of a set group of teachers who participated in a specific teacher pipeline program, a bounded system (Creswell, 2005; Merriam, 2009; Yin 2014). The singular and narrowed focus on African American alumni of a specific teacher pipeline program (i.e., my "cases") validated the applicability of qualitative case study methodology. Through the stories of four individual African American teachers, I reported the success 
stories of the participants on their distinct journeys along the academic pipeline.

Examining the context and associated complex conditions embedded within was an essential element of my research. Yin (2014) described case study as "an empirical inquiry that investigates a contemporary phenomenon (the "case") in depth and within its real-world context, especially when the boundaries between phenomenon and context may not be clearly evident" (p. 16). In other words, the variables and phenomena studied are highly situated within the context and this indistinguishable quality makes them difficult to define in advance (Merriam, 2009). In my study of African American teachers, the factors that contributed to their recruitment and successes were embedded within the context of their experiences.

Another feature of case study design that sets it apart from other research methods is the types of research questions posed (Yin, 2014). Yin (2014) contended that posing "how?" and "why?" questions are preferred and favored in case study design. My questions were exploratory, and as Yin (2014) described, exploratory questions lend themselves to various research methods, including case study methodology. An interpretive, naturalistic approach to qualitative research emphasizes participant perspective, context, and meaning-making (Creswell, 2005), which is rooted in constructivist theory (Baxter \& Jack, 2008). Social constructivists posit that learning is a collaborative process; in other words, learners are not learning in complete isolation, learning occurs in a social context. This notion of learning in collaboration with others, not as an isolated solo-activity, is foundational to case study research (Yin, 2014). With regard to case study design, Baxter and Jack (2008) noted: 
One of the advantages of [case study] approach is the close collaboration between the researcher and the participant, while enabling participants to tell their stories. Through these stories the participants are able to describe their views of reality and this enables the researcher to better understand the participants' actions. (p. 545)

An effective way for me, as the researcher, to capture participants' voices was through interviews.

Interviews are commonly found in case study design and provide an opportunity for in-depth inquiry, and the relationship between the researcher and the participant is often developed during face-to-face interviews. As Yin (2014) asserted, "One of the most important sources of case study evidence is the interview" (p. 110). In this study, I used semi-structured interviews for data collection. With semi-structured interviews the researcher asks a series of predetermined questions but the format of the interview more resembles a "guided conversation rather than structured queries" (Yin, 2014, p. 110). Though more structured than an open-ended approach, the semi-structured interview approach is often "guided by a list of questions or issues to be explored" (Merriam, 2009, p. 90). During my inquiry, a semi-structured interview allowed for some flexibility and permitted topics to be explored, while still having elements of organization and format. Interviews allowed me to query participants for more details, which aided in collecting richer information and provided opportunity for clarifications. As Yin (2014) noted, "Case study research requires an inquiring mind during data collection, not just before or after the activity" (p. 73).

Moreover, in-depth interviews played a vital role in my research to examine the factors that contributed to the recruitment of African American teachers. At the core of my research was my desire to understand their experience, and "the meaning they [made] 
of that experience" (Seidman, 2013, p. 9). Kvale and Brinkmann (2009) described the importance of narrative stories, in that they are "a powerful means of making sense of our social reality and our own lives. The interview is a key site for eliciting narratives that inform us of the human world of meanings" (p. 55).

As a data collection method interviews have disadvantages. Besides the obvious time and resource intensive format and the need for human subjects to be involved, which can be viewed as unpleasant or prying to some participants, there are also concerns with the self-reported information (Merriam, 2009; Seidman, 2013). Self-reported information is susceptible the interpersonal issues that can exist between interviewer and respondent; as Merriam (2009) conveyed, "The interviewer-respondent interaction is a complex phenomenon. Both parties bring biases, predispositions, attitudes, and physical characteristics that affect the interaction and the data elicited" (p. 109). During the indepth interviews I conducted, I attempted to acknowledge factors associated with complexity of interviewer and responder interaction. I sought to be an attentive, respectful, and active listener; attentive to situational cues and approached inquiries in a manner that was respectful to the participants by limiting my attention to the predetermined interview questions (Kvale \& Brinkmann, 2009). Yin (2014) posited,

Being a good listener means being able to assimilate large amounts of new information without bias. As an interviewee recounts an incident, a good listener hears the exact words used by the interviewee... captures the mood and affective components, understands the context from which the interviewee is perceiving the world and infers the meaning intended by the interviewee (not by the researcher). (p. 74)

That being said, the interview protocol helped to create an equitable environment for each interview, as well as provide me with a script to review in advance of the interview with reminders about details, general tone, and format. 


\section{Multiple-Case Design}

Worth noting, case studies can be either a single-case design or a multiple-case design, and I considered both options in relation to my study. According to Yin (2014), researchers choose single-case designs "where the case represents (a) a critical test of existing theory, (b) an extreme or unusual circumstance, or, (c) a common case, or where the case serves as a (d) revelatory, or (e) longitudinal purpose" (p. 56). In contrast, multiple-case designs, are applied when the researcher is interested in exploring "differences within and between cases" (Baxter \& Jack, 2008). Multiple-case study design lends itself to gathering data from more than one case and thus allowing for comparing and contrasting results, and ultimately drawing conclusions from the facts (Baxter \& Jack, 2008). Yin (2014) contended that there are benefits of a common set of evidence that is collected from multiple cases, as findings are likely to be stronger than the analysis of a single case. Thus, I applied a multiple-case study design, with each participant representing a distinct case. Data collection focused on the experiences of this homogeneous select group (e.g., African Americans), and research was bound by their affiliation with a specific program (e.g., Teacher Pipeline Program). Inquiry was aimed at capturing the nuances and context of each participant's journey into teaching as a career-from their early career aspirations, college experiences with advising and in the teacher pipeline program, admission and enrollment in graduate school, and finally to the point when they received their teaching license- - which allowed for analysis within and between their experiences. In the following sections, I provide more detail about the participants, procedures, including instruments and measure, as well as the data and analysis of my study. 


\section{Pilot Study}

After the Institutional Review Board approved the study, I consulted with the Research Integrity Coordinator who determined that the pilot study met requirements to proceed. The pilot study was conducted to ensure that the pre-questionnaire survey was appropriate and to determine the effectiveness of the interview questions.

Pilot study participants were chosen based on recommendations from the Teacher Pipeline Program and my dissertation advisor. A small group of African American educators, graduates of the same Teacher Pipeline Program as the participants in the proposed research study, were contacted via email.

For this pilot study, interviews were conducted in July-August 2015. Pilot study participants received a copy of the pre-questionnaire and a consent letter with permission to record the interview. The interviews were conducted in school district central office buildings, in the participants' offices, at a time that was convenient for them. Follow-up conversations took place after the interviews to obtain their feedback about the instruments and the study. After review of the recorded interviews, I made minor adaptions to the pre-questionnaire survey based on the recommendations of the pilot study participants.

\section{Participants}

To be selected for this study, participants needed to meet specific criteria. The criteria included all participants (a) were adults who had participated in a specific teacher pipeline program, (b) completed a graduate level teacher preparation program in Oregon, and, (c) were African American or Black. To select these participants, I employed “purposeful sampling” (Creswell, 2005 p. 88). 
Purposeful sampling is an approach to participant selection for a qualitative study that is intentional and based on the phenomenon being studied (Creswell, 2005). As mentioned, participants were graduates of the Teacher Pipeline Program (TPP) in Oregon. The TPP admits students with diverse racial backgrounds, but for the purposes of this study, only African Americans were allowed to participate. Thus, the purposeful sampling strategy termed "homogeneous sampling" (Creswell, 2005, p. 206), was used to intentionally limit participants who are all similar to each other in some way(s) (e.g., African Americans), while also being rich with information as it related to the phenomena studied. One other defining characteristic critical for limiting the sampleemployed the homogeneous sampling strategy—all participants from the TPP must be alumni. In other words, foundational to the phenomena being studied is the component of success, and all teacher pipeline program participants must have achieved success and be licensed teachers. Notably, the number of individuals recruited for this study was small, as it typical in qualitative research design (Creswell, 2005). By focusing on this limited number of individuals, I was able to conduct in-depth interviews, providing a nuanced picture of the participants' experiences navigating all of the points along the academic pipeline to a career in teaching.

Four African American educators agreed to participate in the study. All four of the participants were working in an Oregon school; three were classroom teachers, while one had recently transitioned from the role of teacher and was serving in an administrative capacity. They had a range of more than one to eight years of experience as teachers.

Two of the participants were women, Deanna and Carmen, and two were men, 
Noah and James (all pseudonyms). Noah and James were born on the east coast of the United States, spending the majority of the early years in that part of the country, while Deanna and Carmen were both native to Oregon and had never lived elsewhere. All four of the participants attended community college prior to transferring to the university to earn their Bachelor's degree. Their educator preparation programs were also mixed; Deanna and Noah were prepared to teach elementary school and Carmen and James were prepared to teach middle and high school levels. One of the participants, James, was a career changer, coming into the profession after having a career in the military for 20 years.

\section{Procedures and Data Collection}

In the following section, I describe the procedures used to conduct my study, including participant recruitment, informed consent, maintenance of confidentiality and retention procedure, and data collection instruments.

\section{Recruitment}

After the Institutional Review Board granted approval of the study, I worked closely with the Teacher Pipeline Program (TPP) Director to determine a date to present my research to alumni. To solicit participation, I planned to present information about my study at a TPP alumni event. My plan was to describe topic of my research study at an alumni advisory board meeting, as an agenda item to be considered for a future alumni meeting. This potential alumni meeting agenda item was shared with alumni in other conversations with the TPP Director. Unfortunately, the TPP alumni meetings were not scheduled for several months. Therefore, TPP Director identified a pool of individuals based on her email correspondence with alumni who expressed interest in learning more 
about this research. With the assistance of the TPP Director, I contacted 14 prospective participants via email (see Appendix A).

Given the director's support of my study and access (via email) to TPP alumni interested in learning more about my study, participant recruitment was straightforward. I provided potential participants a brief description of my study in the form of a flyer (see Appendix A) attached to the email, including information about the interview process, time commitment, proposed timeline, as well as information about confidentiality. In addition, I answered individual questions over the telephone and through email, posed by eight potential participants with regard to my study. Upon agreement through email, I received six prospective participants. Due to time restraints and work responsibilities on the part of the prospective participants, two of the six individuals did not participate in the study.

\section{Informed Consent}

Once participants expressed interest in participation of my study, I obtained written informed consent (see Appendix B) that included detailed information about expectations as a participant in my research study. For example, the participants had an opportunity to review data collected in the form of a transcribed copy of their interview.

\section{Maintaining Confidentiality}

The completed informed consent form remained secure in my home office to protect their identities. I maintained digital information on my password-protected computer. I maintained written data in my home office, such as the written informed consent form, which remained locked when I was not at home. To protect their identities and ensure privacy, I used pseudonyms for all of my participants. In addition, I kept all 
data confidential — only referring to participants by their pseudonyms, and never using the participants' names, or the names of other individuals, places, or schools they mentioned during the course of this study, in written or electronic form, unless I was communicating with them directly. I destroyed the digital recordings six months after transcription was completed. As proscribed by the IRB, I plan to retain all notes, data, and informed consent documents for three years after the dissertation defense.

\section{Data Collection Instruments}

In all, I collected four informed consent forms and conducted in-depth interviews with these participants. Each participant was interviewed two times for approximately 90 minutes each time. Most of the interviews were conducted at the participant's school, with the exception of one interview that occurred at the university library. Interviews were occurred from October 2015 through January 2016. In the following sections, I describe the two instruments used to gather data: the pre-interview questionnaire and the interview protocol.

Pre-interview questionnaire. Upon receiving the signed informed letter of consent, I sent all participants a copy of the pre-interview questionnaire (see Appendix C). This questionnaire was used to collect a limited amount of demographic and specific information about the participants prior to the interview.

Interviews. Upon receiving the completed pre-interview questionnaire, individual interview times and locations I conducted the interviews based on the participants' availability and preferred location. I offered nonspecific location suggestions to the participants, such as a local library or their place of employment, and define appropriate criteria (e.g., quiet and private room). I allowed the participants to 
determine the dates, times, and locations of the interviews. The in-depth interview format, as explained within the description of case study methods, was designed to provide detailed rich context-based information about the experiences of each participant. The interview questions, embedded with the context of the interview protocol, are fully outlined in Appendix D. The interview protocol included a main set of questions as well as a number of sub-questions that I used to elicit more information or to provide clarity regarding participant responses. I interviewed each participant two times for approximately 90 minutes each time. The first interview focused on their family and life experiences, pre-college, and undergraduate college experiences, including community college and university. The second interview focused on their decision to be a teacher, graduate school, the TPP, and the educator preparation program. In addition, there were a few questions at the conclusion of the second interview, which asked participants to share ideas for attracting more African Americans into the teaching profession in Oregon.

Interview protocol. Prior to each interview, I arrived at the interview location in advance and spent 10-15 minutes reading through the protocol that included reminders about preparation, tone, and format; the protocol also included the verbal line of inquiry (i.e., the interview questions) to guide the conversation. In my attempt to establish rapport with the participants and provide an experience for the participants that was equitable, I kept mental notes in the back of my mind. Yin referred to this mental agenda as the mental line of inquiry (Yin, 2014). This mental line of inquiry, as opposed to verbal line of inquiry, emphasizes thought processes and mental notes. I followed recommended case study data collection protocol, but questions and exchanges were not scripted and/or predictable (Yin, 2014). I adapted the interview questions and my 
responses based on the content of our conversation during the interview; I remained flexible with the format (Yin, 2014). Yin (2014) suggested that the role of the researcher is similar to a detective; thus, I perceived my role during the interview process as a friendly investigator.

The Anti-Deficit Achievement Framework (Harper, 2010, 2012) and the literature reviewed in chapter 2 , related to my overarching research questions and interview items, see Table 3. The theoretical framework pipeline points are sequential in nature and are listed on the left hand side column in Table 3. The research questions, which related to the pipeline points in complex and contextual ways, are listed in the middle column and are repeated for each pipeline point. The fourth research question (RQ4), however, is not listed in relation to the pipeline points, because it is less focused on the participants' experiences in the academic pipeline. The third column includes the interview questions. The interview questions are divided between the pipeline points, because they are also somewhat sequential in nature.

Table 3

Alignment of Framework, Research Questions, and Interview Items

\begin{tabular}{|c|c|c|}
\hline $\begin{array}{l}\text { Theoretical } \\
\text { Framework Pipeline } \\
\text { Points }\end{array}$ & Research Questions & $\begin{array}{l}\text { Interview Protocol: } \\
\text { Interview Items }\end{array}$ \\
\hline 1. Pre-college & RQ1: What do African & 1. Tell me about your family \\
\hline Socialization and & American teachers report & while you were growing up. \\
\hline Readiness: & $\begin{array}{l}\text { as reasons for choosing } \\
\text { to become a teacher in }\end{array}$ & 2. Tell me about your parents' \\
\hline a. Familial Factors & Oregon? & $\begin{array}{l}\text { (depending on questionnaire } \\
\text { response) occupations and }\end{array}$ \\
\hline b. P-12 School & & educational backgrounds. \\
\hline Forces & & $\begin{array}{l}\text { 3. Tell me a little about your } \\
\text { experiences as a P-12 student. }\end{array}$ \\
\hline c. Out-of-school & & 4. What conversations did you \\
\hline
\end{tabular}




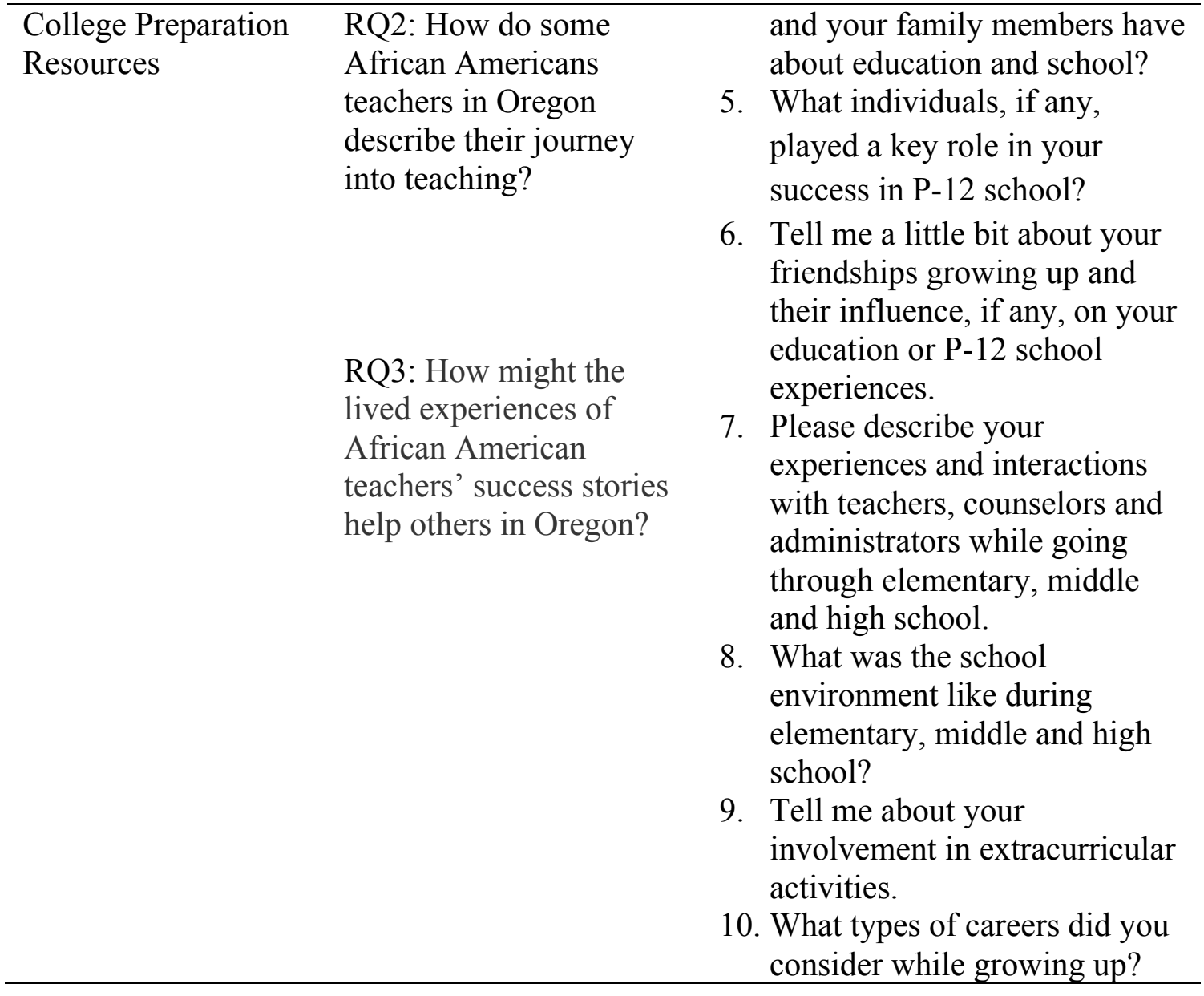




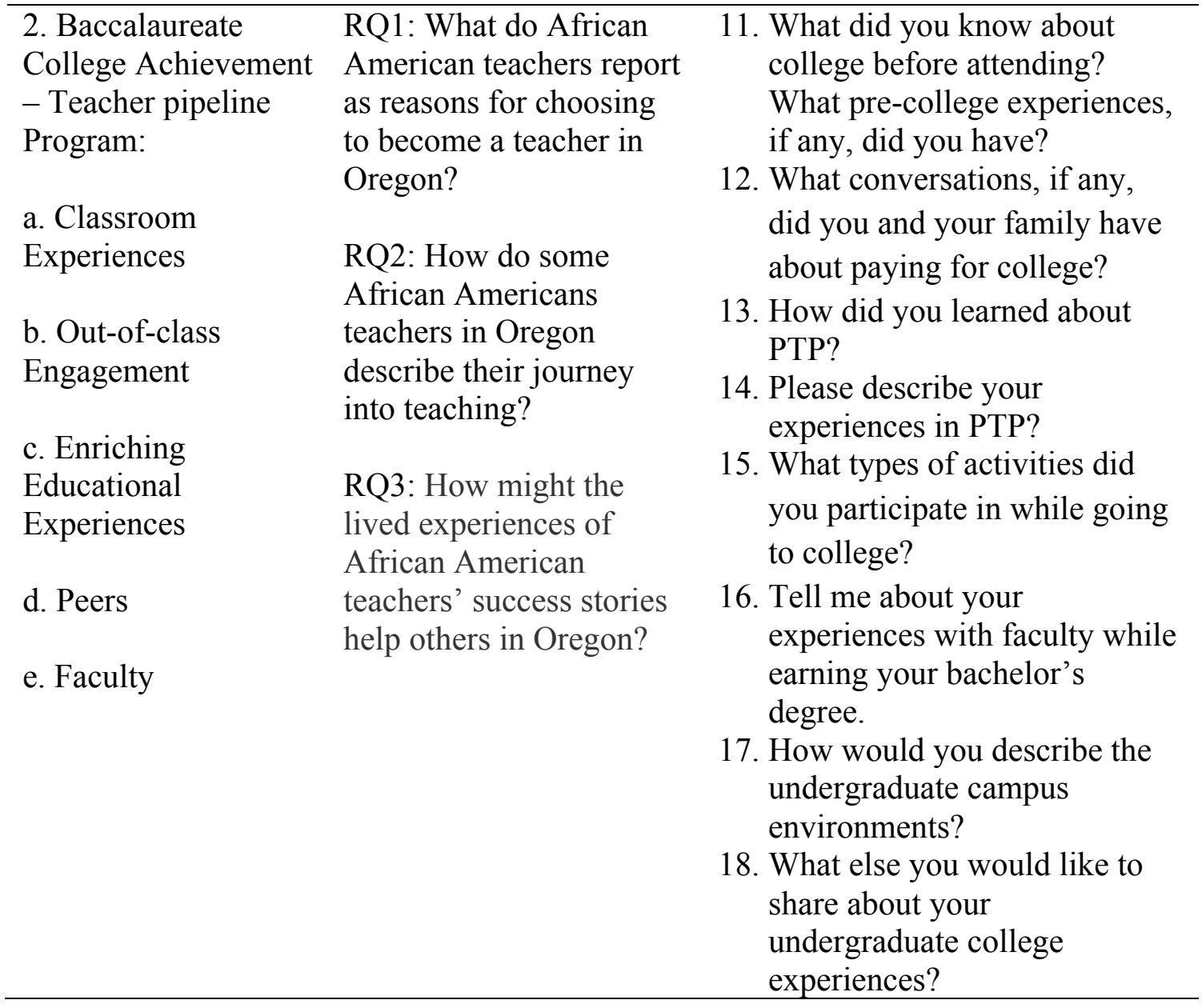




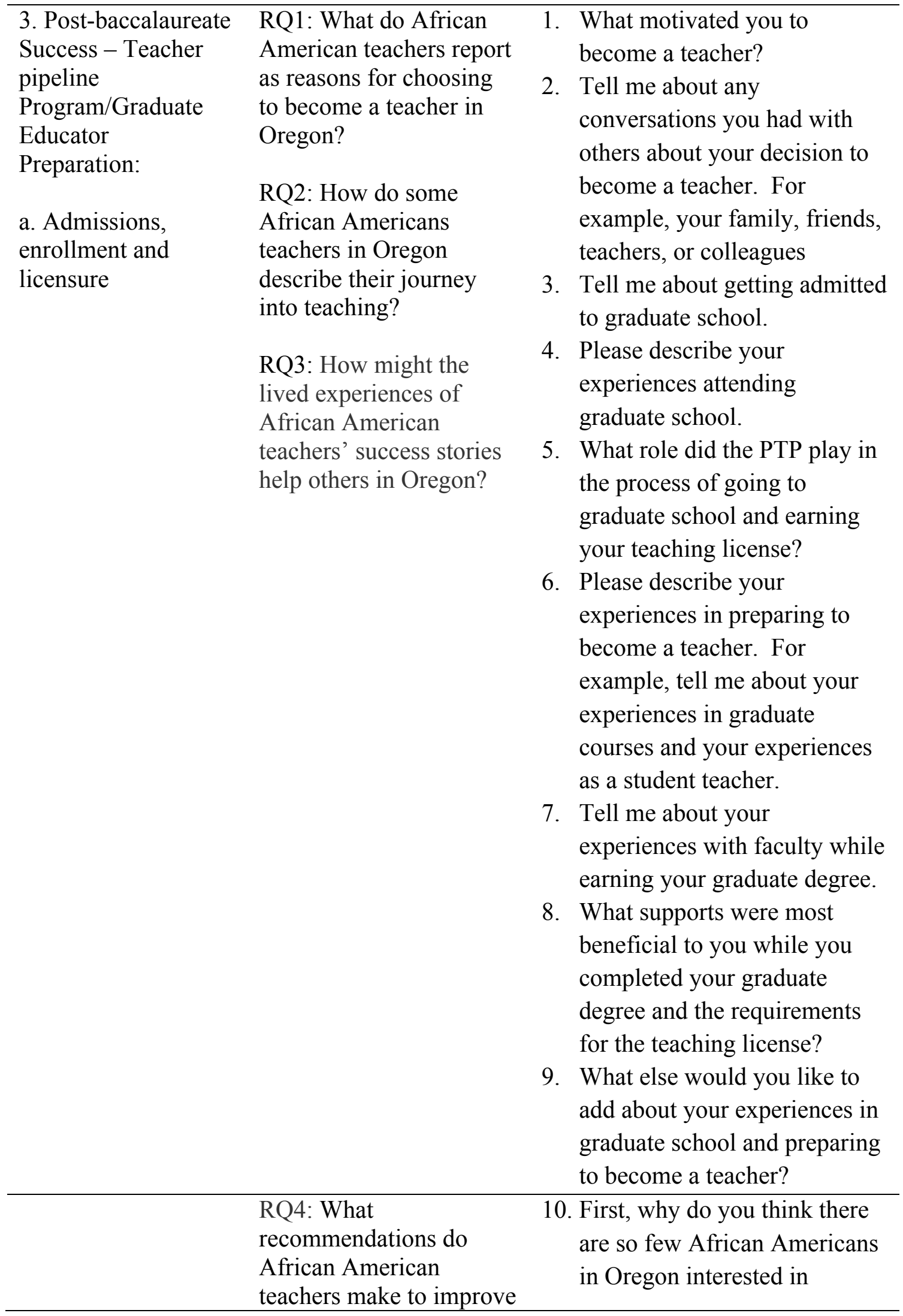


recruitment efforts and

African American representation in the teaching profession? teaching as a career?

11. What are your suggestions or ideas for attracting and recruiting more African American teachers in Oregon?

12. What else would you like to share with me about becoming a teacher in Oregon?

\section{Role of the Researcher}

In the introduction of my dissertation, I shared some important information about me, specifically about my interest in pursuing this research. I mentioned that I am a White woman who was raised in a privileged environment, and that I have spent time grappling with identity issues (i.e., learning about White privilege, what it means to be White in our society and the unearned entitlements, such as the conveniences and opportunities, afforded to members of the dominant culture). While I know that social injustice affects us all, my attentions have been focused on working as an ally to make visible the complex configurations embedded in our social system, especially issues around access and oppression. This path led me to pursue a dissertation topic in that vein, which brings me to my role as a researcher.

As a researcher, I strived for the "highest ethical standards" (Yin, 2014, p. 76). Yin (2014) described ethical standards as including, honesty, responsibility, professional competence, ensuring accuracy, and credibility. With these standards in mind, in my role as the researcher, it was important to recognize both the human role involved with qualitative research, and specifically my role as a White woman researching a topic focused on, and with, African Americans. Thus, I acknowledged explicitly my own 
biases, and as the researcher, I was aware of my outsider's perspective. I was not a graduate of the teacher pipeline program, nor am I an African American. I acknowledged my experience in working with teacher preparation programs for over fifteen years in my professional life. Although my duties in this capacity were primarily in an administrative role, I have worked with many prospective teachers, including graduates of the TPP, in their route to obtaining an Oregon teaching license. While in this position, I advised students about state licensure requirements, especially with regards to navigating the state's testing requirements. My experiences may be viewed as tainting my perspective on barriers some students have encountered in their pursuit to a career in teaching, as well as the strategies I have observed some students use which have led to success. I viewed my sensitivity to and knowledge about these issues as a strength; I have "a firm grasp of the issues being studied" (Yin, 2014, p. 73), considered a desired attribute of a case study researcher.

Throughout this study, I worked intentionally to remain aware of and sensitive to my own racial background, a White woman, when interacting with the participants in my study, African-Americans. As Seidman (2013) suggested, "Maintaining sensitivity to issues that trigger distrust as well as exhibiting good manners, respect, and genuine interest in the stories of others can go a long way toward bridging racial and ethnic barriers" (p. 102). Importantly, I took my role as the researcher seriously, and I considered myself a guardian of the teacher pipeline program alumni data. I conveyed that I do not consider African Americans as being from a monolithic culture made up of like-minded individuals; I recognized that each person's journey is unique and participants in my study each had their own perspectives and sets of experiences to share 
in their path to a teaching career.

\section{Data and Analysis}

To better understand the participants' journeys to becoming teachers, some of my data analysis began during the interview sessions and additional analysis occurred as I transitioned to writing field notes in my research journal-descriptive and reflective field notes that I wrote after each interview. Creswell (2005) defined descriptive field notes as "a description of the events, activities, and people (e.g., what happened)" and reflective field notes as "personal thoughts that researchers have related to their insights, hunches, or broad ideas or themes that emerge...”(p. 214). Per Merriam's (2009) suggestion, I wrote my reflections immediately after each interview, which included, "descriptive notes on the behavior, verbal and nonverbal, of the informant...”(p. 110). For this reason, I scheduled and spent at least 30 minutes of my time, after each interview, writing in my research journal.

Each interview was audiotaped with a digital recorder, and I personally transcribed each interview, verbatim. Though this task was time consuming, by transcribing the data myself, as Merriam (2009) suggested, I benefitted from becoming intimately familiar with my data, and this served as "... another means of generating insights and hunches about what [was] going on in [my] data" (p. 174). After transcription was completed, I sent the text for both interviews to the participant for member checking, or what Maxwell (2005) described as "respondent validation" (p. 111). Maxwell asserted, "[Respondent validation] is the single most important way of ruling out the possibility of misinterpreting the meaning of what participants say and do and the perspective they have on what is going on..." (p. 111). Only one participant provided 
limited edits to their text, which focused primarily on grammatical errors.

I read through the final transcriptions in their entirety at least once immediately after each participant sent me confirmation of the review. I followed this reading by reviewing my own field notes from the interview, which helped me to develop an overall understanding of the case. Given the exploratory nature of my "how" and "why" questions and the approach of using a multiple case study approach, my findings were derived in a two-step process. First, I completed a constant comparison analysis of each individual case; as Merriam (2009) described, "The constant comparative method involves comparing one segment of the data with another to determine similarities and differences" (p. 30). I used an open coding technique (Merriam, 2009) to explore key ideas and phrases, and then grouped these further into categories or themes. Using the interview data, I generated codes about family, racial and cultural identity, parental involvement, socio-economic status, community, school and college experiences, peers and friendships, experiences with teachers and faculty, academic supports, and more.

I also created profiles of each participant to further examine my data, found in the next chapter of this dissertation. In comparing participants' experiences based on the developing categories and themes across cases, codes were further refined. This second stage of analysis is what Yin (2014) described as "cross-case synthesis" (p. 164). The key ideas that resulted from the first stage of the analysis were used to make comparisons across cases, and though the process used in the first stage of individual case analysis (e.g., coding, categorizing) was very similar to the within-case, additional themes resulted in the cross-case analysis. Worth noting, while composing the participant profiles, I read through all of the transcriptions multiple times, reviewing previously generated 
categories and themes and also in identifying the similarities and differences across the participants' experiences along the teacher pipeline to career attainment.

As a final note on data and analysis, the application of the conceptual framework was useful in determining elements for data collection, as well as with the analysis of the data. As Yin (2014) wrote, “A case study inquiry...benefits from the prior development of theoretical propositions to guide data collection and analysis" (p. 17). Accordingly, I used the Anti-deficit Achievement Framework (Harper, 2010, 2012) to ground my multiple case research study with a structure that is both chronological and topical, a model that helps determine key themes in advance. As I interviewed the participants, transcribed the data, reviewed the final transcriptions, and created the individual profiles, I assigned codes, refined codes, reviewed my research journal, and was cautious to listen actively to each unique journey and remained open to evidence collected.

Reliability and validity. Qualitative researchers frame discussions of reliability and validity of data in terms of trustworthiness, authenticity, and credibility (Creswell, 2005; Maxwell, 2005; Merriam, 2009). Maxwell (2005) contended that there is no absolute guarantee, "Validity is relative: It has to be assessed in relationship to the purposes and circumstances of the research" (p. 105). First, to address threats of validity, as mentioned in the section on data and analysis, participants reviewed their interview transcriptions for accuracy. Again, Maxwell (2005) described this method of obtaining participant review of the data as, "...the single most important way of ruling out the possibility of misinterpreting the meaning of what participants say and do and the perspective they have on what is going on..." (p. 111). Second, I used a comparison method, a cross-case analysis, to verify my interpretations of the results. Using the Anti- 
Deficit Achievement Framework (Harper, 2010, 2012), which provided a foundation with findings from previous research, I compared and contrasted the experiences of the participants in my study. This type of comparison strategy addresses one of the concerns with qualitative methodology, as it provides a basis for the conclusions with corroborative results (Maxwell, 2005).

I sought to achieve trustworthiness in my study by accurately including thick, rich descriptions using the voice of the participants collected from in-depth interviews. Interviews were conducted in settings that were chosen by the participants, often in their own school or office, and all were conducive to hosting a friendly conversation. In addition, verbatim thick, rich descriptions of each participant in the form of a profile allowed for in-depth understanding about each case.

\section{Summary of Methods}

The use of qualitative multiple case study methodology to study the career trajectory of African American teachers in Oregon was most fitting. Case study allowed me to explore the journeys of the participants-African American teacher and graduates of a specific teacher pipeline program — to gain an in-depth understanding of their experiences. Multiple case study design allowed for cross-case analysis of the rich, thick descriptions of the participants' experiences. By using these methods, along with purposeful sampling, in-depth interviewing, and an awareness of my own biases, I was able to conduct a study with the aim of unearthing corroborative evidence regarding African American teachers' motivations, supports, and tenacious acts contributing to their success. 


\section{Chapter 4: Findings}

In this qualitative case study, I explored the factors that contribute to the recruitment of African Americans into a teacher preparation program in Oregon. Specifically, by examining the success stories of African American teachers, I sought to discover insights into their motivations and identify significant influences regarding African American teachers' supports on their path to a professional life. Employing a qualitative case study approach, along with the Anti-Deficit Achievement Framework as a theoretical lens, I used four research questions to guide my case study investigation:

1. What do African American teachers report as reason for choosing to become a teacher in Oregon?

2. How do some African Americans teachers in Oregon describe their journey into teaching?

3. How might the lived experiences of African American teachers' success stories help others in Oregon?

4. What recommendations do African American teachers make to improve recruitment efforts and African American representation in the teaching profession?

The purpose of this chapter is to summarize the collected data and to present the findings. The details of these findings are presented across two chapters. This chapter includes the profiles and the responses to the research questions, and the next chapter focuses on the themes developed from the data analyses. Before exploring the findings from the data that pertains to the research questions, in this chapter I present the methods of analysis of my findings, and the participant's rich and descriptive profiles, the four cases. Each profile, or case, is an historical account of an African American in Oregon on his or her journey to a career in teaching. Each case is reported in three stages along the teacher pipeline, including events that occurred in early childhood and P-12 school 
years (i.e., Pre-college Socialization and Readiness), to their undergraduate college experiences (i.e., Baccalaureate College Achievement) and finally, to their lives as graduate students completing preparation programs (i.e., Post-Baccalaureate Success and Graduate Educator Preparation). I chose to include detailed portraits of each of the participants using their unique, individual stories. I intentionally present each profile separately and completely, for the reader to focus attention on each distinctive and powerful story. Importantly, I present the voices of my participants honestly and candidly, while being aware of my own biases of being a White female-discussed in more detail in my role as the researcher in the previous chapter.

After the four profiles, I report responses related to each research question, highlighting key elements of the narrative that directly support my interpretation of these findings. I conclude this chapter by noting limitations and summarizing the research findings.

\section{Analysis of Findings}

After soliciting the participation of four African American teachers, I conducted in-depth interviews over four months, October 2015 through January 2016. In addition to interviews, I maintained a research journal with descriptive and reflective field notes. I wrote in the journal after the interviews, during and after transcription, and used my field notes as more evidence to support what I found during the analysis of the interviews. I found that transcribing the interviews proved an excellent method for gaining awareness and familiarity with the data.

After transcription and member checking was completed, I used a close line-byline analysis of the data by reading the transcripts multiple times and coded them 
accordingly. I read the interviews no less than four times each, while also writing and reviewing notes in my research journal. The coding process was carried out by assigning codes to phrases and paragraphs in the data; in addition to being associated with the respective data, the codes were added to a larger list of generated codes. I used a constant comparison analysis of each individual case and open coding to produce a large set of codes that I revisited constantly, ensuring that codes remained consistent.

In the initial analysis, I created a list of descriptive codes, code families, such as "P-12 school," "undergraduate college," and "graduate school." Not surprising, these code families correlated with the Anti-Deficit Achievement Framework and were organized by the semi-structured interview questions, aligned with the framework and somewhat chronological. Examples of other descriptive codes generated from analysis that fit well into the code families and were more topical in nature, which I simply called codes, included "role model," "neighborhood," "racial identity," and "college plans." Some of the codes were placed in more than one code family, for example, the 'faculty' code was found in both undergraduate and in graduate school. I also created subsets of these codes, examples within the TPP code, subsets included "registration support," "stigma," "advising," and "alumni." A list of my codes is displayed in Appendix E.

I further refined coding categories after writing the participant profiles. The process of writing the narratives added to my understanding of each participant's distinct story, and as with the transcription, allowed me to gain further familiarity with the data.

After codes were refined and reorganized multiple times-which included collapsing some codes together if they had similar meanings, ensuring I had exhausted possibilities, and confirmed all data was coded properly - I searched for pattern codes 
within and across the cases. The codes generated were then clustered around each research question, with some overlap. For example, RQ1, which focused on reasons participants reported for choosing to become a teacher, common codes that clustered included, "White teachers," "negative P-12 school experiences," and "commitment to student success.”

Then, I completed further analysis related to the overarching purpose of my study, to understand the factors that contributed to the career success of the participants. I closely examined the influences leading to success, and in doing so; strong patterns and recurring themes were evident. For example, all four participants shared multiple examples of how their sense of community contributed to their success in college and the graduate educator preparation program; this theme I called, belonging. All participants discussed how the role the TPP contributed to their success; examples of support they received were abundant. The concept, however, that was most frequently mentioned in relation to success was accountability. Lastly, participants expressed a desire to be agents of change, which I have highlighted and discussed in more detail in answering the research questions in this chapter. The notion of social justice and actions relating to equity was a more common theme found across participants, and they connected these ideas to an intrinsic motivation to succeed. This theme was brought up repeatedly, in a variety of contexts, such as in college classroom experiences, curriculum in graduate school, and connection to the community, just to name a few. I deemed this theme to be, commitment to equity. I discuss the three prominent themes, belonging, accountability, and commitment to equity, in more detail in the next chapter. 
In the following four segments of this chapter, I present the profiles of the four participants in my study: Deanna, Noah, Carmen, and James. Each profile describes a detailed account of an independent, reflective, and dedicated professional who was open and willing to share his or her story.

\section{Deanna}

Deanna's narrative begins with stories of her childhood, including details about her family and close relationships, and then moves into her school experiences, $\mathrm{P}-12$ through community college and university. Her decision to become a teacher is highlighted, as well as elements about the TPP. As with all of the interviews, her profile concludes with a description of how she completed graduate school and earned her teaching license.

\section{Childhood and P-12 School Years (Pre-College Socialization and Readiness)}

In this section, I focus on family, friendships and Deanna's family involvement in her schooling experiences.

Family, friendships, and schooling. Deanna lived in the same metropolitan area for her entire life, although not all in the same region of the city; she moved around a lot throughout her life, especially in her youth. For a majority of her young life she lived with her mother, who was a single mother caring for Deanna and her younger sister. She and her sister sometimes lived with her grandparents and her two cousins, without her mom. Her father's parents lived in a house in an urban neighborhood. Deanna spent a lot of time in her grandparent's neighborhood, including weekends and extended weeks during the summertime. She described it as one of the main places where she grew up. 
Deanna's mother was 16 years old when Deanna was born; she disclosed, “... when she got pregnant, [her parents] didn't want (Deanna's mother) to live at their house, so she went to this women's home; then got her GED." Her mother worked in a fast-food chain restaurant until about the time her sister was born, and then in other low-wage service industry jobs until Deanna was in her teens. When Deanna was a young adolescent, her mom started working for a hotel chain in the downtown area. Around the time her mom married Deanna's step-dad, they began living in the same house located closer in to the city center.

Deanna spent some time with her father, but she never lived with him. She described him as “...kind of a partier... who never grew up.” Her grandparents, however, were very present in her life. She remembered them as consistently being there, whether it was for week-long visits during the summer months or for long weekends. They would also make efforts to attend school events, such as book fairs, carnivals, and so on. Her grandparents worked in government/public service-her grandfather for a transportation agency and her grandmother as a teaching assistant in elementary schools. Post-retirement her grandmother continued to be involved in schools in a grandparent volunteer program. Deanna recalled, "She was always at schools, involved."

Deanna talked about her home environment as it related to school; she said:

So my mom, because she was a single mom, she worked often. ...she didn't finish school, she didn't graduate from high school. School was important to her, and she wanted both my sister and I to do really well, but she didn't really have the capacity to support us ...there were never really any conversations [about school].

As far as friendships during her elementary school years, Deanna recalled: 
I think I just kind of played with everyone at my apartment complex. I went to a school [where] I was like one of eight black kids. So, for me, fitting in was a really big deal. So I tried to stay up to par with everybody else.

As typical during early adolescence, friendships became more important to Deanna. She said, "It wasn't until middle school, that I had a best friend who I did everything with. She came from like a family of five. Her parents were on it, as far as like homework being done.” Unfortunately, because she moved around and attended several different schools, Deanna's friendships changed often. She did not always choose friends that had a positive influence on her. She conceded:

[W]hen I transferred I made friends with some kids that were not the best influence. So we would skip class here and there. When I was in eighth grade too, I did. I met a friend who I would skip class with often.

Deanna explained that she did not really have any career ambitions when she was younger, except for wanting to be a firefighter. At home Deanna did not receive a lot of support when it came to academics, though there was, however, some encouragement; she knew her mother and step-dad wanted her to do well. She revealed:

My step dad, when I was in middle school and high school, was kind of on me about homework. Not really in a supportive way, more so like, 'Why aren't you doing it?' 'Where is it at?' 'I know you should have homework!' There were never really any conversations.

In addition, her grandparents, although very supportive in buying books for Deanna and her sister throughout their childhood, did not talk with her about school or her academics. As Deanna stated, “...we were just kind of independent in that area.”

P-12 school experiences. Deanna's elementary school years, first through fifth grade, were spent at the same school, in a suburban area, which was at the time, 
predominantly White. Almost all of her teachers in K-grade 5 were White. In fact, throughout K-12, Deanna only remembered having two teachers of color, both female; one was an African-American music teacher in elementary school, and the other was an African sixth grade teacher.

While attending elementary school, Deanna felt she was not a strong student. She recalled:

I was one of those kids where I was definitely not doing well. I remember being in elementary school and being pulled out of class to go into a reading group. But I was never like a troublemaker; I was a very quiet student. So I kind of like, slipped through the cracks. I do remember though, in fifth grade, that's when it was very evident how far behind I was.

In reflecting on the school environment, she said, "I guess as far as an elementary school goes, it was welcoming, but I always felt very different there, very out of place."

The consistency of her elementary school-life ended when she got into middle and high school. Deanna attended three different middle schools and three different high schools over a period of seven years. Some of the moves to new schools were based on her family moving to a different part of town, and some were based on her request to attend a different school due to the her academic performance and negative experiences with students and teachers. As she described, "High school and middle school was not a great experience for me.” In addition, transitioning from elementary school to a larger middle school environment was also challenging for Deanna, "I remember transferring from elementary school to middle school, it just being this huge shock, the school was so big and we had to go classroom to classroom."

Deanna has many negative stories about middle and high school. For example, she recalled: 
My eighth grade year when I went to a predominately Black school... that was one of the worst experiences I've ever had in education. It was awful, just a very hostile negative environment; it was horrible. I just remember the school environment was very negative. I had come from [a predominantly White suburban school] where the classes I went to seemed pretty structured.

She also recalled one story where a family friend offered a financial incentive for her to do better at school.

Thinking back to eighth grade, I had a really horrible three months. I was failing everything, except for shop class, and my parents were freaking out, like, 'What was going on? How could this happen? How could you be failing everything?' And so, one of my stepdad's friends made this bet with me, [he promised] '.. for every A [grade] you get, I will give you \$20'. And so, when I transferred to a new middle school, I held him to it. I asked the teachers how I could get extra credit. So when I showed up with five A's, my stepdad and mom were like, you made that promise with her and she did it so you need to get on it.

She continued:

I was trying to do well... because I wanted to get that $\$ 20$ for every A. It was the first time that I ever went to my teachers, and I asked what else can I do? Is this good enough? Did I get the homework right?

In the classroom environment, Deanna reflected on her performance and effort as not being her best, trying not be noticed, and as also being "a really quiet student." She disclosed:

I didn't want to be the kid that sat in the back of the room, but I didn't want to be the kid that sat in front, so I would just sit in the middle and try to blend in the best that I could.

Deanna also described some of her experiences in high school:

I had a really terrible teacher my freshman year.... a science teacher. I remember at one point, he asked me why I even bothered coming to school. I was failing his class. I don't know like what or why he said that... But you know, in hindsight, I think, what a horrible thing to say to a 14 year old. 
She added:

I mainly remember kids were just really mean. There was so much drama between girls and guys... I had this really horrible year, and so I begged my mom in the middle of the year, to just please get me out of this school.

As far as extracurricular activities in high school, Deanna participated in one sport. She recalled, "I ran track, which that was really great for me...," and she participated in this activity consistently throughout high school. However she did not run track her senior year because she was working. Overall, Deanna lamented how she lacked a sense of agency when it came to school, saying:

Throughout school, I didn't really seek the help of anyone. I guess I just didn't really know that there were so many resources available for people to help me. I just kind of stayed quiet and figured that my teachers would like me well enough to hopefully pass me.

In her senior year, however, Deanna got involved with a program that improved her schooling experience. The Service Program (pseudonym), which allowed her to earn credits she was missing and provided her the opportunity to be a camp counselor - away from home for six weeks, only returning home for the weekends. During this time she also served as a volunteer in an elementary school. These were not only significant and rewarding experiences for her, but they also permitted her to graduate on time, which was very important to her. Deanna remembered realizing, “... [O]h my goodness, I am behind in credits. I wanted to graduate on time. It was really important to me. My mom didn't graduate, so that was something I really wanted to do."

The Service Program director also left a positive impression on Deanna. She noted:

I remember there was the woman that ran that program, who was, you know, just really helpful. Even though I was behind in credits, I felt that she made it that I 
felt welcomed. But that was my senior year, and really that is the only [influential] teacher [throughout K-12].

Plans for (not) going to college. When it came to thinking about life post-high school, Deanna described not having a solid plan.

To me, just getting done with high school was all I cared about. I worked at [large retail chain]. When I was a junior I got my first job. For me, like making money... like, this is it. I'm already making money; I am on my way. So I felt really successful then. I had no plan to go to college.

While Deanna did not plan to attend college, she had a few pre-college experiences while still in high school. One of these experiences was with a high school teacher or counselor, who was someone her stepdad knew. She remembered:

He was part of this program to take kids around to different colleges. And so, we went out to [rural university], and that was the first time I ever stepped foot on a college campus. For me though, it just seemed so far out of reach. Just because, you know, my mom never went to college, and neither had my dad, so I didn't even know the first thing about going to college.

Deanna also remembered an experience where she toured a college in the metropolitan area, and recalled, "Even then, I just thought, this is fun; I got out of class to come here." College was clearly not something she thought was an option for her. "No one in my family had gone to college." She added, "My family didn't talk about college." She elaborated:

My mom went to beauty school when I was, I think, I don't know, 10 years old. For her that was a really big accomplishment, that was something she wanted. And so I thought for a little while, I thought maybe a vocational school? [L]ike the flight attendant academy; I always thought about traveling. That was something that seemed really exciting to me, and I wanted to do that. So I thought, if I become a flight attendant, I can see the world. 
With regard to college, she said, "[J]ust thinking about my experience growing up, I didn't know anybody who was going to go to college or was in college."

\section{Baccalaureate College Achievement, Teacher Pipeline Program (TPP)}

In this part of Deanna's profile, the focus is on her undergraduate degree. Deanna did not start college with career ambitions in mind. Her impetus to take a college course began with college credit vouchers during the Service Program in high school. She shared how the voucher, and most importantly her decision to become a teacher, led her down the pathway to a degree.

Community college. Deanna explained how a voucher she received started her college career, “...[S]o we ended up with like a $\$ 1200$ voucher to use. I found out that if I took one class, like a one credit class, then I could then cash in the rest of that voucher." Deanna's grandmother was the one who encouraged her to use the voucher and take a course at the community college.

When I was 19, I moved in with my grandparents, so I lived with them. My grandmother earned vouchers [through the grandparent volunteer program] to take college courses. She took an art class... and I thought that was so funny, my grandma is at [community college]. She told me, if I took a class, they would reimburse you for the rest. I was like, yes, I am going to buy a new computer, and so I took yoga.

Deanna continued, “...[I]t got my foot in the door of college. I thought I was just going to use it for one term and save whatever was left, but then I ended up taking a writing course and a math course."

Deanna described what is was like going to community college:

... that was my first experience back in school. That was the first time I went to a school where I saw people that looked like me. A school that was immersed with 
culture and diversity and people of different ages... and so for me, it felt very welcoming. It felt like, I can go here. No one is going to judge me.

It was not just the community college environment that Deanna remembered positively, she also described the effect of the teachers.

I had this writing teacher, and to me... I just thought he was so great, and he made me want to go to school and take more classes. That was my first experience actually loving school. So that, to me, kind of shifted the way I thought about school.

She added:

...[T]hat was the first class I really ever enjoyed. You know, as far as like an academic class went. I felt like I was really learning, it was so exciting. So that kind of like kicked it off for me.

It was not easy; Deanna found college very challenging. She recalled, "Despite the fact that I really liked and enjoyed being in college, it was very challenging for me."

At the same time she was taking community college courses, she met the man she was going to marry, and was introduced to his family. Deanna shared:

During that time... that was when I met my, well at the time was my boyfriend, who is now my husband. His family had been inquiring, 'What are you going to school for? What are your career goals?' And no one had ever asked me that, no one had ever said like, 'What are you going to school for?', and at that point I had no idea. I don't know, I just thought I am going to get my Associates degree, and see where I go with that. So I started to think, well okay, what are my plans after?

Decision to become a teacher. Following these types of discussions she had with her future in-laws about career plans, she started to think about becoming a teacher, and it was her grandmother who helped her, to some extent, recognize that she could achieve that goal. Deanna recounted: 
I wanted to do something more, and I started inquiring with my grandma. [M]y grandmother was in schools, her sister was also involved in schools, so then I just thought, maybe I could try teaching. Maybe I would be good at it. So, that's when I had that conversation with my grandma about well maybe, you know, I think I want to be a teacher.

Deanna's grandmother was acquainted with a teacher in the school where she volunteered who was also a graduate of the Teacher Pipeline Program [TPP]. Her grandmother asked the TPP alum to contact Deanna, and he provided the contact information for the TTP director. She recounted, "So I called her up and she told me about the program and how to apply. That is how it started." Her decision to go through TPP was not without doubts. She disclosed:

When I got into [TPP], I was a little apprehensive.... I was thinking: Am I really cut out for this? Am I going to be good enough? And just having that support really made me feel like, yes, in fact, I will be great at this. Once I was in [TPP], there was just no doubt.

The application process, however, was daunting; she stated, "With [TPP], I remember that was the first application for anything extensive I had ever filled out." Moreover, she recalled:

I had to write all of these lengthy essays. I had never done anything like that in my life. So that was really an intimidating process. I remember having the interview process. There was the [interview] panel, and they asked me a lot of questions about equity and my philosophy about education. At that point, I didn't have one; I had no idea. I just wanted to be a teacher. It [the interview panel] felt welcoming though. Even though I had no idea how to really answer the questions, I felt like they were on my side.

Needless to say, Deanna was thrilled to be admitted to the program. Her family was very proud of her and supported her decision to become a teacher. 
So I can't recall when I got approved but I just remember when I got into that program, I was so excited. I told my mom and my mom told people at work; like, 'My daughter just got into this really great program'. My grandma was so proud.

In addition, she reported:

My in-laws were supportive. My sister in-law is actually a teacher. During the time she was actually in grad school at [the same university]. We had something in common that we could talk about. So my family was really proud of the fact that I was in college, and they were also really proud of the fact that I had gotten into this program.

Her family and friends were supportive of her but going to college and planning to become a teacher. In return, she motivated them to pursue further education as well.

She [my sister] was really supportive. I think for her, because at the time I was starting college when she was trying to finish up high school. High school was really rough for her. I think she saw because I was taking my education seriously, and going onto the next path in life, she felt motivated. At one point we were both taking a class together at [community college].

Deanna's mother did express some concern about her choice of professions:

One time my mom had asked me why I chose teaching, since teachers don't make any money. My mom hadn't gone to college herself, but I think she just had this idea that teachers don't make anything. If you're going to pay all this money to go to college, why not do something where you're going to... it's going to be a bigger payout.

Most importantly, when it came to family support and her pursuits to become a teacher, she stated, "My grandparents, though, they were definitely my strongest support system."

TPP support and university years. Deanna emphasized and described in detail the support she received from the TPP program. She shared that "...throughout the program we had these weekly meetings, monthly meetings, quarterly meetings. When you are new student the first two years you are constantly at [TPP] meetings." In 
describing these meetings that TPP students would attend, she noted that students, "did a lot of equity work."

Deanna also described how the TPP program director was highly involved in her academic success, and she shared an example of when the director stepped into to help her when she was struggling academically.

There were a couple classes that I did not pass while I was at [community college]. I had to retake [subject] a couple times. I had to retake it a couple times, and I just remember being so devastated and having to go to [TPP program director] and say, 'I didn't pass this class', and she said, 'that's alright, we're going to do it again'.

The TPP program director was involved at every stage of Deanna's experience in the program, including with preparing her application to get into graduate school, which required letters of recommendation. She reported:

One of the letters of recommendation I had gotten from a teacher... and the program director was not pleased with it. She said that it wasn't up to par, and she made it seem as if this was going to be the determining factor as to whether I was going to get into grad school. She just said it wasn't as strong as the others, but I think having her there, there was always that fear piece. It made me think, I need to do well.

One of the supports that helped Deanna believe it was possible to attend college was the financial assistance that she received through the TPP program. Though she received financial assistance, Deanna still needed to work throughout college. She had little time outside of working and going to school. Deanna worked in retail, and as she described, "I had a very strict schedule. I worked. I worked all throughout college, up until I got into grad school. I did that full-time, I was working 40 hours a week." 
Passing, and paying for, the required teacher examinations was also stressful for Deanna, it raised her fears and concerns about her prospects of getting into graduate school.

I have already got my undergrad degree and now I don't know if I am going to get in to grad school. There was one more test opportunity before the application for grad school was due. It was like make it or break it, and I just went in... and with everything in me tried to pass that test. And I did, so when I finally got that letter that said you passed, it was such a relief.

After attending community college, Deanna completed her undergraduate degree at the university and described being focused on completing that degree and being expeditious in the process.

It took me three years to get through [community college], and then when I got to [university] I was just so set on getting into grad school because I was so much closer... there was no time to waste, there was no time.

Her main concern seemed to be her goal of becoming a teacher. She paid less attention to being on the campus environment and demographic make-up. Deanna reported:

Coming to [university], though I enjoyed my experience, and again I feel like there were fewer people that looked like me... and less that I could really connect with, but I was just trying to get to this end goal, so I didn't put too much thought into that.

She knew that her fellow TPP students, however, were there to support her. She said:

I met so many people through [TPP]. So then when I came to [university] I came with a group of people, and so we tried to take classes together, and then a few of us went to grad school together. And so that was really fun, I felt for the first time, you know, school was like a fun experience, even as an adult... 
Deanna summed up her thoughts about the TPP program supports in relationship to accountability. "I think having required meetings, the program director wanting to check what classes we were signed up for, and just that accountability piece really helped me." She added, “[TPP] really helped me through the process. Otherwise I wouldn't have had a clue. I wouldn't have known what tests I needed to take or what classes.” Additionally, she recalled, "There were just an abundance of resources [from TPP], and I think that was most helpful for me. I needed that, and I also wanted that."

\section{Post-Baccalaureate Success and Graduate Educator Preparation Program}

Deanna's experience with graduate school is described in the following section, including aspects of the teacher preparation program, student teaching, and how the TPP and alumni contributed to her success.

Admission and enrollment in graduate school. Although Deanna was admitted to the TPP and she successfully completed the undergraduate program at the university, she and her fellow TPP students are not automatically admitted to the Graduate Level Educator Preparation Program. Deanna received support from TPP (e.g., letters of recommendation, tests) in preparation to submit her application to graduate school. She recalled:

I remember the process of applying for grad school was pretty seamless because of the support of [TPP]. We had alumni who helped us with our letters. [TPP director] was very specific with who could write us a letter of recommendation. She (TPP program director) had to proofread them first. When I think about the process, she really took a lot of the weight off of our shoulders.

Deanna's stress with the application process to graduate school was, predominantly, waiting to find out whether or not she would be admitted; “... it was really stressful, if I did not get in, I had no other plans." 
Once she was admitted, Deanna was placed into a cohort. Deanna was one of three students of color in her cohort of 20-25 students. In the cohort model, graduate students take course work together for one calendar year. In addition to the course work, the teacher candidates spend increasing amounts of time in K-12 classrooms as student teachers. Deanna explained:

There were three of us, another African American and [another person of color], so three of us; we were also the only three people of color in our cohort. Starting off was... it was really interesting because these people we were going to be with them for the next year and half. Everyone had come from different places. I just remember I really stuck close to the other two, my other two colleagues from [TPP]; just because... it was pretty stressful, pretty stressful, just right away. We started in July. We had a couple months before we started student teaching.

Student teaching. Deanna's experience as a student teacher was less than positive. She described:

That was a really interesting experience because our cohort leaders, I think they were trying [a new model for student teachers]. It was the first year they had ever done it. It was a pretty awful experience for me. The other teacher candidate was a White woman my age. When I had thought about student teaching — especially hearing about my sister-in-law's experience and former [TPP] program alumniit was always one student teacher in a classroom, you work alongside your cooperating teacher, but that wasn't the case. It was two student teachers to a classroom and it became this competition. You know, who got more time in front to the class, who had a better relationship with the students... at least in my experience. It happened in many classrooms, where it became very competitive.

Deanna continued:

And also my colleague (the other student teacher, who was White), she was very... Let's just say, the role and presence of Whiteness was very apparent. There was a lot of bitterness about the fact she knew that myself and two other colleagues were from [TPP]. At one time, there was this comment, 'Wow, you know I wish I could be Black so I could get a full ride scholarship', and many other conversations like that. 
Deanna did not feel comfortable talking with anyone about her student teaching situation.

She had tried to address the issue with her cohort leaders, but they ended up talking with another student about her situation, which Deanna did not appreciate. She reflected on the experience, saying:

Being a student teacher... I already felt insecure about my role as a teacher and being with someone who was really strong. The other student teacher I was with was very strong, which was great, and she tried to be supportive, but as a result it just made me feel less and less competent about my ability to teach. It was very intimidating. It just made me feel that I needed to prove to them that I'm capable of doing this, or that I could handle it. So that was really rough. That was a really rough year it was just a big competition.

Because of comments made by fellow student teachers, Deanna was reluctant to share her TPP affiliation. Deanna elaborated on the 'TPP stigma' she felt:

Where like everyone is struggling, and even though I had the scholarship, it was still a struggle. This was especially true with my co-[student]teacher. There was just a lot of hostility and animosity, and so I am very careful with who I talk to about how I got to grad school. I do not want them to think any less of me, like my process or how I got here.

Teacher preparation instruction and TPP support. Overall, Deanna did not describe her experiences in graduate school fondly. She recalled:

In my experience, [graduate school] seemed so disorganized, they were trying this new [student teaching] model, which they didn't really have the data to back up or support what they were doing; what I felt it was for their own benefit.

Additionally, she described her experiences with faculty in graduate school:

As far as faculty goes, I thought my cohort leaders were... I thought they were decent. There were times where I just felt.... I didn't really feel as though I was getting what I needed to be a strong successful teacher... It seemed like they were always trying to be cutting edge, and trying something new, and as a result there was just not much consistency. My experience at [university] was okay; it wasn't 
terrible, but I didn't really make many connections with the faculty. I was with my cohort leaders for the entire year and a half.

Deanna also touched on the lack of connection between TPP and graduate school. She noted:

I know [the TPP program director] had meetings for us, where a couple of times they interfered with the [graduate education program] classes, and one of the [university] faculty members... our cohort leader was like, 'What is this program, and why are they asking you to leave?'

While Deanna did not have too many positive comments about graduate school, she believed her student teaching experience led to her employment based on her relationship with the principal at the school.

It was actually how I ended up in this job. I student taught there and [the principal] was really supportive, especially supportive of the teachers in [TPP]. The principal had called up a couple of other principals because he knew I was applying [for positions in this district], and he called the principal of this school, and said 'Hey, this student taught at my school and you should definitely give her an interview', and that really was super helpful.

As mentioned above in relation to earning a Bachelor's degree, Deanna described the role of TPP as a critical component to her success, even while she was going through graduate school and student teaching. She reiterated several times that "[TPP] was the driving force for what got me in school and what kept me in school."

The transition from graduate school to her first year teaching was challenging for her. She described this experience, saying:

[After] going to grad school and then experiencing my very first year teaching, I felt as though I was not prepared whatsoever. In my very first year of teaching... Once I got to my school, I thought... I didn't know what to do. I was given my keys, and they [school administration] were like, here is your room. I just didn't know the little ins and outs of things, and I had to learn a lot of that on my own. I 
think what was really hard about that too, was throughout my entire college experience I had a group of people supporting me along the way, and so finally when I got here, into this building... I thought, oh my goodness. Who do I go to? What do I do?

As she had done throughout the program, Deanna ended up contacting a fellow TPP alum to help her during this challenging time. "She and I stayed in contact, and still are in contact. I tried to get as much support as I could," but Deanna emphasized that she, really struggled that first year.

\section{Noah}

For Noah's profile, the story begins on the east coast of the U.S., where he spent a majority of his childhood. He moved to Oregon as a teenager and continued to stay in the state for college and his professional life, thus far. His narrative highlights his "underwhelming" school experiences, challenges he had with low teacher expectations, and his direct route from high school, to college and graduate school, and to his professional life as a teacher.

\section{Childhood and P-12 School Years (Pre-College Socialization and Readiness)}

The first section of Noah's narrative is focused on his family, P-12 school experiences, peer relationships, and his decision to become a teacher.

Early years and family. Noah grew up in an urban environment close to a large metropolitan city, on the east coast of the United States. Throughout most of his early childhood years, he lived with both of his parents and his younger brother. When he was about seven years old, his parents divorced and his family life changed; he recalled, “... at that point, me and my brother would go back and forth, week to week, because they had joint custody." 
His parents were both in the military, which was how they originally met. Noah's parents received their professional training through their military careers, rather than through higher education. Noah reported, "My dad by trade is an electrical engineer, and my mom by trade is a CPA." Noah's father eventually went to college earning a bachelor's degree in Business Management as a non-traditional student, after Noah had graduated from high school. His mother completed some college before Noah was born, but had dropped out to join the military. He believed his mother also went back to college at some point. Noah described his family's income level as, "We were a low SES, we were poor I guess... Tons of people brought us food because we didn't have food in the house or whatever... We weren't the poorest."

The neighborhood(s) where Noah lived on the east coast and the schools he attended up until eighth grade were majority Black. "[T]hat whole area where I grew up, is overwhelmingly Black. I can count on one hand the White students that went to our school. That's all through elementary school and middle school. I doubt it is over 50 [White students in school].” The teaching population, however, was majority White; "[I]n elementary school all my teachers were White. In middle school, pretty much the same deal...”

Noah shared his view of himself; he said:

I was a troublemaker. I was always a troublemaker. I have always been a troublemaker. I asked my dad once, because we were watching some other kids, was I that bad? And he said, 'No, you just liked to do things that you shouldn't do, to see what would happen if you did them'. Which I think is accurate, because I would just do things just to see how it would roll.

Noah, however, also described himself as quiet: 
In general, as a kid, I was very quiet. Not even because naturally I am very quiet. I think I was about five or six (years old), I said something, I can't even remember what it is now... [and] someone said, 'That's stupid', and so I thought, okay, how about this...I will just say things very quietly, and that way if they are stupid, then nobody hears.

Academics and learning was something that came relatively easy to Noah. He felt that he grasped the material presented to him in elementary school with little or no effort. He had some challenges with being organized (e.g., keeping his desk organized) and he mentioned that this kept him from making honor roll. Organizational skills were something he has struggled with throughout his life, yet he received little support in this area. He explained, "This did not result in any kind of extra supports for me... No one said, 'Hey maybe he has trouble organizing things', which I legitimately do. This is something that I really struggle with to this day..."

In third grade, he remembered not doing his homework, and at the end of that year, he was almost held him back. "They thought that I did not know anything because I did not do any work." His mother, however, advocated that he skip a grade instead, because she felt he was bored and he needed to be challenged. Noah was tested for talented and gifted program (TAG) services, and since kindergarten, he was always sent up a grade for literacy instruction. Thus, instead of moving up to fourth grade after third, Noah skipped fourth grade and moved up to fifth grade. As he described, "I was still too smart; I knew too much. I was just bored. For the rest of my career I continued to be bored, my whole school career; I probably could've skipped another grade."

Middle school years and peer relationships. Noah recounted his fifth and sixth grade years as pivotal in developing his sense of schooling. In fifth grade, he remembered having a teacher that was in her first year of teaching, and she had problems 
with managing the classroom, which Noah admitted was, "not an easy group of kids." In addition, "She just didn't know the culture of the school, she didn't know the kinds of families that we came from, and she came in super nice and super soft." Noah did not attend his local neighborhood middle school because they did not have a TAG program, so he went to a magnet school, located in a neighboring community. As Noah described it, the neighborhood was similar, but it was in, "A slightly worse part of town..." Noah remembered middle school as bring challenging for him, saying:

...[T]hat was a rough time, in part because my dad was moving to Oregon, also because my parent's divorce was starting to take a toll, with the constant backand-forth. I'm like 12, so it's the age where you are really... like, racism is real, and it pisses you off... a lot. You really don't know how to deal with that, and you get in trouble a whole lot.

When Noah was in sixth grade, he started to really dislike school. Noah believed his teacher had a strong dislike for him, in fact, he said, "He could not stand me. He hated me so much." This was Noah's first male teacher.

Sixth grade is about when I started hating school and just being like, this is stupid. Fifth grade kind of, but that was more like, I liked going to school, it's just every now and again school sucked and that annoyed me. Whereas in sixth grade, I was like no, this is pretty whack. I don't even know why... why this is stupid.

In middle school, his parents wanted to ensure that Noah completed his homework, so in seventh grade Noah was required to collect his teachers' signatures in a notebook with his assignments. Noah, however, did not always collect the signatures from his teachers. "I would do one piece of homework so I could get their signature and then I would copy them and write them myself. ... I would forge signatures.” Noah eventually was caught for forging the signature of his teachers, and he was punished. "I 
got grounded for a year." Noah recalled that his parents followed through with this punishment, and he recalled their frustration with him. He reported:

They were reasonable... they would say, 'It would be one thing if you weren't very smart. It would be one thing if we knew you couldn't do it; if you were trying your hardest and you were getting F's. That's not what's happening and we know it. You should be getting A's in all these classes and you're not, that's what we're mad about'.

Unfortunately, Noah felt that the punishment for forging signatures did not have an effect on his behavior, and he did not believe his parents were concerned about the core reasons for his lack of academic performance. He revealed:

They were too concerned about the output, and not concerned enough about the reasons, and that was my problem with it. No one ever sat down and asked me if I was okay. Nobody. No one said, hey, is everything all right? The only time that would even come close to happening was when I did something really bad, and then we would talk about it for two seconds, and even then, by that point, I didn't care. I internalized a lot of things; I'm an internal processor. I would coast by on some classes.

In fact, Noah shared that he liked some aspects of school and was engaged at times, "It is also worth pointing out that despite my immense dislike for doing homework, it wasn't that I wasn't interested in class; when we talked about things that I found interesting I would listen." Even though Noah did not like completing his own homework, he would sometimes complete other people's homework for some form of remuneration. "I would do other people's homework in exchange for gaming magazines.... My parents wouldn't buy any gaming magazines. There was this kid in my class, I would do his homework, and he would give me his gaming magazines."

Noah also remembered a few incidents with other students in seventh grade, which led to him getting suspended from school, as he described, "Seventh grade was 
also the year that I got in fights." Noah was large for his peer group, and his father had concerns about him fighting.

Generally I didn't fight because from a young age... because I have always been like a big, or at least fairly big... my dad was like, we have to talk... 'You can't just be out here fighting people, you really can't. If they hit you, that is one thing, then do what you do. If they don't, then you are not to fight them. I do not care; I do not care what they say, you don't fight them.'

Because he had a few encounters in seventh grade, he recalled, "So that was the year I was suspended twice for fighting."

When it came to peers and socializing, throughout his childhood, Noah only had a few close friends, including his brother. He shared:

I did not have very many friends. I had maybe five of them, who I had grown up with and who I went to daycare with, and who I had known for a long time. We hung out after school and stuff, eventually we went to different middle schools. We were friends.

Noah found it difficult to maintain friendships as a middle school student, saying:

I was a 12 year old who was sensitive, with empathy, and so that doesn't go over well with other 12 year olds. You just..., you take stuff too seriously and then like you get bent out of shape, it just doesn't work.

As far as achievement was concerned, in general, Noah felt that he was not given adequate guidance. Noah was able to pass most of his classes but he was not achieving at a level he was truly capable; he had wished someone had helped him “... learn how to stay organized, and how to do work even when you don't want to.” Most of Noah's anecdotes and accounts of his experiences with K-12 teachers were negative, although he liked some of his teachers; he expressed, "there were teachers that I liked, who I 
respected, but not ones that I admired." One of the few individuals he admired, was his uncle.

I admired my uncle. I looked up to my uncle... [M]y uncle listened to us, he listened to me and my brother. He was one of the few people who would like listen and hear what I say, and not just try to tell me some BS, and so I appreciated that.

Although Noah respected some of his teachers and admired his uncle, he also shared, "I didn't have role models." He did not have people in his life growing up, where he would say, "I want to be like that person when I grow up." In fact, he had respect for a limited number of people he had personal contact with; rather, he discovered that he had more respect for individuals he read about in books. He recalled:

I read the autobiography of Malcolm X when I was like 15 years old ...and, that was very influential. Perhaps that's the first thing that I read and went, wow, yeah. There were lots of things in there that I found very useful. I was like, that makes sense. I see where you're coming from.

Teenage years and moving to Oregon. The summer before eighth grade Noah moved to Oregon where his dad was living. He attended eighth grade in a middle school in a predominantly White suburban school. He did not have much to say about his eighth grade experience; ninth grade, however, he described was a foundational year. Ninth grade was the year that he solidified his dislike for mathematics, mainly due to negative experiences with one particular math teacher. He disclosed:

Math was like one of my favorite subjects up until that point. Math made sense. Math is just puzzles, even 'til this day, math is just like puzzles and games, it's very easy for me. I think very spatially, and so, lots of things in math make sense. I liked math up until that point. I hated it after that, because ninth grade I had this teacher ... I hated [that teacher] for variety of reasons. Number one, she did not respect me, I was not stupid... 
Noah conveyed that this teacher perceived he wasn't intelligent, and he had not previously encountered a teacher who failed to acknowledge his intellect; he lamented, "She just never cared enough to find out."

Additionally, during that same year, Noah learned what it was like to go to a school that was predominantly White (eighth grade withstanding). Noah discovered the difficulty of discussing issues related to Black history with students and teachers in this predominantly White school environment, in particular the topic of Martin Luther King, Jr. Day.

One of the worst days when you don't go to a school that is majority black, and that is Martin Luther King's birthday. It is the worst day ever because all it isand I knew this even in the ninth-grade - it is a chance for White people to sit around and talk about how bad they feel because of racism, and then tomorrow, they go right back to doing whatever it is they were doing because now they feel better.

He further identified the differences between the school cultures and the underlying reason why he disliked talking about issues related to Black history with students and teachers at his new school. He noted:

There was also always this implicit sense when we are talking about Black history issues when I went to a majority Black school, we were talking about something that happened to us. When I moved out here [Oregon], it was a lot more about something that happen to them. That was weird and I didn't like it; I hated that a lot.

Noah went on to explain that his ninth grade math teacher decided to have one of her students read Martin Luther King, Jr.'s, I Have a Dream speech in class.

Then, [the teacher] asked, 'Has anyone in this class experienced racial discrimination?' There are three kids of color in this class and I was thinking about it... She's not asking that question. She's saying the words to that question, but she's not asking that question. But I go, you know what? I'm going 
to put my hand up. No lie, she said, 'That is false, put your hand down.' She told me to put my hand down. She said that I was lying, and to put my hand down. She left the school after that year, and she definitely... had to backtrack apologize.

This experience had a significant impact on Noah. He admitted:

I stopped caring about math; I hated math after that. I told people I always hated math, but that was not true. I didn't figure that out until I was 22. Then I had to go back and be like, why do I hate math? When did I start hating math? I liked math up until that point, it was one of my favorite subjects; it was one of the few [subjects] that I did work in. Then I just hated it, I argued with every math teacher that I had past that point.

The following year, in 10th grade, Noah had another math teacher he found to be argumentative; he stated, "Her impulse was to assume that I was wrong." In contrast, he had one high school math teacher his junior year, a male teacher, who was one of his favorite teachers, because he was honest and respectful of Noah and the other students. He developed a rapport with Noah. For example, Noah would always inquire, when the teacher was explaining an equation, "When are we going to use this in real life?" and the teacher would usually give him an answer. Noah recounted that at some point during the year the teacher would address his question even before he asked, saying:

Without looking up from his book, he would assign the math problems and he would be finishing up explaining about it, and he would say, 'I would like Noah to know that we will not use this in real life and this is not useful at all.' Okay, respect; like that I respected.

Noah also appreciated that this math teacher would not insist that he do his homework when there was time at the end of class, as Noah liked to read his book [unrelated to math]. Noah would also help other students with their math homework during that time, and his teacher would notice that Noah could do the work. Noah noted that the students 
that requested his help were often those who earned good marks and were considered high performing students.

One aspect of high school where Noah found the most success was in Speech and Debate, which he participated in during his senior year. He was good at debating, winning some tournaments along the way, receiving several trophies and medals. Noah had confidence in his public speaking skills, he remembered a few instances in classes where he received accolades from his teachers and peers when he presented or 'performed' in class. In fact, he also did drama.

That's when I figured out that I should drop biology to take acting, because I didn't need biology, I had taken all my science credits. That's when I figured out that I should have taken [drama] my freshman year, because I really liked acting.

Overall, high school was not a great experience for Noah, "My high school career was also very underwhelming, and I graduated with like a $2.1 \ldots$ Once again, I should have never graduated with a 2.1." Noah conveyed how he found the predominantly White school culture an issue for him. He recounted:

In general, the school culture was just so different from my own that it just kept throwing me for a loop, even though it was meant to be welcoming, it was not. It was alienating in lots of ways that it meant to be welcoming, and that was what was frustrating... it was just like overwhelmingly culturally White, and that did not fly for me.

He shared how he felt his teachers overlooked his poor academic performance.

I had a very interesting school experience... I just lucked out and happened to be good at the things that schools measure. There is this long trend of just lack of accountability because I got by... I knew I would... if I just kept doing my own thing it didn't really matter, because at the end of the day, they would pass me. 
Noah believed that his teachers, throughout his K-12 schooling, did not serve him well. He reported, "My school career was fairly underwhelming, I was generally superunderserved by my schools. None of them really caught on to the fact that I have huge organizational problems, to this day I cannot organize things..."

Going to college was something that Noah had always thought was in his future. "I knew that I was going to college in an abstract sense, because everybody had always told me that I was." When he started thinking about his college options, his low grade point average was one concern, but the financial burden of college was the major issue. He recalled what his father said to him, “...12 or 13 [years old], maybe younger, my dad goes... You better get a scholarship because there's no college fund." Prior to meeting with the high school guidance counselor he thought his only choice was college affiliated with the military.

Deciding to become a teacher. It was not until high school that Noah thought seriously about his career options. When he was very young, he had told people he wanted to be a scientist when he grew up, because he liked the image of a scientist with a lab coat, and “...test tubes full of colorful liquid, pouring colors into other colors, blowing things up that was being a scientist." When he was a little older, he told people he wanted to be a mechanic, but his uncle advised, "Don't be mechanic, be a mechanical engineer because you'll make more money." Noah admitted, that even though he told people that he wanted to pursue mechanical engineering, it was not something he truly considered, especially when he learned that math was required. Unfortunately, no one had ever spoken with him, genuinely, about career options, neither at school or at home. 
He recounted:

I did not really consider any careers until I sat down senior year, around the point when I started having anxiety about it, and one of my counselors, for the first time in my whole school career, asked me... 'What do you want to be? What do you want to do?' He was the first person that asked me... and he listened.

This question prompted Noah to think seriously about his options.

I thought about being in math class with [the teacher he liked from junior year]..., and I thought about how not going to school kind of scared me. I thought about how I really liked learning. How I liked seeing that look on people's faces, when they got something they didn't get before, and I said I wanted to be a teacher.

The counselor gave him information about the Teacher Pipeline Program [TPP], and he was committed to submitting his application even though it was late.

I said, okay, teaching. I am very stubborn. So, at that point, I was like, here is the deal. I am going to be a teacher. I am going to apply and get in. I know the deadlines late, but if I don't get in, I am going to... I am just going to nag the program director every single year... until she finally lets me in. That was my whole plan from the beginning. I was like... I am doing this.

Noah's career choice received varied reactions from his friends and family. Given his outward negative opinions about school, Noah disclosed that some people in his life were, "[V]ery surprised because I hated school and they knew that I hated school." However, he said his parents reacted differently, "My parents would say, you spend half your day not doing your work, and the other half helping other people with their work," so teaching made sense to them. He added, “... my parents were really stoked when I finally figured out what I wanted to do." 


\section{Baccalaureate College Achievement, Teacher Pipeline Program (TPP)}

In the following section of Noah's profile, his story of pursuing an undergraduate degree is described, including his experiences in community college and university settings.

Community college. Noah applied, was admitted, and started attending the TPP as a traditional student, meaning that he went right from high school into community college without a break. He took most of his freshman and sophomore classes at the community college and transferred to the university where he completed his Bachelor's degree. Noah did not start college with an understanding of college-life, as he did not have any early exposure to college. The only times he had been on a college campus was during high school when he participated in speech and debate tournaments, but these experiences were limited to viewing the campus as a facility for an event. He did not go on a campus tour or learn about the college while he was there competing. Noah explained, "I knew about college in the abstract sense, I knew about college from movies based on colleges; that's all I knew about college."

Noah described that he just barely got into the TPP because his application was late. He had some challenges when he began the program, as he recounted, "I had to play catch-up when I got there, and I had to start to figure things out as I went along, which I did. That was something that I was not used to, something that was immensely beneficial to me." Additionally, he disclosed, "I had lots of arrogance. I mean, like lots, and lots. I thought I was smarter than like $90 \%$ of people, easily..." Noah admitted that he needed someone to point this out to him, and be told, "Look at all this stuff that you don't know." That person was the Director of the TPP, and she pointed out areas of concern that Noah 
needed to spend more time working on. Noah's initial performance in college was not up to TPP standards; he lamented, "I did very poorly. This is very typical me, this is the thing that proved it continued into college and it wasn't just a public school K-12 thing." Noah also expressed that he, “... had a lot of growing to do.” Moreover, his lack of maturity was a real detriment when he encountered community college instructors he deemed less than satisfactory. As an example, he recalled a class he especially disliked, mainly due to the instructor, "It was a teacher who didn't understand what my particular needs [were] and I sensed that, and so, then I responded poorly. I responded with a lack of effort, with a lack of interest."

Noah's college experience centered on the TPP, and he conceded that without the program he would have, “... dropped out of college seven or eight different times if it had not been for that program. I would have dropped out of college so many times." In addition to taking college courses, Noah described other aspects of his life at that time, including balancing work and school responsibilities. He recalled, "I did drama for a couple of years. I acted in some plays. I did that and school, and... I worked, I don't know, 25-30 hours a week."

Overall, Noah described the community college environment in somewhat positive light, especially as it compared to the university environment, "[Community college] is a lot more community-based, a lot more receptive... There are a lot more resources that are easily accessible and easy to locate and easy to find and not very daunting or stigmatized to use..." As far as faculty were concerned, Noah thought that, "In general, the quality of staff varied wildly at [community college]." He also expressed concern for lowered expectations that faculty had of him, as he stated: 
I think that it was a continuation of the same thing you see in K-12. Where it's like, you are still doing fine, you are still at whatever the benchmark for this level is... So, my job is done. When actually I had a lot of growing to do...

Eventually, Noah had one "very formative teacher" at community college, a history teacher, with high standards, who helped him become a better writer. "At [community college] I had one of the first teachers who ever really ripped me apart for my writing, and that really helped a lot." In addition, he explained, "She was one of the only teachers that I ever had up until that point, it was like my second year of undergrad at [community college], who knew about racism."

University years. After attending community college, Noah completed his undergraduate degree at the university. He shared how the university environment was different from community college, "In general, the attitude is more... stereotypical, like Finding Forrester [the movie].... It is a lot more apparent at a 4-year university that it is not meant for people who do not come from a very specific background." He elaborated, "I think that it is... a lot more heightened at [university], where if you're poor, it's not for you; university is just not really for you."

Noah also talked about his impression of university faculty. He said:

At [university], your bad instructors are terrible, like, they shouldn't be teaching terrible. At [community college] you might have one or two of those, but those are so rare. There is less accountability at [university], and I think that is what shows.

Despite less accountability, Noah admired several of his university teachers. For example, he described one faculty as "fantastic"; he found that ".. her enthusiasm for her subject shined through every single lesson." Noah also had his fair share of negative experiences with faculty. Likewise, his experiences with classmates, non-TPP students, 
were also not always positive. For example, he grew frustrated when it came to conversations about equity and racism, especially in his upper division classes. He recounted, “[T]hey didn’t know anything about racism and they were in the 400-level class, some of them were grad students. I was tired of having the same introductory conversation with everybody when I was ready to have more nuanced conversations."

Noah had the most praise for the TPP. He appreciated having a place, amongst a large welcoming community, where he and other TPP students could come together with a "uniformity of purpose." He summed up his understanding of the rationale for developing a program like TPP, “[T]here are variety of things institutions, for whatever reason, do not provide to students... those things that are essential for students, and so... hey, we've got to provide for ourselves." Thus, "You have a chance to relate your experiences to other people of color, which is something you do not get in a traditional university setting."

\section{Post-Baccalaureate Success and Graduate Educator Preparation Program}

In this section, Noah's profile concludes with his experiences in graduate school and the teacher preparation program, including his critique of the preparation program and the curriculum and instruction received, as well as the role of the TPP in his success.

Admission and enrollment in graduate school. Although Noah was admitted to the TPP and he successfully completed the undergraduate program at the university, he and his fellow TPP students are not automatically enrolled in the graduate educator preparation program. Noah received support from TPP in preparation to submit his application to graduate school. As he recounted, "I lucked out because I had the [TPP 
Director]." He explained that the director provided key information about the application materials (e.g., letters of recommendation).

Noah talked about some of his concerns in regards to cost and access to graduate school, "If you cannot get a loan... or do not have the money saved up, you're not going to grad school for education." He shared why this is problematic, saying:

I believe that process is largely a vetting process to get students who might have the academic qualifications and potential but not necessarily the background and support system, out of the program. That has a negative effect. We don't have enough [teachers] with diverse backgrounds, and that is a direct result of that same kind of thing.

While Noah was not the only TPP student to start the graduate educator preparation program that year, Noah was only one of three students of color in his cohort of 20-25 students. In the cohort model, the graduate students take course work together for one calendar year. With regards to this year-long model with largely non-TPP students, Noah expressed his displeasure, "So it puts you in a really weird space, as like one of the two or three people of color in the program." Noah recounted many instances of challenging discussions - similar to experiences in upper division courses during his undergraduate years - he had with the other students in the cohort.

[W] e would get to conversations that had to do with race, gender, equity ... things like that, social justice... and this thing that happened, where you would notice that the academic level of the entire class would drop to the floor....[We would] be having 101-level conversations about what racism means and what prejudice means... No one seemed to have ever taken seriously the idea that... social justice studies are an academic field and not a touchy-feely thing... They had a hard time understanding that.

Teacher preparation instruction and student teaching. Noah did not feel that he received the best instruction in the program. He summed up his experience, “... 
[O]verall, it was inadequate; grad school was inadequate." Noah was critical of the content of the curriculum in graduate school, and of the quality of the instruction. He described, "[W]hat I think hurts grad school the most... There's not, I do, We do, You $d o \ldots$ It's not even, We do, it's just You do. It's... here's the assignment, do it." He felt there were many times when he submitted his assignments and received very little feedback from his instructors. Noah knew there was a lot more he needed to learn about to becoming a teacher. As he expressed, “[T]here’s actually some things that I don’t know, that I need help with... that I need someone to go through it with me.” Moreover, he said, "I don't feel the things that I learned in grad school were an accurate reflection of what happens in my classroom and of the essential skills that I need to survive in this classroom." Additionally, there were many instances during graduate school classes where Noah did not feel comfortable participating in discussions, especially as they related to topics that related to race and equity. He explained, "If I [got] frustrated, I [was] going to say something, and if I [said] something I [was] going to get in trouble. It's the Catch-22 of that, like, your instructors expect you to be engaged but... within certain parameters."

Students in the preparation program spend a considerable amount of their time student teaching. Noah appreciated having both of his student teaching placements in close proximity, "Right down the hall from each other; they were both at the same building, so it was very nice." However, he conveyed his thoughts about how the quality of the student teaching placements could be improved.

There is not enough critical consideration about placements. I get that placements are difficult, because you have to have teachers that are willing. But you have student teachers that are placed at schools where management is not really an 
issue, and so they don't... learn how to manage a classroom. They can't get a class quiet. They just don't know how to do it.

Noah talked about his experiences as a P-12 student, especially his feelings of wanting his teacher(s) to "prove to [him] that [they] cared;" he expressed his deep concern that the preparation program was not helping preservice teachers adequately reach students in this manner.

Role of TPP in graduate school. Noah expressed being very grateful to have the TPP community while taking graduate level classes and learning to be a teacher. Noah disclosed that without TPP he, "[P] robably would have gotten kicked out otherwise, easily." He talked about the importance of the entire community of TPP and he described how the other TPP students were honest, or "real" with him, how they would let him vent and actively listen to his concerns. Important to note, TPP meetings were considered confidential; Noah recalled, “It doesn't get spread around. It doesn't go back to our professors, [and] it's not about the college, it's about us."

Noah mentioned that TPP students often had informal gatherings, such as study groups as well. He also said that many TPP students benefitted from test support, but that was not an area of concern for him. Overall, he felt that the main benefit of TPP, was the "accountability" piece; he shared, "For me that was the biggest thing." Even though he described needing support, he stressed:

If you have learned to be successful enough to make it to all the way to grad school, you have figured out how to deal with inconsistency in the school system. You would not have made it this far if you couldn't... 
Noah concluded by talking about learning to become a teacher and relating it some thoughts he had heard from Bobby Fisher, the renowned chess champion, about learning to play chess.

... [C]hess is not about how smart you are. It's not about how strategic of a thinker you are. It's not about how clever you are. It is about one thing and one thing only: how much time you spend playing chess. I think that studying to become a teacher is exactly the same way. It is not about what your GPA was, as I graduated with like 2.1 GPA. It's not about how smart you are. It's not about how many things you know. It's not about how fast you process. It's about the time and the effort that you put in. It is about how much time you spend thinking about teaching and thinking about your classes.

\section{Carmen}

Carmen's profile begins with stories of her family and a variety of P-12 school experiences. The narrative continues with Carmen spending her freshman year of college away from home. However, after one year, she returns to her family, and aided by the TPP, her journey to a career in teaching is completed with two degrees and the teacher preparation program.

\section{Childhood and P-12 School Years (Pre-College Socialization and Readiness)}

Carmen's family is highlighted in this section of her profile. In addition, her friendships and many P-12 school experiences are explored.

Family, friendships and identity. Carmen is a native Oregonian who lived in the same region of the state for her entire life, with the exception of her freshman year when she attended a college in a different part of the state. Carmen grew up in a twoparent household along with her two younger female siblings. She described her mother's race/ethnicity as Hispanic and her father's as African American. Carmen's mother went back to school as a non-traditional college student to become a teacher when 
Carmen was in middle school. Carmen's mother went through the Teacher Pipeline Program (TPP), starting at community college and completing a graduate level program, earning her teaching license while Carmen was still in high school. Carmen's father has some college education and has had several different "blue collar" type jobs. Carmen described both of her parents as having a strong work ethic, saying:

[My father] is all about hard work, and you put your best foot forward. You put all of you into it; you come in and you do your best. If you can walk out and say I did my job to my full ability, then you can have pride in that, and so that is kind of what my parents are about.

As mentioned, Carmen has two younger sisters. One of her sisters is three years younger and the other is five years younger. Her parents tried to raise them with gender equality in mind; she shared, "We were raised in that sense of, this is what you do; it wasn't just, this is what a man does, it was this is what a person does." Carmen recalled how their experiences and personalities were very different from one another. She believed that this might have been partly due to her family moving to different parts of the same city while she was young; she added that the family had, “... a lot of housing issues and things going on." Her sisters, however, did not move around as much to different elementary schools as Carmen did, they were younger when they started and remained at the school where Carmen attended fourth and fifth grade. This was the one school in Carmen's P-12 schooling that was not predominantly White; this school had many students of color, including a large population of African American students. However, Carmen did not have a sense of belonging.

I think I felt more unwelcome going to that school than I did anywhere else, because I was so used to being at predominately White schools up until fourth grade. For me, it was literally a culture shock. It was a culture shock for me. I 
had hoped for immediate acceptance, and did not get that. I did not get that because what they heard when I spoke was White. What they saw when I acted was White...so I wasn't really accepted; I wasn't really brought in.

Carmen shared that she and her sisters have had many conversations about their racial backgrounds, how they were raised, the differences between them, and others' perceptions of them. She reported:

It is really interesting to see how all three of us raised in the same household, identify in three different ways. I would be considered to be more White than they are, and that is mostly what people see. People see me and they are like, oh, you are Black, and then I speak and then they are like, oh, you must be White. I am like, no, I am actually Hispanic.

Carmen described most of her friends as being White. In fact, she said:

I felt more at ease within the White community but at the same time though too, I knew that I was going to be judged. I knew that I would be considered different, but I really didn't realize to what degree.

In reference to her high school friends, she recalled:

I was more myself with them than I was with anybody else, by far. However, when I felt I needed to perform in that sense, to act in that sense, I did. It was more towards their protection than anything else. It was literally this puffing of the chest, a bodyguard type sense, and using very colorful language. Acting in a way that was myself, but at the same time was me on testosterone. They didn't really push that, but at the same time, they didn't discourage me either.

She described her closest friend as someone who accepted her for who she was and did not encourage her to behave in any certain way. She distanced herself from peers who expected her to act a certain way. Carmen disclosed race and ethnicity issues that she struggled with throughout her adolescence; she talked about being bi-racial and not feeling like she fit in anywhere. When her family moved out to a predominantly White neighborhood in the suburbs, Carmen explained: 
...where they think you're White but you're not, you are Black, so you still don't fit in. Being Hispanic, you are Hispanic and you are Black, but you don't speak Spanish so you're not 'true' Hispanic. Just kind of being by myself and feeling like I do not fit in anywhere, like I just don't.

K-12 school experiences. While Carmen was young, due to her family frequently moving, she attended several different elementary schools. She described the difficultly of being the new student.

I was always the new kid. For me it was just kind of like, alright, so I'll have to get to know a new building, get to know new students, get to know new teachers and things like that. So for me, socially, I was really awkward.

In addition to being the new student, Carmen was also "one of the few kids of color in a classroom at a time." All but one of the elementary schools that Carmen attended were predominantly White. She described being new and being the sole student (or one of a few) of color in the classroom as hard, thus, Carmen said that she really did not like students her own age, she found them to be "just kind of mean and not very nice." Moving around to different elementary schools had played a toll on Carmen's academics, she said that she would "miss things."

For me math was really hard because I would pick up and leave in the middle of the school year, so fractions were like the hardest thing for me to get and I didn't understand the concept of fractions and how they worked in math until I was sixteen. My sisters, literally my two younger sisters, taught me about fractions.

Unlike math, however, Carmen really enjoyed and excelled at reading, and given her circumstances and self-described "social awkwardness," Carmen would spend much of her alone time reading. She loved, and still loves, to read.

In the school where she attended in fourth and fifth grade, which had a diverse population, she talked about, "Being considered an Oreo, Black on the outside White on 
the inside. But I would tell them I am not White." While attending this school, Carmen had one of her only P-12 teachers of color. Carmen described this teacher as very engaged and a "[r]eally great guy, really fantastic, really good about being engaging and making relationships, and doing all of the things that we talk about now in education..." Carmen felt as though this teacher was attentive to her academic needs, acknowledged her strengths, and made connections with her that she remembers well.

Carmen was in sixth grade when her family settled in one location, so she went to school with much of the same cohort of students for middle and high school. Although she had stability by living in the same location and attending school with the same group of students, she did not describe high school as a positive experience.

High school was really rough. So just being, you know, not only the Black kid, but then, the heavy Black kid. On top of that, they wanted the stereotype to go with it. So they expected me to talk loud; expected me to be ghetto and crazy and head snapping, eye rolling and teeth sucking. All the stereotypes, right down to the tee, and that is not me in any way, shape, or form. I could play the part and I did.

Carmen went on to describe why she felt like she had to play the part of "the [African American] stereotype" in her predominantly White high school. "I did what I felt I had to do in order to just be left alone ... I wasn't being me. I was being what I...just what I needed to be in order to survive from the day-to-day."

Toward the completion of high school, Carmen started to act more like, what she described as, herself. She came to the realization that she did not have to act a certain way; she found that she could start being more of her own person. She described a critical change during this time, associated with her first name. She had always been 
called by what she described as a White nickname version of her name, but by her senior year, people were calling her by her given name.

In talking about high school, Carmen described one of her favorite teachers. He was a White male who taught her in middle school and moved to the high school at the same time she moved to ninth grade. She described positive memories of this teacher, and she was thankful for the continuity he provided as she transitioned to high school. Carmen was connected with this teacher and described him as, "all about his students," as well as honest, caring, and real.

Carmen also described some of her high school teachers in much less positive light, including several unpleasant altercations. In fact, her senior year she decided to pass up the opportunity to take an advanced placement (AP) class in a subject she excelled, because the class was taught by a teacher she had many bad experiences with in an earlier grade. She shared numerous stories about this teacher, including an encounter he had with her mother where he made insulting comments about Carmen's future career prospects. Also, in one instance this teacher sent her to ISS (In School Suspension), something she had not experienced before, and she described her teachers surprise when he told her to go to ISS but she did not know where it was located: "I am like, where is ISS? He says, are you trying to tell me you have never been to ISS before? I said, no, I have never been to ISS before." Carmen's typical behavior in school was not as this teacher assumed. She recounted, "I really did my best not to be noticed. Not to talk. Not to do things." In fact, she referred to one instance where race was brought into a class discussion, and her thoughts at the time were, "I can't speak my mind because you guys want me to be a stereotype." 
On a more positive note, Carmen volunteered as a teacher's assistant for a few of her high school teachers, a role she very much enjoyed. In these instances, she was given responsibility and autonomy. As an assistant, she was able to get to know some of her teachers more personally which she remembered fondly. She described one of these teachers, who was also a White male, as, "one of those people who was just really great about me being me." She enjoyed some elements of high school, or at least the chance to learn from and with teachers with whom she could relate. However, in general, when it came to high school, she admitted:

I actually stayed under the radar because I tried to avoid those (cultural) situations. My parents never shied away in having those conversations about, this is how the world sees us, and this is how you have to act.

Career and college aspirations. As far as career aspirations were concerned, Carmen ruled out many career possibilities she had thought of pursuing, including an architect, a fashion designer and a caterer. The decision to not pursue these options was based on her own perceptions and limitations of her skills and abilities. In addition, at one point after preforming in a national choral competition, an event she describes as “... one of the biggest experiences of my life;" Carmen thought about becoming a music teacher, but because she did not play a musical instrument, she eliminated that option as well.

Carmen described having a strong desire to go college on the east coast. When she talked about going college with her parents, Carmen said:

The firm rule about college was, either you go or you get a job. That was it. There was no in between. There was no, you can try it, you can't try it... It was, you are going or you are getting a job. And so, I knew. I knew I was going to college. I didn't know how I was going to college but I knew I was going. 
From an early age, Carmen was involved with an organization that mentors students attending under-resourced public schools to help them achieve their educational and career goals. When it was time to consider college options, she applied to go on an east coast college tour that this organization sponsored. She reflected on that experience, saying:

I really enjoyed seeing the colleges but then also being on the east coast and having this... epiphany that I don't stand out. We got off the plane and we were in New York ...I am like, I blend in here... I don't think anybody else around me at the time... because they are all predominantly kids of color, I don't think they had the same kind of thoughts that I did; they grew up within the culture, they grew up living blocks away from each other and being in neighborhoods that were predominantly Black. I didn't, I grew up in White neighborhoods.

This feeling of blending in and being surrounded by people that looked more like her, led her to want to go to school on the east coast. She applied to one east coast university and received admission to their pre-freshman summer program, but was unable to go because of monetary reasons. The only other school she applied to attend was a rural university in the Pacific Northwest.

\section{Baccalaureate College Achievement, Pre-Teacher Pipeline Program}

This section begins with Carmen's experiences attending college away from home, and after moving back, her decision to become a teacher. Pursuing this career path, this part of her story focuses on being a member of the TPP community and completing community college and university.

Freshman year away from home. Carmen had a strong desire to go away from home for her baccalaureate experience, and although she do not go to school on the east coast as she had wished, she was admitted to a small rural university. She explained: 
The reason why I applied to [rural university] was because of their teaching program. I went [there] with the intention of teaching. Teaching what, I didn't know. Like I said, I thought about teaching music, but I can't play an instrument. I was undecided my freshman year while I was with them. And that was a bit of a shock going there, too, because I was not in urban, I was in rural.

Many of the academic elements of her freshman year experience away from home Carmen described in a positive light. She described how she found the college experience empowering. She remembered, “...when I got to college I was a lot more vocal. I spoke up more. I interacted more and I decided that I was going to be an English major. It's a good place, it's just small." Carmen participated in student government by becoming the secretary of her dormitory. Ultimately, along with the financial concerns, Carmen found that living in a small college setting to be undesirable. She concluded:

It was rough. I realized it wasn't the best fit. I realized that I like space. I do like rural. I like being isolated. I can't do limited experience. ... I found that to be the hardest thing; it was the hardest thing for me to adapt to was the shift in people.

Community college years and decision to become a teacher. After having spent her freshman year away from home, Carmen made the difficult decision to return home to her family to an environment with more familiarity. She was unsure about what to pursue academically, and although she knew she wanted to continue her education, finances were a big concern, "My thing was that debt, re-paying back what we owe. I didn't want to make that kind of mistake, having to have the debt on top that."

Carmen felt like she made the right decision to come home and continue her education at community college. She said:

I came back home and that was a better choice for me. I went to [community college] and... finished my transfer degree. That I liked. I still liked the smaller class sizes. I liked my instructors. That was a better shift for me. 
At the time Carmen returned home from her freshman year, she really wrestled with the idea of pursuing a career in teaching and applying to the Teacher Pipeline Program (TPP). "I really didn't know if I was going to apply to the program. I mean, it was a smart choice to apply to the program...," but Carmen had reservations about this decision because her mom had completed the program, and though it felt familiar in some ways, she also expressed concerns.

I just didn't know if I had that dedication to teach. I was still kind of in that... limbo. What do I want to do? [I]t was a really big battle of, is this what I want to do? And on top of it, having to be compared to my mother.

Carmen went on to say, "I was still kind of in that mode of, I still want to teach. I still want to work with kids. Just in what capacity? What do I want to do?" Carmen did not take the decision to become a teacher lightly. In fact, her mother, who was a teacher and a graduate of the TPP, told her, “... don't go into it with lukewarm feelings, make sure this is what you want, make sure that you were going to be invested". Carmen described that it took a long time for her to make the decision. Carmen considered many factors when making the decision to pursue a teaching career and complete the TPP, including her own racial and cultural identity, her experiences, and her level of willingness to participate in a more racially diverse environment.

That was an adjustment... I was back with more people of color. ... that was the shift in that experience. ... [I] still didn't trust them. [I] still didn't want that deep connection... I have already been burned once this way and I cannot afford to do it again. ... [I]t was just one of those things of, it took a lot for me ... to engage.

Another factor that weighed in her decision to become a teacher included her own experiences as a P-12 student, "I had nothing but White teachers. None of them looked like me, and if they did look like me I still didn't want to trust them. I didn't know who 
they were or where they were coming from." Thus, Carmen described wanting students to have a different experience:

... I don't want our kids to have the same experience that I had. I don't want them to feel like they're being called out... because of what they are, because their skin looks a different color. Because I don't want them to be called out in that way; I want them to be called out for what they can offer, you know?

Additionally, she declared, "I wanted to create a different education system... I wanted to change not only how things [are] taught but also how students [are] approached."

TPP support. Once Carmen decided to apply and begin her pursuit in becoming a teacher, she shared some of the benefits of being a part of the TPP.

As undergrad students we had monthly meetings, we had monthly seminars that we went to where we would sit down and talk about current issues. Not just historical events, but social issues that go on and represent our communities within the education sector, and within the justice sector.

Additionally, Carmen spoke about how the TPP stressed the importance of community engagement. "We did our own community events as well. We participated in the community. It reminded us to be more part of the community, making sure that we are giving back as good as we get."

Carmen also talked the support the TPP provided around the teacher examinations and preparedness to take the tests. She recounted:

The [TPP] definitely makes sure that you take all the necessary exams before you even apply to grad school. You have to pay for them yourself, of course, but [TPP] tries to help our own... so those that can't afford to take it, they do provide that support. They provide that help if you need that extra help.

Carmen was able to pass the basic skills, general subjects, and one subject matter test without difficulty. However, she had to take and re-take one of the subject matter 
knowledge tests many times before passing. Fortunately, she was able to earn her license with one subject matter endorsement, but had to wait to add the other subject matter endorsement until after she had passed the test. This allowed her to substitute teach while she continued to try to pass the one subject matter test. "[TPP] offered me [test prep] support, but with my schedule it was hard for me to take days off of work."

Carmen continued to help current TPP students with that specific subject matter test even after she passed; she shared all of her notes and materials, and even offered tutoring and financial support. This type of peer support was modeled for Carmen throughout the TPP. For example, she described how the TPP students networked with one another as undergraduate students: "So that is one of those things... [TPP] in that sense is really great. As far as trying to help each other.”

Carmen also highlighted the close relationship she had with the program director of the TPP. She emphasized the substantial amount of support she and her fellow received from her, as well as the important role of the director played in nurturing a sense of belonging and community. Carmen's description of the community, in some ways was like a family.

University years and connections to teaching. Beyond Carmen's experiences with TPP — and like many of her fellow TPP students — for much of her undergraduate years she was employed outside of school:

I worked a part-time job. I worked retail. I had to quit that job by the time I got to [university]... Well, I quit during my junior year. I went through winter term and had to quit; I was working almost full-time hours. 
However, Carmen did not have to work, "I also was a single individual living at home, so my expenses weren't high. I wasn't raising a family and trying to go and do school again...", like her mom experienced years previously.

As far as faculty and fellow students (not including fellow TPP students) were concerned, at both the community college and the university, her experiences were satisfactory, as she said, "Yeah, my undergrad was pretty standard." She shared a few stories or odd situations that took place, but she deemed these as outliers, not the norm. She summarized her experiences with faculty, saying, "I didn't really have good teachers or bad teachers; I just had teachers. The ones that stand out in my mind were the ones who pushed me in different directions, either socially or intellectually." Carmen mentioned only one undergraduate faculty member that she thought was below par, but even in sharing her negative experiences she also commented that she "could tell that (faculty member) was passionate about the work, and was passionate about what she did...."

Carmen shared that obtaining her undergraduate degree was not always easy and she worked hard.

I spent a lot of time just catching up, taking summer courses and things like that. I always felt that I was behind, like I got to do this... I got to do that. I had a couple instances where like I said, teachers said random things, or random things happened... but nothing that really deterred me from wanting to do what I wanted to do.

Carmen recalled two experiences during her years as an undergraduate student that influenced her decision about the subject matter content and the grade levels she wanted to teach. The first experience was during community college, in a practicum experience at a local middle school. This was the first time she realized wanting to work 
with sixth, seventh, and eighth grade students. The second experience was in a political science course at the university, when a faculty member used hands-on and interactive approach, similar to mock-government. These highly practice-oriented experiences during her undergraduate years left long-term impressions on her.

\section{Post-Baccalaureate Success and Graduate Educator Preparation Program}

Carmen's experience with admission and enrollment in the educator preparation program is described in the following section. Several elements of the program are discussed, including her experience as a student teacher, instruction she received, and the role TPP played in her success.

Admission and enrollment in graduate school. Though Carmen was admitted to the TPP and successfully completed the undergraduate program at the university, she and her fellow TPP students were not automatically admitted to the Graduate Level Educator Preparation Program. Carmen remembered clearly the graduate school application process and interview experience. She recalled, "I felt anxious, in a sense, because I was trying to make sure that I was representing who I am as an individual, as an teacher, also just as a team player..." Her association with the TPP weighed on her mind.

I wanted to make sure that I represented myself the way I needed to, and make sure that I represented [TPP] well, because that was the point. I was going in there as a [TPP] student...

She understood that the graduate program seemed to be seeking students of color, "Yeah, they could take me; they need people of color" and at the same time she was concerned about the presumption that TPP students were automatically admitted to graduate school. This false notion was never said directly to her by anyone, but she stated that it had, 
"been some of the feedback that our students have gotten in the past." She added, "I wanted to make sure that I didn't get in there based on that. I wanted to make sure that I got in for being me, so that way no one could say that to me."

Role of TPP in graduate school. Carmen emphasized the important role TPP plays in supporting TPP students' understanding and development of cultural competency. She recalled:

In my experience [TPP] filled in the gaps of the graduate program. Making sure that we're invested in our kids and not just from an academic standpoint... We are very, 'village' culture; it takes more than one person to raise a kid and that is part of our role as teacher, to provide that support.

She explained how TPP modeled student investment beyond academics, and the philosophy of building and maintaining relationships, within the program. She shared how TPP alumni return to support current students, and she described how the TPP students continued to help each other throughout the graduate program and more about the role the TPP played in supporting them as graduate students. Carmen reported:

As grad students we had [TPP] meetings that we tried to do every month to check in with each other. Our elementary cohorts and our mid-level cohorts are separate, so we would try to get together every month and de-brief... and kind of vent about what we were experiencing in our classes. A lot of it, just being the one-sidedness, the lack of multiculturalism, the lack of representation, the lack of acknowledgment... Hello? We are here? You still have to teach about us too, and not just what the textbook gives you on 2 pages. For us, it was a lot of trying to get together and share resources, and not just textbooks, but also outside resources...

Carmen added, "I had one other person [in the cohort], and one of us would buy one book and the other one would buy the other book and then we would share it and trade it with each other." Carmen was one of two students of color in her cohort of 20-25 students. In 
the cohort model the graduate students take course work together for one calendar year, and in addition to the course work the teacher candidates spend increasing amounts of time in K-12 classrooms as student teachers. Carmen described her experience as a student teacher in a positive light, saying:

Student teaching was good. I was lucky. I was placed with a [TPP] alum. They helped me figure out lesson plans. They helped me sit down and create units. They gave me resources to use, and made sure if I needed something, I had it. Not so much of, let me do things for you but here is the guidance.

However, when she said she was 'lucky', she did so in contrast to some of her fellow TPP student teachers. She believed that had she not been placed with a TPP alum as a cooperating teacher, that her experience would have been "supremely different." That is, “a few of our students who didn't have a [TPP] alum tended to have a rougher experience..."

They ended up having to be moved, usually because the student and the teacher had a difference of opinion, a different point of view, and sometimes neither one was willing to compromise. I have known [TPP] students who had to be moved from their [cooperating] teachers either because of their own personalities or the teachers', most of the time, unfortunately, it is the teacher because the teacher is older..., the teachers are primarily White, and so we [TPP students] have a harder time.

Graduate educator preparation instruction. Carmen described one of her experiences in graduate school, taking a course on multiculturalism, as being "the hardest class for me to take." Her frustration seemed to be related to the instruction of the course. "It was just really difficult, and the reason why was because the instructor didn't really teach multiculturalism." She recalled:

We read Lisa Delpit's 'Other People's Children', and when my White counterparts got in my group, I was the only person of color in my group at that 
time, and surrounded by White females... and a couple of them were angry.... I am like, okay, and my teacher is standing behind us while we are having this conversation, right behind me, and instead of engaging and explaining the point of view of the author, he walked off. He didn't address it.

In reflection of this small group activity, she does not harbor negative feelings for the other students, just the instructor and the manner in which the course was taught.

Carmen also described one other challenging experience, which almost led to her not completing her graduate program. She recalled, "I had an instructor and we clashed, we clashed. Personality wise...we clashed." This tenured faculty member was the sole instructor of a required methods course at the time she was in the program, and the course was tied to the culminating activity required to complete the program.

Carmen described her experiences with the faculty member, saying:

We had issues. Technically, I failed the course. I didn't pass, because you are expected to pass with a B, at the lowest, and I did not, and I had to retake the course. ...Everything was a huge mess. I didn't think I was going to graduate. I didn't think I was going to be able to teach. I was really reconsidering what I had chosen.

Carmen stated, “... [this] was the only class that I had done poorly in the entire time I was there." Fortunately, she was able to complete the course the following year with a different cohort and a different instructor; "[the new instructor] understood more about the multicultural aspects. She understood more of where I was coming from as far as how to teach my students, how to reach my students, how to get them to understand..." In retrospect, Carmen described the experience in a positive light, as it helped her gain confidence and provided a platform for professional growth.

It was good for me to tell you the truth. It was good for me. The experience wasn't pleasurable in any shape or form, but I was old enough... to realize I 
needed it. I needed the push. I need a bigger investment. This teacher had made the mistake of telling me that my students couldn't do something, and I proved her wrong. My babies proved her wrong, and they did it. They blew the assignment out of the water.

Unfortunately, she believed that, "[t]his [tenured faculty member] had a history of... I am not quite sure how to term this... bias, towards African American students, males in particular."

Carmen expressed concern about the lack of modeling provided within the teacher educator program, "When it comes to classroom management they actually need to give you a way to practice it without being in the classroom..." She added:

The classroom management style that they teach you in graduate school is, let me come down here and talk to you at your level...let me sound patronizing and see if that fixes the issue. Where my approach is, you better not do that... Sit down in that chair and don't make me tell you again.

In contrast, TPP taught her to address classroom management with a cultural lens. She explained:

It is the cultural standpoint, you cannot ask the child if they want to sit down. Question: Would you like to take a seat? Answer: No, I'm fine standing. You are giving the child an option. Children of color are not raised with the option. We are told what to do. That is all there is to it. I was told what to do. ... [W]ith [TPP] we talk about that... along with our cohort we would talk about that, and it's the same thing, it's cultural. We are not given options. We tell the child what to do, and the child understands. This is the tone that I get at home. These are the words I get at home. If I'm getting the same tone and the same words at school, conditioning tells me from learned behavior, my behind better be in my chair.

Additionally, Carmen shared that a cultural lens was not necessarily just about race.

It's not just a cultural Black and White thing. It's cultural, it has to do with socioeconomic status, and it's what they understand. Kids who are raised in the neighborhood, kids who are raised in the culture, get it. They understand where we are coming from, period, point blank. The people who don't understand and 
the kids who don't understand, are the ones who are not in the culture, and so we have to adapt to that to...

In summary, Carmen described her experience in graduate school as sometimes challenging, “... it was rough. It was an experience for sure. Grad school was definitely an experience, not all bad, and definitely I learned.” Carmen expressed concern about some of the 'other' future teachers she had met in graduate school. She lamented, "This person is going to graduate and will end up being a teacher of our kids, and you are terrified because you can't stop it. You can't stop it." She however, also had hope that just as she intended to keep learning and growing as a professional, so would other teachers.

\section{James}

James' story begins, like Noah's, on the east coast of the U.S.; James did not move to Oregon until later in life. James' profile includes sections about his childhood, family members, and his P-12 experiences. After a career in the military, the narrative continues with his decision to become a teacher, followed by his college years as a nontraditional student with the benefits of being a member of the TPP, and concluding with his experiences in the educator preparation program.

\section{Childhood and P-12 School Years (Pre-College Socialization and Readiness)}

The first section of James' profile is focused on his childhood, family, school experiences, peer relationships, and his decision to join the military.

Family and upbringing. James was born and raised in an urban environment, in the northeastern part of the United States. His parents were married when he was born, but divorced when he was three years old. For the remainder of his childhood, he lived in 
a single parent home with his mom. He described his family as "pretty low income," and living in a neighborhood that was predominantly African American. James and his mom always lived in the same neighborhood. They moved once, but the second house was less than a mile from the first. The racial tensions and political movements of the era had an impact on his neighborhood, and he shared one memory of violence that took place close to his home and school. James disclosed:

I had two Black Panther headquarters in my neighborhood. One was on the way to school... They had a shoot-out at one of those locations... that was over the weekend, and Tuesday it was open to go back to school and utilize the street. We would walk by the brownstone, and sandbags in each of the six windows, and you would see all the bullet holes [in the walls].

James added, "When they were doing the attack on the Black Panthers, you did not go out in certain places at certain times, regardless. Just because you were AfricanAmerican you stayed away.”

His mom was an executive assistant in a very high profile location in the center of the city; "... she wanted to be a career woman." Moreover, his mom was 33 years old when James was born; he said, "For that time my mom was considered a spinster when she had me." At some point in James childhood his mother changed positions. He recalled:

She started working for our church. I was raised Roman Catholic, also because my going to a Catholic school, [and] she ended up working for the parish. Whoever the head priest was at the time, she started working for him, so he was connected politically. She started meeting all of these political people, and getting networks. 
James described his home life as being quiet, not a lot of communication. His mother seemed to parent from the perspective, “... children were seen and not heard, and so we did not communicate a lot about life." He went on to say:

My mother's philosophy was, I don't care even if you're right, you do not argue with an adult at school. The adult is always right. If they have done something wrong, you be quiet... If you talk back to a teacher, I don't want to hear what you have to say.

He also mentioned, "I became more acclimated to an older world sooner than my peers being an only child." His mother would take him to events with her. "She would take me to places where there were adults and a mature environment." While his mother may have been not been very communicative with James in the home, he asserted, "There is no doubt I knew my mom loved me.” James added, "Looking back on it as an adult, that is pretty much what my mom did. She farmed me out to whom she trusted that would help me..."

Male role models. James did not have "a lot of male influences" in his life. He did not share anything about his father growing up. However, he said, "My mother's father was still alive and we had a relationship... My grandfather was one of the 10,000 Men Named George," James explained what that meant:

From the 1920s up until the 1950s [one of] the only jobs that an AfricanAmerican male could get was as a porter on the railroads. Because the affluent riders didn't want to belittle themselves and use the ' $N$ ' word, nor did they want to take the time to call someone by their name, so they came up with everybody was George.

Over the course of his grandfather's life, as a porter for the railroad, he had three different wives with nine children among them. James clarified, "My family had three hubs..." along the east coast: one in the southeast, one in the mid-Atlantic, and one in the 
northeast, which mirrored his grandfather's train route. Thus, his grandfather's time with individual family members was limited. Nevertheless, James had memories of being with his grandfather and described him as "a middle class, well-off African American male." James remembered his Sunday visits and how he would give James everything he had in his pockets. James fondly recalled:

One day I asked him, why do you always have on a jacket? He said, James, in the society in which we live you are going to find obstacles. As a Black man, you are going to need to try to eliminate as many obstacles under your control as possible. One of the ways people deny you is through your attire. When you go to places you will see that they have dress codes, and dress codes are designed solely for us, to prevent us from getting in. If you wear a button-down shirt and wear a jacket, they cannot deny you from getting into an establishment.

James took his grandfather's advice to heart and has dressed accordingly throughout his life. In addition to his grandfather, another influential male relation in his life was his uncle. This uncle was his mother's youngest brother [from a different mother], and he had some fame in the entertainment industry, as he "... was the deep voice in [popular music group of the era]." James described:

I remember... my junior-senior year of high school; my mom started having me hang around him a little bit more, trying to put someone positive in my world. I remember spending a lot of time with him and that's where I started a lot of my introduction into society as well. That was a very educational time... He reinforced that you always have to be your best as a Black man, so be prepared.

James recalled one instance when he was driving his uncle's new Cadillac home for the weekend and was pulled over by the police. The police officer initially did not believe his story about the car and questioned his uncle's occupation, but in the end, James was permitted to go home with the car. James surmised, "It was too nice a car for what [the 
police officer] thought I should be in." He explained that his upbringing had a significant impact on the outcome of that interaction.

Those types of experiences, when those happened... I had a lot of friends that got into further trouble for the way they responded. I have to say, being connected to my moms' friends and being put into those different environments at that age, it saved me a couple of times.

In addition to his grandfather and uncle, when James was about 13-15 years old his mother introduced him to an African American male college student. “...[My mother] connected me with some college guy, he was in a fraternity, for two years he was my mentor." James recalled how having diverse experiences with his mentor and others helped him grow more mature.

I got to go to parties with my mentor... high school and college parties. My lesson... and this is what carried into other things, was to observe. [My mentor] used to tell me, 'Don't say nothing unless somebody asks you question, and if they ask you something that you really don't know, say you don't know and come get me'.

He reiterated, "So, I got to become acclimated on how to conduct myself a lot earlier then some of my peers." Moreover, James did not typically interact with Whites in his own neighborhood. He recounted how his mother intentionally exposed him to White people, saying:

[My mother] started putting me more in with... where there were white people. She did not communicate to me but she was teaching me intentionally, until after the fact, until I was grown. I started getting taught how to conduct myself around White people, and that is the way it was put me.

K-8 school and friendships. James' friends, and many of the other children that attended his elementary school, had all known each other for most of their lives. "I'd say out of a class of 30 , there were 15 who all went to the same day care... and all of our 
significant childhood events were with these group of kids." James described his elementary school, recalling:

I went to an all Catholic elementary school... it was coed. If you didn't go to public school you went to private and at that time, all private were pretty much Catholic schools. [I went to] the one in [my neighborhood] ... it was $99 \%$ African-American student population.

James' K-8 elementary school required that students wear school uniforms, common for most Catholic schools at the time. Though the student population was predominantly African American, the teachers were almost all White. He recalled, "In my 18 years of and education, I have had two African-American teachers... One was in the sixth grade... he was a graduate of [the same Catholic school]." This teacher actually was raised in the neighborhood. James reported:

He was in a family that had 10 children, and all 10 went through [same catholic school]. So he ended up becoming a teacher and came back to be a teacher... which was wonderful. Now I realize how big of a deal that was...

James felt that his experience going to elementary school was very different than many of his peers.

My upbringing was different than most of my peers because, well, I'd say half of them. Every single teacher in the building new who [my mom was]... I hated elementary school because my peers... they got to talk back, and all they had to say to me was, 'I'm going to call your mother'.

Because his mother worked, James confessed, "I was a latch key kid." In fifth grade, he had the key to his house, went home after school, and was without adult supervision until his mom came home from work. James conveyed that not having his mom home after school gave him some independence. 
I had a freedom because mom worked. I had the opportunity to experiment and try things, but I was one of those people... I learned not to take somebody else's opinion, for the yes or the no. So, when I wanted to say no about trying something it was because I knew that wasn't what I wanted.

James said his behavior "was all just 'kid in the city' street stuff;" however, he disclosed that at one point he "started drifting toward a group of kids..." who were making some bad choices. For fear that the group might turn on him in a negative way, and because he felt, "I'm not as bad as you guys," he made the decision to not participate.

In contrast, James also recounted neighborhood friendships that were very positive and provided him with good role models.

I had a kid that lived across the street from me and he had three older brothers, so they were our example of what to be. Because he had a mother and father that lived together, the dad was a postal mail carrier, and mom worked, as a matter fact, in education. So they were all going to college, everybody went to a college, and all three boys went to Historically Black Colleges. They were our example.

High school and life lessons. Instead of sending him to the high school his neighborhood friends attended, James' mother made the decision to send him to a different high school. The neighborhood high school was "considered the Black high school..., it was in a predominately Black and Spanish neighborhood.” In contrast, along with being located in a White neighborhood, James' high school was “Jesuit led, [and] all boys. I was one of three African American boys in my graduating class." His mother had a coworker who recommended it, and she thought this would be a better education. James proclaimed, "I never had a choice." He felt that his mom's decision was not the norm and by choosing this option she was "...stepping outside the box by sending me there." 
James found the transition to this school to be very difficult; "...it was kind of dramatic for me, that change." He added, "Nowadays they would call it traumatic.... I had an altercation every day of my freshman year, either physical or verbal." Not only that, but his friends from the neighborhood treated him differently. He explained, "My peers ostracized me... when they found out. It was like, oh, you're Mr. Goody TwoShoes." He deemed having his childhood friends treat him negatively as "one of my first lessons about human beings; they can flip on you." Eventually his neighborhood peers accepted his change of school and "respect was given because we are all AfricanAmerican, we were friends." However, James felt like he was living two lives. He lamented, "I lived two different lives. When I was at [Jesuit high school] I was Mr. [last name], I was Mr. James [last name]. When I went back to my neighborhood I was James, I was J [just his initial]...” On the weekends and after school James would play with his friends from the neighborhood, he emphasized, "It was that kind of camaraderie and upbringing, but for me it was two different lives."

James made new friends at his high school by getting involved with sports, specifically football. "I made friends and I assimilated, as I played football. I was pretty athletic." He added, "The quarterback of our football team, we became really good friends. He was Italian. So, that was the first White home I got to go into. It was an experience..."

Unfortunately, his friendship with the quarterback did not last. James shared the story, recounting:

In our senior year we were going to the playoffs... I got suspended and [the quarterback] was so upset with me. He saw me in the cafeteria..., he [said],... 'Why did you act like a [n-word] and get kicked off the team?' This person, who 
was my best friend, I was crushed. We never had the same relationship afterwards... He realized how badly he had hurt me and he didn't know how to fix it. That was one of my first lessons of how people act when they are not happy with you and you look like me. I left high school with the understanding that I have to take care of myself.

Military and (pre-college) career. While James was in high school, his uncle, a musician, brought him to a recording studio where he saw sound technicians working with musicians to create an album. This experience left an impression on young James and he explained, "That is where I got the desire to be a recording engineer.... I got to watch and listen, watching them break down every sound ... it was just fascinating." From that point, he decided to pursue a career as a recording engineer. He shared how college, however, was not initially part of his plan.

I knew I had to keep pace with peers and I knew I did not have the money to go to college. Being an athlete I liked the camaraderie as a team, so the military seemed like a viable option. I knew I had to do something, so that is why I went into the military.

He felt the military offered him a viable pathway to his desired career: "I investigated it, and I wanted to get into communications, I wanted to be a recording engineer. So I joined the military branch, and I got qualified to get into the communications field." James saw the military as a step toward a career, but not necessary as a career in itself. "My goal was to save money, and then get out and go to college in four years." His plan, ultimately, was to have a career in the communications industry. James ended up spending 20 years in the military. The communications industry was undergoing turbulent times and job prospects were limited, so, he reenlisted for another four years, and another four years after that. He recalled: 
It came time to make the decision again, and I said okay I am at eight years. If I reenlist for four that puts me over 10, so they got me. So I was like okay, what do I get if I stick around? You get retirement from that very first month until you die. So, I [thought], that doesn't sound like a bad deal. I ended up staying, retiring [after] 20 years.

At the time of his retirement, he was stationed on the west coast, and he eventually relocated to Oregon. Within the first few years of living in Oregon, he ended up getting a corporate position, which he described as “... the best job I have ever had". He appreciated the salary and the "perks;" he said, "When you walked into the door, regardless of what position you're in, you got a cell phone and a computer... either a laptop or desktop that you didn't have to pay for." Unfortunately, his corporate life did not last long. The corporation ended up in bankruptcy. While he sought a new position, he recalled, "It became apparent that I was going to have to go back to school to get some credentials, just to compete with those who had degrees." James added, "So it was like, okay, instead of having a mid-life career crisis, I had a mid-life career change.”

While contemplating his career options post-military life, he was approached by an acquaintance, a state legislator, who suggested to James that he become a teacher. The state legislator was an advocate of the TPP, knew the Program Director of TPP, and she encouraged James to apply to the program. He explained, "I had done [some college] early in my career. So the credits... they were too old. When I decided to go back to school and do the educational thing... [state legislator] directed me to [TPP].”

\section{Baccalaureate College Achievement, Teacher Pipeline Program (TPP)}

In this section, James' story focuses on his decision to pursue teaching, his experiences as a college student, and what he perceived as the supports he received from the TPP. 
Decision to become a teacher. James had not considered teaching as a career before or during his military service, yet, once the idea was introduced to him, he thought about his own experiences as a student, especially the lack of Black teachers in his own education. "I started looking at my own education... I started looking around and there weren't a whole lot of Black males in education. Well, I said okay, maybe this is something I can do.”

James found that his decision to become a teacher and his passion for the profession deepened as he progressed through the teacher pipeline.

Once getting into the process, it became even more apparent that is was necessary that I became an educator, because the ignorance and denial of our society is just too great. That was the deciding factor, to go ahead and do it, and to continue to pursue it... as I experienced the same old obstacles I had experienced all my life.

James disclosed that he experienced racism and prejudice while living in the Pacific Northwest, and that he found Oregon to be unlike anywhere else he had ever lived. $\mathrm{He}$ did not provide too many details, but he said that his decision to become a teacher was reinforced by living in this environment.

... [B]eing someone who has lived elsewhere, it was very apparent to me... the Northwest is like another country. Regardless of color or ethnicity, if you have lived anywhere outside of the Northwest, you would realize the northwest is like its own entity.

While racism is not unique to the Pacific Northwest, he briefly described the difference between growing up in the Northeast and what he experienced in Oregon,

The northeast is very segregated. The difference is you know where you're supposed to go and not go... [In Oregon] the segregation is different. You are told to come, but then when you get there, you are not welcome. 
Importantly, James' decision to go back to school to become a teacher, as a nontraditional student and career changer, was unquestionably linked to the TPP; he did not consider other teacher preparation programs or other pathways to teaching. He summed his thinking at the time, “... it will benefit me to have like-minded people to be around, who are going through stuff, and the program is set up to help you with all that. So I said, okay, great. So I became part of [TPP].”

Undergraduate life. James was concerned about being a college student at his age. "My biggest fear was going back into a classroom with [younger] people. I didn't know what my... educational-classroom abilities or skills were like anymore." He shared how TPP "made it a lot easier" and how, "It eased of my angst being fortysomething, being [older] and going back to college, starting all over."

James followed the typical academic pathway defined by the TPP. He attended community college initially, and then he transferred to the university where he completed his Bachelor's degree. As far as his impressions of these campuses, James did not share very many anecdotes, other than to say that he felt the campus communities felt very different to him. He stated:

The [community college] campus is open, young, old, everybody is there. But [university], despite its 'community' [motto]...; [it is] very different. More of the stereotype, more of what you would not expect... and that was one thing that kind of blew me away. The vast difference between [community college] and [university]. The neighborhoods and environments are not different; it is just the organizations [that are different].

Overall, James did not describe having a positive undergraduate experience. He emphasized how he "felt marginalized at [university]." He believed that other (non-TPP) college students did not perceive him as an "equal." James explained: 
Pick a stereotype, I experienced it. At both [community college] and [university]. More isolated at [community college], but it did it happen. ... [T] hen when people [found] out I was connected to [TPP], it would even go further in the [wrong] direction. I paid my money, I am going to classes like everybody else, but there was this perception, that we (TPP students) were not equal... that we were not doing the same thing.

James shared a lot about the 'stigma' he felt from being affiliated with TPP. He expressed his concerns that people "... had the idea that [students] coming from [TPP] were given their degrees as opposed to earning their degrees, and that things were made less stringent; that [TPP students] did not have do as much qualifying." He also found being the only African American in his undergraduate classes, or only one of a few, very challenging.

Most of my classes I was the only [African American], or one of less than five in a room. This is really what I mean when I say Oregon is a different place: In my junior year at [university]... there were less than five people in a class of 75 people, in an African American history class. That is when I said, I am an in Oregon, and that is when I realized, it is always going to be like that.

The one positive comment James had to say about his undergraduate university experience was that he greatly appreciated the support of his undergraduate advisor. "My [undergraduate] advisor at [university] was probably the most positive [aspect]; he was my positive experience at [university]." This advisor was a White male, with a reputation at the University for helping students achieve success. It was James' understanding that this individual was an advisor assigned specifically to advise TPP students with university requirements and admission to the graduate preparation program. With regard to admission to graduate school, James recalled, "He helped me find classes that I could 
take to meet [content area] requirement [in the] summertime, so I did not get off schedule."

TPP support. Fortunately for James, his undergraduate college experience included involvement in TPP, as it supported him in many ways throughout his college career. He shared many examples of services he received from the program. He stressed, "When you are going to a college, you know, you are just a number. [TPP] allows you to not feel like just a number."

James talked about the connection to the TPP community, maintained by regularly scheduled meetings. "Weekly, you are having meetings. Monthly, you are having meetings. We had regular meetings that were mandatory. To the point where... It was acceptable to miss a class, but it was not acceptable to miss a [TPP] meeting." James shared that the content of the meetings varied, sometimes the topics addressed being a teacher of color in a profession dominated by the White-majority culture.

James also talked about the role of the TPP director. When James first inquired about the program, he was surprised to learn that the director was a White women; he expected the director to be a person of color. In reflection, he shared, "I have to say, after my first year at [community college], I understood why she was the director." He also communicated that the director served as a "major support" throughout, and he underscored the importance of having “... some type of nurturing entity" to help students through the program. He emphasized:

As a person of color, you need to have some support of like-mindedness because of what you're going to go through... [It is] just the nature of what you're entering into and dealing with, it's going to be a struggle. 
He added, "[It] was very beneficial having the reinforcement of, not only [the TPP director], but a group of people... like-mind, who can support one another as you go through the struggle."

In addition, James found the early access to college course registration a benefit for TPP students. He explained:

For example, we were able to register for classes early. The rigor of having to go through registration was taken away. In doing that, [we got] to register with other people whom [we] know, who [helped us] decide... One of the biggest unknown difficulties of college life is selecting the right professor. It can make all the difference in the world.

James also appreciated the supplemental college advising that he received throughout the program. He disclosed, "It is more valuable than you realize. Helping me navigate through college life 20-years older than the average person I was, made a big difference." Tutoring was another support available to James and TPP students. He remembered study groups in TPP were common, and he understood the value of not having to seek out assistance or tutoring from a "student center note board." Rather, in TPP, he recalled, "People who were good in one area could be available to help you," and "you had more direct lines to people to get aid and assistance."

\section{Post-Baccalaureate Success and Graduate Educator Preparation Program}

James' experience with the graduate educator preparation program is described in the following section, including aspects of the program's curriculum, his student teaching experience, and his thoughts on how the TPP supported him in graduate school.

Admission and enrollment in graduate school. Within a few terms of completing the Bachelor's degree program James applied to the graduate educator preparation program. He discussed how the process was challenging for him, in that he 
was not admitted initially. He recalled, "I [got] denied and I [was] freaking out. Yeah, I [was] freaking out, because wait a minute... I have a 3.75 GPA..." He was informed that he needed to complete a prerequisite content area course, which he was previously unaware he needed, prior to starting the program. "Fortunately enough there was some [specific subject course] going on over the summer," which he took, was then admitted, and started the graduate school on time.

Overall, James expressed his dislike for the admission process, "I think there is hypocrisy to the process that is simply there because people won't allow other people in." With regard for attracting a more diverse pool of teacher candidates, James added:

I think it is a great opportunity for someone to get into education via the [community college]/[university] route, via that path. But I think there could be more work done with their program, in its attempt to be diverse. I am sure they all claim that there are people of color involved in the structure of this process... [They] need to give them more of a say-so...

James talked about his experience being in graduate school, and being in a cohort of 20-25 students. In the cohort model, the graduate students take course work together for one calendar year. James recalled:

I was the only African American in my cohort. There were other [TPP] students [in graduate school], [but] not in my particular cohort. We always had [students] going through that were [TPP], [and] sometimes you lucked out and were in the same cohort and sometimes you didn't.

Graduate school curriculum and faculty. James conveyed his disappointment in the lack of content in the graduate program that addressed diversity and equity. He recounted, "I had a term of diversity. The teacher was my same teacher as [community college], they brought him over to teach that class." Given that teachers often stay in the 
profession for many years, he added, "It has to be more than just a term... [these are] people who spend anywhere from 20 , to potentially 40 , years in one mind frame."

One of James' cohort leaders was a veteran teacher with 30-years of elementary school experience. He acknowledged this instructor's years of experience in the field, however he was learning how to become a high school teacher. He recalled:

One of the things I noticed was that [the cohort leader's] anecdotes and their pedagogy was elementary style... So, what we ended up having to do was take the things we got from that particular individual and manipulate it to be applicable to the high school environment. ... if [a student was] not savvy at doing that [they were] in trouble.

His other cohort leader was a tenure track full-time faculty member. He "resented the fact, that [they were] never there because they were always away publishing something or away speaking about what they just published." Learning about what was required of a faculty member, James admitted:

My graduate experience was learning what I don't want to do, from a certain extent. ... II]f you're going to be a doctor [Ph.D/Ed.D] and a published one, well, that means that's (e.g., publishing, speaking at conferences) part of it. I did not want to do that.

As far as other faculty in the educator preparation program, James said that he did not make any personal connections.

James felt the instruction in graduate school was lacking, not just with regards to diversity, but he thought he would have benefitted from more "practical instruction" in the college classroom. For example, he suggested:

A mock classroom... Have the [college] student create a course lesson... a lesson plan and carry that lesson plan out with [graduate students] being students... And then [faculty] can see how we act in the role... give us better critique without the pressure of being [in the K-12 classroom]. 
Student teaching. In addition to the course work, teacher candidates in the preparation program spend increasing amounts of time in K-12 classrooms, as student teachers. James talked about his experience, specifically about the setting and the population of students in the suburban school district where he was initially placed.

I began to learn that there were kids that lived in [suburban area] that had never ever been to downtown [city], or to the [shopping center in city]. And then I started thinking, if you live in the [suburban shopping center] area... everything you need is in your area. Why do you need to go anywhere? I can see how kids, especially if their parents shelter them a little bit... I could see... why there is such a vast difference of understanding each other in this particular instance or environment; ... [they] do not venture out of your comfort zone.

James' did not complete his student teaching at that suburban school. He explained that his cooperating teachers told him he would not be able to stay, and he added, "No one from the university knew they wanted to do this." He further elaborated his experience receiving this news during what he thought was a regular debriefing meeting with one of his cooperating teachers.

She thought that I was too friendly with the kids, [and she said], '... I think you're too friendly, and when you have to be a disciplinarian your authority is going to be under-minded because they're going to see you too much as a friend'. ... I [did not get] any suggestions from her as to how to fix that, and she proceeded to tell me that she [had] talked to the vice principal and [said], 'We think it might be best that you find another placement'... [and] 'Well, we think you should go to another school'.

He added, "Then the other teacher... She was relatively new, so she went along with the other teacher. It was like, really? I don't even get a chance to fix what you're saying is wrong?" Thankfully, the [TPP] program director asked [TPP] students to check with their [cooperating] teachers to see if there was anyone... willing to take on another 
student teacher," and James was able to find another placement. James still is not sure why he was asked to leave the building.

In addition to his unnerving experience of being "...kicked out of the building" where he started his student teaching, James expounded on his concern with how the graduate program managed the supervision and evaluation of student teachers.

My major concern... Your [cooperating teacher] and the university supervisor control your world as a student teacher. Whether you want to acknowledge it in this manner or not, the reality is, you are pleasing those two people. If there is such a vast cultural difference..., and you can't figure out how to close that difference, you are going to have a unique situation.

TPP support in graduate school. James highlighted the important role TPP played in his experience, "From day one of registering to... your first class to the day you get your license from [state licensing agency]; [TPP] makes the process less daunting." He added:

Outside of [TPP], there are not a lot of supports for graduate students. It is pretty much left up to you to try to find some kind of supporting entity to help you. As a student in the midst of the journey, where do you turn for support? I do not feel that [university]'s [preparation program] gives that kind of support...

He shared how TPP helped him to understand the school district culture:

You also have to navigate a school district. ... [Y] ou have to become familiar with whom you are going to work for. A lot of, I would say $60 \%$ of, the [TPP] participants had not thought about education as a career prior to their decision to do this [program]. So, they are very naïve and ignorant about educational systems... districts, how they work, things like that. The way [TPP] is organized and designed, you learn about your school district along the way.

He added, "Part of [TPP]'s goal is to help you get hired." 
This concludes the four profiles, the cases of four teachers' journeys into the teaching profession. In the next segment of this chapter, I address the findings related to the four research questions that guided this study.

\section{Findings Related to Research Questions}

In this segment of Chapter 4, I report my analysis of the stories of Carmen, Deanna, James, and Noah — using the four research questions that motivated this studyand describe some of the commonalities and differences found along their pathway to a career in teaching. In doing so, I do not seek to label or compartmentalize their experiences nor reduce their complex and unique narratives. Rather, in looking across these narratives, I seek to weave their individual accounts into a larger context that sheds light on some of the motivations, inspirations, and nuanced understandings of their experiences while still honoring their separate and distinct experiences.

\section{Research Question 1: What do African American teachers report as reasons for choosing to become a teacher in Oregon?}

The African American participants reported a number of reasons for opting to become teachers; their main overarching reason, was to make a difference in the lives of students, specifically, students of color. The participants' ideas on how to make a difference in the lives of students were similar, but how they described their feelings was nuanced and unique. Fueling their desire to make a difference, a commonality across participants, was their memories of negative P-12 school experiences. All of the participants discussed their own school experiences as an impetus to their career choice, and all four participants talked about having mostly White teachers. 
I divided their "make a difference" rationale, into two frames. First, making a difference for P-12 students for the participants meant helping students of color find success, the focus was on supporting and relating to students. Second, their desire to make difference also meant, being change agents; working to make schooling different for future generations.

Supporting and relating to students. The participants' descriptions of helping students by supporting and relating to them included, simply being present, as a teacher of color. For example, Deanna who grew up in Oregon and described much of her school experiences surrounded by White teachers in a White school culture, stressed, “...I just thought maybe I can come to a school and kids like me can feel like they have someone that they can relate to." Carmen, similar to Deanna, grew up in the same part of Oregon, and she declared, "I really want to make sure that the next generation that comes out after me, knows... We want you to succeed. We need you to succeed."

James had a very different K-12 experience than Deanna and Carmen, he attended all Catholic schools on the east coast, and his schooling occurred a decade or more earlier. James also came to the profession of teaching much later in life; he had a twentyyear career in the military and a few years in corporate life prior to seeking a career in teaching. Like the other participants he shared how his K-12 school experiences impacted his decision to teach, “...once the concept was put into my head that [teaching] was something that I might be able to do, I thought about my own experience as a student in our educational system. ... I began to remember how I felt as a student not seeing anyone that looked like me." He added, "So I decided I wanted to be an educator. ... I want students like me to see that you can be successful." 
Noah, who like James, grew up in a different part of the U.S. prior to eighth grade, described having mostly White teachers and many negative K-12 experiences. He explained how he enjoyed sharing his academic struggles with his students; he explained, “... [it] make[s] a great story for kids now, especially my kids who have the same problems as I did." He went on to say, "For my kids that don't do very well in school, it points out that you can get somewhere even if your GPA is very low. GPA is only so important, it's about the work that you put in."

Agents of change. Some participants used the term change agents, while others talked about the importance of social justice, collective action, and equity work. All participants described in some context, how the role of being an agent of change was a reason they wanted to be a teacher and/or a reason they continued to be a teacher. For example, Carmen shared, “...[T]he biggest motivation [to become a teacher] was the experiences I had as a kid. I really didn't want those to be repeated with future students. I wanted to create a different education system." Carmen added, "I believe that this work is necessary. I believe that this work is valuable. It's what I needed to do.”

In talking about her own school experiences and about the experiences of current students, Deanna lamented, “...schools aren't always a joyous experience.” She added, however, that “...just getting my foot in the door, and being here... and being present, I feel like that does make a difference; having my voice heard." Speaking up is not always easy, but it is critical for change to occur.

James' classmates, like Noah's up until high school, were all African American. He found living in Oregon to be very different than the northeast or any other part of the country, and ultimately his decision to teach was centered on becoming an agent of 
change, "I wanted to make change; I wanted to effect change in this community." James summed it up well when he said, "I wanted to be that beacon of light, so to speak; I wanted to be that for a kid that didn't have another person... That was my driving force to become an educator." Noah talked about being underserved by schools, and his poor performance despite his abilities, he stated, "To be quite candid, I had a lot of [bad] teachers and so I said, well, school doesn't have to completely suck. And so I said, well, let me do something about that."

Just as the four participants' decisions to become teachers had some commonalities, their pathways to teaching had another critical common feature- the Teacher Pipeline Program (TPP). Their decisions to apply to the TPP were most likely driven by the aforementioned motivators, but the existence of a respected and creditable program cannot be overlooked as another factor in making the decision to pursue teaching. It was not part of the inquiry (and would be considered a hypothetical question), but worth posing in hindsight to the study: Would these individuals have chosen teaching as a career had this program option not been available? It was available, so we will not ever know the answer to that question, but we can undoubtedly say that these four teachers trajectories into teaching, had they pursued this profession, would have been different without the program. Or maybe they would not have pursued teaching at all?

\section{Research Question 2: How do some African Americans teachers in Oregon describe their journey into teaching?}

The four participants described their journey through stories about (a) the people who influenced them and (b) the challenges they encountered along the way. 
Descriptions about the places they attended, such as the community college and the university, were also discussed; the data was limited and I chose not to include it in response to this section. Additionally, programs (e.g., TPP) were discussed in detail, and related to this question. However, the data overlapped significantly with RQ3, and I made the decision not include data about TPP in response to this research question.

The people. Participants shared how an influential person introduced them to the concept of teaching as a career. In Deanna's case, her grandmother, who had served in supporting roles in elementary schools knew a teacher, a TPP alum, in the school where she was a grandparent volunteer. The alum spoke to Deanna and provided her with information about the program. Deanna shared her experiences taking community college courses without career ambitions, and then how her initial interest in becoming a teacher shifted into a potential reality when she found out about TPP, as she recalled, “...okay, well now I know I'm going to have a support system.” She said emphatically, "I still believe that the program is the reason I went to college and stayed in college."

For Carmen, like Deanna, a relative played an important role. In Carmen's situation, that relative was her mom, an alumna of TPP. Carmen was very familiar with the program through her mother's experience; Carmen was in middle and high school when her mom was in the TPP. Initially, Carmen wanted to pursue her own path. She sought other pathways to teaching including attending college in a different part of the state, however, after a year, she returned home and eventually applied to TPP. Additionally, Carmen stands out from the other three participants, as she had a variety of experiences working with children prior to beginning the TPP, from babysitting to helping her high school teachers as a teaching assistant. Her interest in teaching may 
have started as early as elementary school when she was part of a tutoring program with younger students, she recalled, "... it was one of the first distinctive experiences I can remember having to encourage and teach somebody else." Additionally, during her freshman year away from home Carmen served as a tutor for a local elementary school.

James and Noah did not have family members involved with education, nor did they have personal connections to TPP alumni. They were both "tapped on the shoulder" by people familiar with the TPP. For Noah, it was a high school counselor. For James, a family friend, who was also a state legislator and who was well acquainted with the TPP program's director. Importantly, in these four cases studies, whether a relative, friend or acquaintance, the participants were only one degree away from someone familiar with the program. In other words, individuals well acquainted with the program or having intimate knowledge about the program served as recruiters, to some extent, in all four scenarios.

One other influential person played a significant role on their paths to become teachers: the program director of the TPP. Participants fondly recounted stories of their experiences working closely with the program director and they all shared the vital role she played in their journey to a teaching career. For example, Noah shared the importance of, “...having a mentor and director whose head and heart are both in the right place, that is not something that is very common." Also, Carmen and Deanna both described their relationship with the director in a familial sense; Deanna said, "...it was like a parent who knew all about education was there by my side." Carmen disclosed that she and her fellow TPP student would sometimes refer to the director as "Mom" or "Momma [X]," "And she is, she is our [TPP] mom." 
Challenges. Deanna, Carmen, James and Noah also recounted struggles they experienced on their journeys to teaching. There were a number of challenges described by participants, but through analysis the following three topics, were identified multiple times and by more than one participant; they include a TPP stigma they perceived, mainly from other college students, their student teaching experience, and the graduate school curriculum. Initially, I was hesitant to frame this research question on challenges, because a framework that focused on success and achievement guided my study. However, I recognized that a challenge is not a deficit, and it was the participants' skills and abilities to navigate these obstacles and persevere that contributed to their eventual success. The challenges described herein are actually a testament to their achievement.

TPP stigma. One common problem, or struggle, disclosed by most of the participants was the stigma they experienced from being affiliated with the TPP. All of the participants, except Noah, reported a sense of unfair judgment about their academic abilities, based on membership to TPP. James declared, "Those stigmas were there," it got to the point where he did not want to tell anyone he was a TPP student. "During my undergraduate work, I was really cautious about whom I spoke to and divulged that information. We were finding that people would use it against you, just simply because of their perception about the program.” Deanna echoed James' sentiments of concern about sharing affiliation with TPP, she elaborated:

I think one of the hardest things, and I realized this during grad school was that... So, I went through this wonderful program, [TPP] and I was so proud of it. I really felt good about being from that program, but I also knew that because of that program there would be some hostility amongst other colleagues, feelings like, 'Oh, you got a scholarship because of the color of your skin'....It makes it seem that I didn't work as hard for it, or I didn't really earn it. 
Importantly, the participants did not permit the comments, or the feeling of being judged by other students, stop their progress or end their affiliation with the TPP. They may have been reluctant to disclose information, but they persisted.

Student teaching. Deanna and James described having negative experiences during their student teaching in the educator preparation program. Deanna described her experience student teaching as a "competition" she was in with another graduate student, a White teacher who Deanna felt was unaware of her privilege. However, Deanna shared that despite having a negative student teaching experience, she found the administrator of the school where she was placed to help her secure employment. She recalled, "He was wonderful. It was actually how I ended up in this job." She received a letter of intent to hire before completing the program and graduating. James was also hired immediately after completing his student teaching, but he was initially placed in a different district. In his first placement, he was asked to leave without due process, and as he recalled, “...to this day, I do not know whether it was the teachers lack of being able to deal with not having control of the room, whether it was a male-female thing, or whether it was a race issue." He may have ended up employed by a different district had he remained in his initial placement, and given that he moved into an administrator position; I believe he is content with the outcome.

Graduate school curriculum. All four participants discussed disappointment with the graduate educator preparation program. They all expressed their discomfort with being the only, or one of a few, African American students in their cohort of 20-25 students. However, they had expected and the TPP prepared them for that reality; rather, it was the curriculum and instruction they experienced during graduate school that 
resonated as the larger concern. Several participants discussed the limited amount of content that addressed race and equity, and lack of appropriate classroom facilitation when discussions came up on topics related to diversity. Deanna shared, "There just didn't seem to be... cultural relevance in many of the assignments we were asked to do," and Carmen elaborated on the lack of multicultural content, adding her understanding of the importance of cultural competence, saying:

That was something that grad school really didn't push, it didn't push the multicultural aspect, and it didn't push the relationship aspect. It pushed that you should have a connection with your students, you should be able to communicate with your students, but nothing to solidify that...

As far as teaching diversity in the program, Noah described, "We took one class in the summer term, and that was like the limit... that was like you could tell, was meant program wise, to be like us talking about it so they could say that they did it." He described how he would often be the (one) student in his cohort to interrupt bias; he explained, "[Y]ou get a certain amount of comments... You get like about five times you [point out racism or inequity], before you become that person."

James talked about the lack of instruction as it related to diversity as well, and he also shared his concerns about limited experience and training, "Graduate school gives you familiarity with the terminology and concepts. The way it is designed now it doesn't give you enough opportunity to practice.”

Carmen's conclusion to the educator preparation program was rocky; she ended up having to repeat a method's course in the program, extending her program for another term. However, she recounted the unpleasant events with little resentment and with a positive spin, "It was good for me to tell you the truth, it was good for me. The 
experience wasn't pleasurable in any shape or form, but I was old enough... to realize I needed it. I needed the push."

Again, the tenacity and perseverance demonstrated by all participants, in the face of challenging circumstances was remarkable. Several of the participants recounted how once they were close to finishing and earning their licenses, their confidence grew; as James stated, "By the time I was in [grad school].... You couldn't stop me at that point."

\section{Research Question 3: How might the lived experiences of African American teachers' success stories help others in Oregon?}

As described in detail in their profiles, and partly in highlighting elements of their journeys to become teachers in RQ2, Deanna, Carmen, James and Noah all demonstrated resilience, perseverance, and kept their long term goal in mind as they pursued their degrees and earned their teaching licenses. The lived experiences of the four participants had similarities and differences, the following are three elements which emerged from the cross-case analyses as significant, and could be useful in helping future teachers and educational stakeholders in Oregon design programs for teacher candidates of color: a) financial, b) advising and student support, and c) community.

All four participants highlighted elements of the TPP that were most helpful to them and led them, in part, to success. I have focused my response to this research question on the TPP. Obviously, these stories of success are not replicable, and one participant's success cannot be attributed entirely to a program, or from a single experience that occurred in the past. However, all four participants had similar thoughts about what they benefitted from the most while seeking their professional careers, and 
most of their accounts highlighted key elements of the TPP. The first element I discuss is the cost of college and financial support participants emphasized as key.

Financial. Financial assistance for TPP students was a major factor in their decision to enroll in college. James, however, was unique in this regard; he received tuition from the government as a military retiree and did not need additional tuition assistance. He stated, “... instead of the program tuition [they] would give me, [I suggested] just put it toward another student. I'll follow everything else, I just won't be paid by you." Worth noting, his tuition was not paid by the TPP program, but he did receive a form of government sponsored tuition assistance. When Noah came to the end of high school, he knew he did not have financial support from his family, ...I knew that from a young age if I was going to college, I was going to need a scholarship... it was made perfectly clear; there is no college fund. There is no 30 or $40 \mathrm{~K}$ laying around for college.

Like James, one of Noah's considerations at that time, was going into the military, as his parents had done before him. He shared, "I did think about going to the Naval Academy, until I went, wait, [I] hate authority...," and so he quickly ruled out that option. When he learned about the TPP through his high school counselor, which eliminated the costs of college to large extent, he reported, "I applied, like right then..."

Carmen attributed one of her reasons for leaving the first university she attended was due to financial hardship and the university's process for distributing her financial aid. She divulged, "They played with my money. Their calculating was a little off. They wouldn't release checks on time, or they would not release it until this time or that." She went on to say that the financial burden weighed on her mind, "My thing was that debt, re-paying back what we owe. I didn't want to make that kind of mistake, having to 
have the debt..." Like the other participants, Deanna expressed concerns with affording to go to college and she shared how important the financial support was to her:

The financial piece was huge! Because I feel like that was what kept me..., at least that's what I thought would keep me away from college. You know my mom she never went, and well I thought she can't afford it, so I can't afford it. That financial piece in knowing that like I could go to school and not have to worry about paying for it, was really helpful.

Advising and student support. Through my analyses, I surfaced several areas of advising and support from the data collected for this study. Listed in separate sections are a few of the areas that participants accentuated as beneficial, including academic support and student support services.

Academic support. Community college and university students may receive academic supports from the institution, such as writing centers, etc., and in addition to these types of support, for TPP, seeking support from and within the program community was reported as a critical component. The community in this case, is defined broadly, and included the program director as well as the other TPP students. For example, all of the participants mentioned the importance of study groups. Carmen recalled,

A lot of students will get in study groups and work with each other. We try and take the same classes with each other in undergrad, and so we have that is well. That way they are studying in groups and not studying alone.

Deanna shared how the TPP program director would monitor the academic performance of TPP students, "[She] wanted to know what classes we were taking. There were certain classes we had to sign up for, and you had to get a certain GPA to stay in the program." The TPP program director helped Noah understand that the academic patterns and 
behaviors he had developed in high school were not acceptable in college. Noah recalled:

[She] recognized that I was being lazy and I was not doing 100\%, and said, 'Hey, I know that this is not your best, so you need to try harder. This is not going to cut it'. So I did it...

James found his university experience, earning his undergraduate degree, lacking in many ways, but the one area he stressed as the positive was the academic advising he received from one university advisor. This person directed him to courses, while required, would also enhance his skills as a high school teacher, and helped identify appropriate courses that worked with James' scheduling needs.

Student support services. Student support services in TPP were plentiful. Participant descriptions of supports received while navigating college life, beyond typical coursework or academic support, included, regular program meetings, course registration support, admissions support to graduate school, additional seminars with guest speakers and panelists, test preparation support, etc. Deanna recalled, “... [the TPP program director] had people from [the community college] come in and talk to us about how to register, and the days to register, and she would send out emails to remind us. Because I didn't know any of that." Deanna shared:

[TPP] was always there to help... with the process of getting into grad school and [also] once we were in grad school there were meetings we had to have as a grad school [students] with the program director, and so the support was always there. It was mandatory; it was part of the process...

Similar to Deanna, Noah recounted how TPP helped with admissions to graduate school. "Without [support from TPP], I would've never gotten in. It wouldn't have occurred to 
me that you should ask people for letters of recommendation in January because then you'll get them by March."

All of the participants discussed the important role TPP played in helping students pass the required licensure examinations. Carmen explained, "Test prep was huge." Though Noah did not need support in this area of testing, he elaborated on why it was so important and importance of maintaining a positive attitude; he explained:

We talked about tests, which was a huge thing. ... Tests are a gate, and they are a gate that we all intend to get past, so let's work together to get past those. That was very valuable for lots of students... I lucked out and I test very well; that wasn't an issue for me. But that was very helpful for a lot of students. ... we do lose students because they can't pass the test.

Deanna seemed to benefit from the test preparation support; she described:

I remember there was a test I needed to take, actually two I needed to take... that was a really big hurdle for me because I think I took that test five times. I was really struggling with the math portion of the test. I took both [sections of the test] multiple times.

She expounded on the stress she experienced taking and re-taking the examinations, and of the added expensive. "[TPP] helped out a couple times, but then it was kind of like... We can't afford to keep paying. So that was... that made me really nervous, because I thought I had come this far."

Community. All participants described the value of the TPP community, a critical element of the program, a community of learners who they relied on for a myriad of needs. Emphasized were opportunities to dialogue about key topics such as culturally relevant pedagogy, the inclusion of guest speakers, and the intense discussions that occurred, both in group settings and in private exchanges with other members of TPP. 
Importantly, the community of TPP extended to newly admitted student to alumni who completed the program decades ago.

Noah. Summed up well by Noah, when he described how the community supported him along his way; he reported:

That feeling... that sense of both of camaraderie but also political alignment. That I didn't have to sit here and talk about topics, like whether racism is real. [It was]... having people who care about you, having people who are in this exact same struggle with you...

He emphasized, “...[there] is a large culture of community” which included:

... classmates that I had in class, other people that were in different cohorts in grad school, people who were not even in grad school yet, people who were still at [community college]... across the board.

Deanna. Appreciative of having a community of TPP students, similar to her, as she went through graduate school; Deanna explained:

You know as far as grad school went, it was really nice having a group of people that I knew would be there. I think that was what was most helpful. I feel like too, having someone in the program that looked like me, someone who was maybe experiencing some of the same things that I was.

Deanna also found the network of TPP contacts to be helpful when she was seeking her first teaching position; she reported:

When I was graduating and applying for positions. I was applying for a first grade position at one school and I had called a few people [TPP alumni] who I knew worked in first grade, and asked, 'Can you help me? What kinds of questions will they ask?' So that was really helpful.

James. This sense of community was also important to James because he was relatively new to Oregon, he did not have a family or support system in the area. He highlighted, "One of the reasons why I joined [TPP]... was because I knew I wouldn't 
have a whole lot of people to bounce things off of... I wanted to utilize that organization as a means to do that... [TPP] was my sounding board."

Carmen. The TPP community went beyond their program members, and included the larger community context in the region where the TPP was located. Carmen described how students were encouraged to engage in community events; she recalled, "We did [a specific community event] every single year. We get out there and promote the fact that we are here and what we are fighting for is equity within the educational system, and equality as well." Additionally, Carmen shared how alumni remained involved with the program, "[Alumni] let [TPP students] know that they are not in the struggle alone. It's a battlefield and believe me, we are an army."

\section{Research Question 4: What recommendations do African American teachers make to improve recruitment efforts and African American representation in the teaching profession?}

The participants made a number of suggestions for improving the recruitment efforts of African American teachers. To answer this research question I have organized the participant responses into three main concepts, (a) understanding the Oregon landscape, (b) experiences with youth, and (c) district level support. The first concept addressed by participants when asked to share their ideas on how to increase numbers of African American teachers in Oregon classrooms, was ensuring that prospective teacher candidates, policy makers and school district personnel understood the Oregon landscape (e.g., history of racism, school climates, representation of African Americans in education). The second concept that became evident with the cross-case analysis was experiences with youth, several of the participants emphasized the importance of 
exposing P-12 students to experiences with youth. Finally, participants addressed issues

related to equity with regards to the school district level support that was necessary to make change in recruitment efforts of African Americans a reality. A sampling of responses given by participants to this line of inquiry is presented in Table 4.

Table 4

Sample Participant Responses to RQ4

\begin{tabular}{|c|c|c|}
\hline \multirow[t]{3}{*}{$\begin{array}{l}\text { Understanding } \\
\text { the Oregon } \\
\text { landscape }\end{array}$} & Noah & $\begin{array}{l}\text { "Oregon has a very, very, very, long detailed racist } \\
\text { history of exclusion." } \\
\text { "People forget that, most of the state is rural and } \\
\text { conservative." } \\
\text { "I grew up around } 90 \% \text { Black people, so I was a person, } \\
\text { and I was a Black person when I moved out here." }\end{array}$ \\
\hline & Deanna & $\begin{array}{l}\text { "So I think teaching in this state, it is a bizarre place, in } \\
\text { the sense that it is very White. ... It is just very White." } \\
\text { "I just think anyone who comes to work in Oregon who is } \\
\text { a teacher of color just has to be prepared for the fact that } \\
\text { they will probably be one of very few." } \\
\text { "[I]t doesn't seem like it's a profession that's available for } \\
\text { people of color. } \\
\text { "I think it's going to continue to be a struggle within our } \\
\text { state." }\end{array}$ \\
\hline & Carmen & $\begin{array}{l}\text { "We don't see ourselves in our classrooms. We don't see } \\
\text { [teaching] as a possibility. Not because it is not possible } \\
\text { for us to attain, but because there are so few of us... and } \\
\text { we are scattered around. We are just not represented." }\end{array}$ \\
\hline \multirow[t]{3}{*}{$\begin{array}{l}\text { Experiences with } \\
\text { youth }\end{array}$} & Noah & $\begin{array}{l}\text { "Get experience with all those ages. Figure out the ones } \\
\text { that you are partial to, the ones that you like." } \\
\text { "...Get your feet wet. } 95 \% \text { of your job is talking to kids. } \\
\text { If you do not like talking to kids, you are going to hate it." }\end{array}$ \\
\hline & Deanna & $\begin{array}{l}\text { "I think if there were more opportunities for high school } \\
\text { students to be in a classroom, help volunteer just see that } \\
\text { there is that level of success... that may entice people to } \\
\text { want to go into the teaching field." } \\
\text { "I think that it is just getting people in the building, and } \\
\text { seeing... Because I thought... Once I got in here, I } \\
\text { thought, I can do this." }\end{array}$ \\
\hline & Carmen & $\begin{array}{l}\text { "[It] was one of the first distinctive experiences I can } \\
\text { remember having to encourage and teach somebody else." } \\
\text { "I was a tutor at the local elementary school, at a K-5, } \\
\text { tutoring them in reading, math..." }\end{array}$ \\
\hline
\end{tabular}




\begin{tabular}{lll}
\hline District level & James & "...every other field that requires the same or equal \\
support & amount [of education, professional development, license \\
& requirements], gets paid more; so that's the first thing." \\
& "You get nothing [when you walk into a district], unless \\
& you are fortunate to have a cooperating teacher who gives \\
& you some of their stuff." \\
& "Being a transparent organization that lives up to what it \\
& preaches." \\
\hline Carmen & "A lot of districts are hiring teachers of color from out of \\
& state. They are going to [other states] and bringing back \\
& teachers." \\
& "We are seeing that Oregon doesn't want us."
\end{tabular}

Understanding the Oregon landscape. Deanna, Carmen, James, and Noah were asked to share their ideas on how to improve recruitment efforts of African American teachers in Oregon. Participants began by discussing the history of Oregon and the landscape of teaching in this region. For example, Noah provided some background; he referred to former laws that kept people of color from residing in the state, "I am talking all the way back to the original Oregon charter." In addition to laws in the state of Oregon, he pointed out that there have been a number of factors contributing to less people of color living in some cities; he explained, "Portland, Oregon also has a very long history of displacing communities;" he added, "[T] he construction of things like Interstate 84 which paved through black neighborhoods. It's this particular city, especially, the state as a whole. If you look at geographic distribution of how people vote, most of the state is conservative." Noah experienced racism when he moved to Oregon; he described:

... you get the underlying feeling like you're not wanted here. That's something that you can feel, even if you can't always explain it. Particularly, you can't put it into words that make sense and are accurate to what you are feeling, [but] you can sense it; children can sense it. 
Deanna disclosed concerns that Oregon teachers of color may encounter within the profession.

I just think people have to be prepared for the fact that like... I always think about it like... the mad Black woman. You know, the way I am talking to students. There is always that fear, with White colleagues and with White administration, that I am talking to kids in a way that their parents are going to be offended.

Deanna described why students may not think of teaching as a future profession for them,

How few kids see teachers who looked like them. So it seems like a very White profession. It's female, it's White, so if you're not one of those... If you are not White, then you probably think, oh that's not for me.

She added, "So to become a teacher... It probably doesn't even cross their minds."

Experiences with youth. Some of the participants offered suggestions to help improve recruitment P-12 students into the profession, and their ideas centered on providing opportunities, and encouraging prospective teacher candidates, to gain experience with working with youth. For example, Deanna related this to her own experience volunteering; she shared:

I look back on my high school experience when I was volunteering in the third grade classroom and [at the time] I thought, maybe I did kind of like that, so maybe I will give teaching a try. I think it has to start early. Schools always need volunteers. If there is some type of recruitment within college, early on, or at the community college level. I think starting early while people are still kind of trying to navigate what they want to do.

In addition, Noah shared his thoughts on recruitment efforts. His recommendation to prospective teachers was to "Get into a classroom and get some experience with students, students in elementary school, young students in elementary school, older students in elementary school, students in middle school, and students in high school." 
Participants described how their own experiences with youth, growing up led them, in part, to consider teaching as a career. Carmen shared how having experiences working with youth in her past, laid the foundation for a career as a teaching. She had many experiences, which included, tutoring second graders when she was a fifth grader in elementary school; babysitting regularly for a couple with a young child in high school; serving as a teaching assistant for a few of her high school teachers; and working as a tutor in an elementary school her freshman year of college.

District level support. James presented several factors that if they were to change, would improve recruitment efforts. The first was related to salary or compensation; he explained, "In order to be in front of a classroom, you've got to get a Master's degree, or to stay there you have to have that. You've got constant professional development that is part of your legal license, and you do it or you lose it." Additionally, James thought it would be helpful if teachers were supported more when they started in their positions; he thought districts should provide new teachers with classroom essentials, to help them get started. He reflected on how in his experience working in a corporation, employees were given computers and cell phones, so they were properly equipped to do their jobs; he posed the rhetorical question, "When you go into education, what do you get going into a classroom?" He thought a change in this practice was warranted and might attract more people into the profession.

James' other recommendation had to do with the school climate. He was candid in describing the racism he experienced in schools as a teacher and administrator, especially at the district level. He described the experiences of teachers of color starting 
employment in the district, as being similar to the experiences new high school students of color have when they attend his predominantly White high school.

The same way my freshman or any new student has to walk into this building and make a decision on assimilation to exist... Every educator of color who walks into this district eventually has to make the same decision. That's not inviting. That's not welcoming. That is not any place you want to stay.

For James, the district and the schools must be willing to engage in dialogue with regard to race and equity issues; he stated, "If you are not willing to continue coming to the table to talk about it, regardless of how uncomfortable it is, it is never going to happen."

Carmen's perspective on district level support focused on employment practices; she expressed her dismay with whom she observed was getting hired. "The biggest thing that I am seeing from the education system is that they say, we want... we want... we want; it's a lot of lip service, it's not a lot of follow-through." She went as far to say, I think they are moving towards having less teachers of color, to tell you the truth... They don't see us represented in the community anymore as much as they would like to, or as much as we used to be. A lot of our teachers [of color] are still going out of state, because that's where they are getting jobs.

Carmen was adamant about districts hiring practices being biased; she believed that teachers of color, especially African American teachers, were not being selected for jobs or offered teaching positions.

In this section, I have addressed answers to the research questions. In the next section, I move on to consider the limitations of my study. 


\section{Limitations of Study}

Consistent with most multi-case studies, the methodology allowed for an in-depth exploration of the stories of four African American teachers pathway to a career; however, the small number of participants limits the ability to generalize the findings. While the findings provide insight into specific strategies for academic engagement and support services, they should not be considered generalizable to all aspiring teachers or teacher preparation programs. The intent of this qualitative multi-case study was to explore the aspirations and experiences of African American teachers- graduates of a specific teacher pipeline program - to explore the factors that contributed to their success. A larger sample size with more variability among participants would have definitely contributed to the data.

As with interview data that requires participants to recall past events, memories may be reframed and thus, data collected was reliant on participant memory and honesty. Another limitation of the study was the purposeful sampling strategy used to collect the data. This was partly due to the criteria of selecting recent African American graduates who had completed their programs within the past five to ten years, and despite the support of the TPP program's director it was still difficult to identify and recruit participants. Some of these participants were further removed from their P-12 experiences and graduate school, and this may have led to differences in responses and ability to recall events. While the four African American teacher participants provided rich data for analysis and further insight into their journeys along the teacher pipeline to a career in teaching, additional participants with more recent experience would have provided a richer data set. 
All four participants also noted positive experiences in the TPP and fond memories of the TPP director; however, one participant mentioned that not every student, or prospective student, had similar experiences. Including more participants in my study would have provided additional narratives to consider, possibly more critical lenses. In that vein, the line of inquiry emphasized an assets-based framework, and thus, questions were focused on what worked, steering responses in the direction of what led participants to success rather that asking them to be critical of their experiences. Expanding the study to include questions with a bent toward critique may have provided more findings along those lines.

Additionally, because the participants in the study were working teachers, the interview time needed to be limited. Teachers live busy lives, especially during the school year, and scheduling was challenging. In most cases, scheduled interviews occurred afterschool or during planning days. In addition, initial interview times were often changed, as the teachers' schedules were often bound by opportunities that did not conflict with competing priorities (e.g., committee work, staff meetings, student-related meetings). Yet, participants were open to spending more than an hour with me, and wanted to share their stories, once the interviews began. If I had more opportunities to meet and talk, I may have gained more insights in response to my research questions.

\section{Summary of Findings}

The purpose of this chapter was to present the findings of this multi-case study, and to provide an interpretation of the findings based on the research questions posed. Chapter 4 began by presenting the profiles of each of the four participants, each profile or case, provided a detailed account of the participant's journey along the teacher pipeline to 
a professional career in teaching. Points along the pipeline were common across all participants' narratives, and included experiences during childhood, baccalaureate or undergraduate years, and graduate school life. Significant events, people, places, and supports were highlighted, especially as the related to the TPP.

The findings presented in this chapter, steered by the research questions, provided insights into the journeys of four African American men and women, to their careers in teaching. Their desire to make a difference in the lives of P-12 student was the main reason that participants reported for choosing a teaching career. They also spoke of their own school experiences, specifically having mostly White teachers, and negative school experiences in K-12, fueling desires to be agents of change.

In describing the professional journeys of these four African American teachers, an influential person, familiar with the TPP, played a role in guiding them toward a career in teaching. Their stories were unique, but their career trajectories were similar, as the TPP program of study — from community college to graduate school—was highly structured and influential. For example, all participants described the TPP director as a positive and powerful force that contributed to their success. To help educational stakeholders in Oregon understand how to support efforts of diversifying our state's teacher workforce, three areas (e.g., financial, advising and student support, and community) most significantly affected participants, and should be considered with future endeavors.

Additionally, participants identified understanding the landscape of Oregon as it relates to teacher diversification - that is, race and racism, past and present - as an important frame to consider when recruiting teachers of color into the profession. 
Multiple and varied experiences with youth, such as volunteering in schools, was stressed as a pathway and potential recruitment tool for prospective teachers of color. District level actions were called into question and more concerted efforts to attract and welcome teachers of color were recommended; salary, benefits, school climate and improved hiring practices, were discussed as potential ways to make efforts come to fruition. In Chapter 5, I present the major themes identified from analyzing the data. I describe the relationship of the major themes to the original literature and theoretical frame, and provide recommendations and implications for practice. 


\section{Chapter 5: Discussion}

The primary aim of my study was to examine the factors that contributed to the recruitment of African American teachers in Oregon, exploring their journeys to a career in teaching. To do so, I conducted a qualitative multi-case analysis collecting the narratives from African Americans who completed a teacher pipeline program. The following research questions were posed to guide the inquiry:

1. What do African American teachers report as reasons for choosing to become a teacher in Oregon?

2. How do some African Americans teachers in Oregon describe their journey into teaching?

3. How might the lived experiences of African American teachers' success stories help others in Oregon?

4. What recommendations do African American teachers make to improve recruitment efforts and African American representation in the teaching profession?

In Chapter 4, I reported the findings of my study and provided an analysis of the data, including responses to the research questions. In this chapter, I report findings related to the overarching purpose of my study, the influences that contributed to the success for the four African American teachers. During data analysis, I looked across cases, and using constant comparative analysis, I identified broad themes and patterns. The first theme, belonging, was most evident in the data related to community and I noted participant's sense of community was reported in depth and breadth. The second theme revealed, accountability, which was a concept frequently mentioned in relation to the TPP and seemed to be foundational to participant's success. The third theme, commitment to equity, was discussed, in part, in the participant's desire to be agents of change, discussed in answering RQ1. Social justice and concepts related to cultural 
competency and cultural relevant pedagogy were repeated in a variety of contexts, such as in college classroom experiences, curriculum in graduate school, and connection to the community, just to name a few. These three major themes provide some insights into the how and why participants persisted and persevered with their endeavors.

This chapter includes a synthesis of the findings with definitions and discussions of the three major themes, illuminated through the voices of the participants. Aligned with each of the themes is relevant literature and scholarship, including Harper's (2010, 2012) Anti-Deficit Achievement Framework. I have also explored how findings are related to the larger context—how educational leaders and policy makers can potentially use my findings in the effort to recruit and support more African Americans with their goal to become teachers. I conclude this chapter with implications this study may have on African American teacher recruitment in Oregon, and I provide recommendations for practice, policy, and future research.

\section{Major Themes Related to Success}

By shining the spotlight on a select group of African American teachers and their journeys to a teaching career, I sought to uncover insights and perhaps discover what drew them to the profession and to understand how and why they persevered and ultimately excelled to earn both a graduate degree and a teaching license. I wanted to learn from the stories of teachers, specifically success stories of African American teachers in Oregon. A number of themes emerged from the cross-case analyses, showing that the participants had some common characteristics that may have contributed to their achievement. Due to the nature of being enrolled in the TPP, participants described common core elements of the program that they believed to be significant their success. 


\section{Belonging}

A sense of belonging, considered a universal need by scholars (Baumeister \& Leary, 1995; McMillan \& Chavis, 1986; Osterman, 2000), was not always described as something the participants in this study experienced in their formal school settings. Literature on student success and academic tenacity has proven that a sense of belonging influences achievement (Dweck et al., 2011). All of the participants described how belonging, or lack of belonging, played a significant factor related to their learning throughout their lives, from their early K-12 school experiences through their years in college and graduate school. McMillan and Chavis' (1986) definition of belonging, or sense of community, is often cited in the literature; they defined a sense of community as “... a feeling that members have of belonging, a feeling that members matter to one another and to the group, and a shared faith that members' needs will be met through their commitment to be together" (p. 9).

Three of the four participants had K-12 Oregon school experiences and all four participants attended college in the state, of those experiences participants reported feelings of isolation, marginalization, tokenism, and exclusion. In contrast, the TPP stood out as being the antithesis to their other Oregon school experiences, providing them with a strong sense of community, camaraderie, and support. As James expressed, "I had like-minds... I had people"; he elaborated in more detail, "The navigation of a college life and career can be daunting, can be complex. Having a group, like [TPP], to lessen some of the complexity of navigating through college life is a god-sent."

Their sense of belonging in TPP was linked to their view of themselves and their abilities. As posited by Bandura (1986) a strong sense of self-efficacy influences 
behavior and has a positive effect on motivation and performance. As found in this study, researchers reported that efficacious beliefs can significantly influence student success in general, and career pursuits more specifically (Bandura, 2001, 2012; Gushue, Scanlan, Pantzer, \& Clarke, 2006). Participants' involvement in the TPP was reported to impact their career trajectories, such as through their student teaching placements with alumni; the influence of such resulted in high self-efficacy expectations leading to persistence and resiliency.

Various types of TPP support_-from overt tangible acts of assistance to having someone listen and validate their concerns - were described by the participants as important for supporting them through personal and academic challenges. It was, however, the moments of true connection, described by the participants, which made most evident the power of their community and their strong sense of belonging. For example, Noah, recounted a time when he was struggling, which led to a brief, albeit impactful, conversation with a member of the TPP community:

... [O]ne of my fellow [TPP] members, who was two or three years behind me, he said, 'I just want you to know that everybody here is proud of you, and you are needed, and we thank you so much'. I didn't know that is what I needed to hear right then, but that was exactly what I needed to hear right then.

Belonging, like a sense of community, was described by participants in detail and included concepts related to relationships, like-mindedness, culture, and being both the giver and the receiver of support and encouragement. Even though most of the participants described how school and schooling were not pleasant experiences for them, they reported enjoying time in school settings when they were with their fellow TPP 
students. Deanna recalled, "I felt for the first time, you know, school was like a fun experience." She continued:

It was nice to just have people who you can call and say, 'Can you help me with this?' So I didn't really seek out the help of any staff or faculty, it was more so my [TPP] colleagues, we all helped each other out.

Carmen reflected on the highly significant role of the TPP director-from Carmen's decision to pursue a career in teaching to the support throughout the program, as well as the director's continued presence in Carmen's life as a teacher. Carmen described the relationship with the director as familial, in that she and her fellow TPP students sometimes referred to the director as their 'TPP mom'. “...I call her [by her first name], I call her [by her initials], but usually when it is just her, I am like, mom.” Carmen described a similar type of relationship she had with some of her middle school students:

I have a student who calls me mom. I have a student who calls me auntie. I have students who call me by terms of endearment and I don't take offense to it. At first I did. At first I was like, I am not your mom, but then I realized what he meant is like, you are my school mom. I am like, oh, okay. I got that, I can be your school mom, I can do that.

She framed this familial relationship in cultural terms, "We really emphasize connection. ... It is cultural."

Relationships and mentoring were critical concepts reported by participants, and are consistent to what was found in the literature related to success and achievement for students of color. For example, mentoring is a common program feature found in pathway, or pipeline, programs that serve prospective teachers of color (Clewell \& Villegas, 2001). According to Clewell and Villegas (2001), pathway programs prepare 
students to serve in the role of mentor for their P-12 students, and they often demonstrate how to be mentors by modeling mentoring and encouraging mentoring opportunities within and amongst program participants. Furthermore, in a study on success of African American high school students, researchers found benefits to mentoring, but more importantly, "trusting relationship enabled [participants] to develop an inner motivation to succeed" (Land, Mixon, Butcher, \& Harris, 2014). That inner motivation to succeed will be discussed more in relationship to the theme of accountability in the next section about the major themes.

Noah stressed the roles and responsibilities of peer support that that came with being a member of the TPP community:

[A]s a student that is beyond their second year of the program, it is part of your responsibility to make sure that students that are entering the program understand [they] are going to make it through. [Saying to them] 'You are going to make it to this point, I was sitting right there, I remember that day when I was sitting right there and I was thinking, man, I don't know if I am ready for all this'. It's that personal piece; it's the individual people.

Additionally, he expressed that, "I'm the kind of person that needs to trust, or I'm just going to shut down on you." He undoubtedly found that trust in the TPP community.

Carmen shared how the TPP taught her the importance of establishing rapport and relationships with students that extend beyond the standard school-year timeframe, "You want your students to wraparound. You want your second grade students to come back and invite you to their high school graduations, even though you haven't seen them or haven't had them in your class for 10 years." Carmen added how TPP modeled maintaining long-term relationships with students through their alumni engagement: 
Our alumni ... go back to our seminars, ... go back to our colloquia. So if we have a time in the day, we go back to a [TPP student] meeting and we show [current TPP students] that we are here.... We let them know that they are not in the struggle alone.

The TPP 'wraparound' approach, as described by Carmen, deepened and sustained the sense of belonging among the participants. Several participants deemed alumni involvement and connections as one of the most powerful aspects to the program. Deanna emphasized, “... the [TPP] connections were there, and that was really helpful." She recalled, “...we always had a list of phone numbers and emails of people from the program." As an example, she said, "there was a student who I had met who was a year ahead of me, so while I was in grad school she was in her first year of teaching, and I would try to talk to her as much as possible."

I found that for these four individuals, and most likely for the other students in the TPP, belonging takes on more significance as they embark on their careers as teachers. James summed it up well when he said, "When you are the minority or you are the oppressed person, having someone who can relate to what you are going through can be a comfort as you go through it." James' sentiment was supported by Booker (2007), and connected to research on belonging in a study of African American high school students. Booker reported that, "students revealed that feeling of comfort and tolerance were essential to personal descriptions of belonging" (p. 301). If participants remain in Oregon to teach, they will most likely be required to work in predominantly White schools, schools where they may have experienced isolation, marginalization, and exclusion in their youth. Sustaining their sense of belonging, as well as comfort and tolerance, through active alumni involvement in the TPP, may serve them well. 


\section{Accountability}

Participants shared their insights into their own academic struggles and achievements, and accountability was repeatedly mentioned as a factor that aided in their success. Accountability, especially in the education sector, is often viewed as a focus on test scores, the standards movement, and university accreditation (Bouwma-Gearhart \& Hora, 2016; Taubman, 2010). While evidence based research and data driven decisionmaking may be considered common elements in discussions about accountability in education, the focus of accountability in this study, as described by the participants, is more simplistic in nature. A culture of accountability as a prominent theme in this study was defined by participants as the establishment of rigorous expectations, the oversight of progress, and the act of encouraging achievement through ongoing feedback.

Accountability was discussed in relation to a variety of learning contexts, both formal and informal. For example, participants conveyed they wanted to be taken seriously as college students and prospective teachers, which to them meant, faculty needed to help make learning rigorous with routine assessments about their performance.

Several of the participants shared how their parents and families established high standards for them at an early age. Findings in this study, linking parental influence to accountability that factored into achievement, are consistent with the research literature (Harper, 2012; Harper \& Davis, 2012; Perna \& Titus, 2005). In Harper's (2012) study, which highlighted the Anti-Deficit Achievement Framework, he found that parents and family members had a strong positive influence, specifically in initiating educational activities outside of school settings. James talked about his mother, a career woman and single parent, "[My mom] found me resources for what she could not do. She always had 
jobs that were connected to people that knew people." He also described how she modeled a strong work ethic, “It wasn't until I became an adult that I realized how much finagling, hustling...that my mom did for us." James also recalled, "My mom, she knew that education would be my ticket, so she was the involved parent," and he described how his mother held him accountable for his schoolwork and his behavior. James' grandfather explained to him the importance, especially for African Americans, of striving to do well, "So I took that from my grandfather, that you are always being watched, so you always have to be on your best."

Consistent with the literature, participants understood that teachers who had low expectations of them sometimes did so based on racist attitudes and damaging assumptions (Landsmen, 2004). Scholars have described how low-teacher expectations are described as one of the issues holding back students of color in their pathway to success (Harper, 2012; Villegas \& Irvine, 2010). Noah was most vocal about his experiences with lack-luster teachers and low expectations. He stressed the dearth of accountability he found throughout his schooling. "Nobody really cared... because I would always meet benchmark... so it didn't matter." He was pleasantly surprised when he began the TPP and found the director to challenge and push him. Noah explained, "I needed people getting on me...telling me time to turn things in... and tell me when deadlines were... making sure that I was sticking to those deadlines. And also hold me accountable." He added,

It was mainly about the accountability pieces. Mainly about the pieces of somebody going, hey, you need to improve. Hey, you need to do better. Hey, you can do better, so I'm going to need you to start stepping it up. For me that was the biggest thing. 
Noah also expressed his gratitude for a faculty member that he encountered in college who encouraged him academically:

It was one of the first classes that brought me into contact with my own level achievement relative to my potential... [T] hat was one of the few classes I ever had where someone had ever said that my writing needed work.

Despite the perceived stigma related to the TPP as being easy or less rigorous, TPP presented participants with a challenging course of study, more work than what is required of other prospective teacher candidates. Carmen described the stigma, "A lot of people think that you get in to the [TPP] and you were given the spot. No, we earn it every single step of the way." She added, "... we are not handed anything. We work just as hard as [other students]. In fact, with our [TPP] classes, it is like taking another class on top of it. ... I probably wrote more essays in my four years of [TPP] than I did... than I feel like I did in my college experience.” Carmen went on to say that the TPP required her to complete additional work and pushed her, academically, beyond what was required of her in her college courses. She shared, "[W]e [were] given articles, we read them, we talked about them, and we talked about other cultures and also did research papers." All four participants described academic challenges they had while completing their degrees and educator preparation programs. Deanna disclosed, "I think one of the hardest things for me though, not being a student who came from a family where academics were a top priority... Just knowing how to study, take notes, or write a paper... was really challenging."

Mandatory TPP meetings were held regularly and were well recalled by all participants. In fact, accountability was most frequently discussed in association with the 
TPP, and more specifically in relation to the TPP director. Many referenced the TPP director's routine review of their assignments, grades, and overall academic performance. Deanna shared:

There were times when the program director would get our papers or works that we had done, and say, 'No, this is not good enough'. I wanted to do well for myself, so that I would get the grades..., but I also knew that I needed to do well for her.

The director's influence was described as wide-ranging, from introducing TPP students to concepts about racism and equity to making suggestions about professional appearance. Deanna recalled:

The [TPP] program director really, all throughout my experience in the program, it was like you go to school looking nice. You do not dress sloppy. You never show up for student teaching looking sloppy. She meant that, because we are being judged the second we walk in the door, so we don't need that on top of people already judging us.

Deanna emphasized the importance of accountability in TPP, saying:

So when I think about [TPP], how much it supports people who come from a background where maybe they don't know much about college, and just how to ... navigate the whole college experience, and just set accountability. It was really big.

Stories shared by participants acknowledged benefits of being held accountable; they expressed their desire for high expectations affording them the opportunity to demonstrate educational excellence. TPP not only honored this request for accountability, but it helped drive participants to succeed. For example, when participants came into the program with insufficient academic preparation, TPP supplied them with supplementary academic support. If they encountered racist and culturally insensitive campus environments, TPP meetings offered them safe places where they 
were permitted to vent and receive validation and support. Intentional program features such as these should not be mistaken as lowered expectations; rather, these examples of support services embedded within TPP furthered the culture of accountability and propelled participants to succeed.

\section{Commitment to Equity}

The commitment to equity, and to helping K-12 students like themselves, seemed to provide participants in this study with the mental fortitude to persist. Lortie (2002) identified five themes that draw individuals into the teaching profession, the second theme he identified, the service theme, (i.e. service to the community and making a difference in peoples' lives) is consistent with the commitment described by all four of the participants. The decision to become a teacher, as discussed in response to the RQ1, and factors that participants reported as contributing to the career choice included their own negative school experiences and their desire to create better school environments for future generations of school children.

According to Achinstein and Ogawa (2011), “Teachers of color are committed to serving the educational needs of students from culturally non-dominant communities" ( $\mathrm{p}$. 4). Consistent with this growing body of research, participants' motivation to seek teaching as a career was described in terms of being role models and being able to relate to students in culturally similar ways. James shared, "Going through my experience becoming an educator, made me want to be one more. I think that is the simplest way to put it. I want students like me to see that you can be successful." He reflected on where he initially wanted to teach, and how that changed for him: 
So I wanted to be in schools like [high school with African American population]... then after my first two years, then I get sent [to a predominantly White high school]. My first year was, like, wow. You need me here, I think, more than they need me over there, because you do not have a clue of what life is like for someone that looks like me.

Initially I framed this theme, not simply as a commitment, but as an informed commitment to equity. I did this because I wanted to emphasize what I interpreted as the participants' keen awareness about Oregon schools; they all seemed highly cognizant about the predominantly White culture found within schools, not to mention the history and general population demographics of the state. In other words, they made their choice to become teachers with their eyes wide open.

For James and Noah, who moved to Oregon from other parts of the country, they described the White culture in the Pacific Northwest as very unwelcoming. James described the feeling of being marginalized in college classes and while attending the university. He had some similar feelings about his high school experience, and in reflecting about his current position at a predominantly White school, he remarked, "My high school world was a lot like African American kids that come here. That is probably one of the reasons I relate with them so well..." Noah described, "The underlying feeling" of not being wanted, and he shared, "That's something that you can feel, even if you can't always explain it. Particularly, you can't put it into words that make sense and are accurate to what you are feeling. You can sense it; children can sense it."

Deanna and Carmen, native Oregonians, were well informed about whom their colleagues would be once they entered the profession. Deanna explained, "Something that I am always conscious of, or conscientious of, is the fact that I am a Black teacher." Deanna went on to say, "Becoming a teacher in Oregon [as a person of color], I think, 
there are definitely some tricky things to navigate, which if people do not have support, it is easy to just give up on." Despite the racially alienating atmosphere they experienced growing up in Oregon, or maybe because of it; both Carmen and Deanna chose teaching as a career.

Participants also spoke candidly about their racial-justice oriented professional missions and their desire to be agents of change. Carmen declared, "You can't sit here and cry for change and then not fight for it. It doesn't work like that." Participants used terminology such as battles, struggles, and fights to describe what they would face as teachers of color in a predominantly White profession. James explained, "I am becoming 'the other' as soon as I walk through the door." He talked about how the TPP was designed to prepare teachers of color for this reality.

Monthly you are having mandatory meetings where you were getting social education. You've got guest speakers coming in. You're being educated on the life of a teacher in an environment where you are a minority. ...going in as a minority, to make change, you're going to have to face battles. Hence, [TPP] is designed to help you... to gain a stronger skin for what you were going to have to deal with... [TPP] is teaching [us] how to find personal ways of dealing with being the person who is the initiator, who is the confronter.

Although my study was not a review or program evaluation of the TPP, the findings provided insights and a glimpse into some of the accomplishments of the program. The description from my study, by four African American TPP alumni, were in alignment with what scholars reported of a similar pipeline program, the Multilingual/Multicultural Teacher Preparation Center (M/M Center), in California. The article about the M/M Center shared highly effective practices associated with the recruitment and retention of CLD teacher candidates. Just as the participants had a strong 
commitment to equity, Wong et al. (2007) reported that their graduates were, "actively engaged in the process of becoming multicultural, social justice educators," and furthermore, they exited "the program with a strong desire to work in low-income and culturally and linguistically diverse communities" (p. 21).

All of the participants talked about race and equity in education in Oregon, particularly when they discussed their recommendations for improving recruitment efforts and African American representation in the teaching profession. Noah shared his frustration with the ignorance he found in Oregon when it came to having discussions around issues of race and equity, saying:

People don't tend to know..., especially when it comes to issues that surround race, racism and equity. People don't know what they're talking about.... They don't know enough to know that they don't know what they're talking about. So they say things that kind of sound like what you would say... but they don't know what they mean, and they don't have the same meaning behind them.

Deanna shared some of the advice she received from the TPP program director; she said:

... [The TPP director] instilled in us ... I need to be one step ahead, I can't slack. I can't let things fall by the wayside, because then, not only am I not doing my job well, but then it's like this Black teacher isn't doing their job well. There is always that piece. That is something that is just part of everyday.

Participants' projections for being successful with their endeavors to make change were sometimes bleak and discouraging. Deanna mentioned:

One of my teaching partners last year who taught second grade, a Black teacher, she left. She moved to New York; she said she was not staying in this state any longer, she said she had been here long enough. Because it is so... it is just very White.

Despite their strong aspirations to lead future generations and be agents of change, all of the participants mentioned some limitations to what they felt they could do to improve 
conditions for students. James, who was the only participant who moved into school administration, shared his feelings of powerlessness as a teacher:

The politics really began to weigh heavily on me, as a classroom teacher. Going into teaching I questioned my ability as an individual; I didn't know if I would be able to function in this environment. The politics of education is right in your classroom and as a classroom teacher you really have no power to affect change... I began looking at going into Administration for that reason.

Noah also expressed concern, "I wonder how much I can do. Like, how much can I possibly do from the inside? There is a limit to that."

However challenging they found their struggles to be, they consistently offered uplifting stories about their students and their rationales for teaching, which spoke volumes about their commitment to social justice. For example, Carmen was very passionate and animated when she discussed matters related to her classroom and the students she teaches; she had a lot of excitement in her voice when she talked about the subject matter, in particular the contemporary issues, her students, and their learning. The population she currently teaches is from low-income backgrounds and predominantly African-American; she shared how her students were eager to, "think about our government and politics..." She continued, "Especially the kids I am working with right now, they want to know about the politics, they want to be engaged... They want to have those arguments, they want to have those discussions." Noah shared some advice, framed with an equity lens, for prospective teachers of color:

It's important that you be critical, that's the most important thing. Never stop analyzing the way in which power works in your school. Never stop analyzing the ways in which you are... serving [or not serving] kids at your school. You have to then commit to doing the work. It is not easy. It's a lot of work, for [not] much payoff outside of the kids. So if the kids are not the huge pay off for you... 
Which for me it is, I mean, I get to hang out with seventh graders all day. I love it.

\section{Implications}

Based upon the findings of this study, my goals are (a) to increase awareness about the successes of African American teachers in Oregon; and (b) to share the value of relationships, community, collective action, and educational excellence that the teachers in this study described on their pathways to their professional lives. The results of this study speak to researchers and educators interested in understanding the challenges and opportunities for diversification of the teacher workforce. The singular focus of my study on African American teachers speaks only to one sector of our population, and briefly touches on the racially ill climates that discourage people of color from choosing teaching as a career. Findings from this study are nuanced and complex, each participant's success story was unique to their own set of experiences; their experiences cannot be reproduced. That said, understanding their stories and the findings discussed herein, have implications for various invested stakeholders (e.g., prospective teacher candidates, P-12 schools and districts, and higher education institutions, educator preparation in particular) in practical ways.

\section{Students of Color}

First, the participants in this study provided specific recommendations for students of color, and possibly for prospective teacher candidates of color. Noah said, "I think in general, students need to take a critical look at their schools, and ask, okay, how can we change that? And feel like they have a voice and a sense of agency." They also provided testaments to success that prospective teachers may find motivating; as Deanna recalled, "Once I was in the [TPP], I knew everything I needed to do to get to teaching so 
there was no question about it." Participants reported that they learned through their experiences in pursuing their careers, that they were not alone. Carmen disclosed, "So, for me, when I joined [TPP] and really started feeling, not just my pain, but [also] the pain of others around me who had the similar experiences, and finally understanding that I wasn't the only one feeling this."

\section{School Districts}

Implications for school districts and the contextual factors in P-12 student learning are evident. As fundamental to the Anti-Deficit Achievement Framework is an emphasis on the social and cultural elements of a participant's life. As evidenced from participant descriptions, our schools — especially P-12 settings—serve as socializing agents. Our educational institutions, in overt or subtle ways, impart values, beliefs, and norms. As Noah pointed out:

Lots of kids don't make it, not because they don't have the academic chops, but because they can't cope with the fact that school is not all about your academics. It's not about doing the right thing and doing the wrong thing; it's about understanding how to navigate power.

Disparities in academic achievement continue to persist amongst racial and cultural groups; the predominantly White teaching force in our nation would benefit from taking more time to learn about their role and responsibility in making changes to practice. Listening to the insights of the participants in my study with regard to the P-12 school forces might be one place to start; taking time to listen to the voices of ethnically and linguistically diverse colleagues and students' in their classrooms may be another. 


\section{Colleges and Universities}

There are no quick fixes for changing campus climates to be more inclusive and welcoming. However, lessons learned from exemplar program models such as the TPP, provide some critical components, and may have implications for higher education administrators. This study builds on the growing body of literature on diversification of teacher education programs (Sleeter \& Milner, 2011), where scholars have recommended, “...not attempt[ing] to change teacher education program but rather to build[ing] support systems into, around, and through them" (p. 85). Participants described how TPP provided continuity and connection for them, a somewhat seamless college experience as they navigated through their degree programs and two separate institutions. Graduate preparation programs, however, may seem far removed from the undergraduate program experience, especially for students that begin their study at community colleges. As Wong et al. (2007) noted:

The disconnect between undergraduate education and teacher preparation programs results in inconsistent advising and a lack of articulation across campus units that, when coupled with myriad credentialing requirements, generates a long list of obstacles that hamper the progress of students unfamiliar with higher education, a group that is comprised disproportionately of students of color. (p. 15)

Students without a program like TPP, may not necessarily be made aware of teaching as a career option while pursuing their bachelor degrees, since education may not be listed as a major available to choose from to earn their bachelor's degree and/or the pursuit of a post-bachelor or graduate degree might not be a consideration. Thus, programs, like TPP, become all the more critical to graduate level preparation in supporting potential teacher recruits in 2- and 4-year institution. Ensuring articulation and a seamless 
experience as students transfer to the university and apply to graduate school is just one of the many student support service ideas highlighted by the participants as key to their success.

\section{Recommendations}

Creating space for discussions about race, racism, and equity, especially in educator preparation programs, would impact not only teacher candidates and their experiences in the teacher pipeline, but this dialogue might be continued in K-12 classrooms, with students, after they become teachers. I recommend restructuring colleges and universities, and more specifically schools of education within institutions, in ways that acknowledge and value racial and ethnic diversity. Schools of education must do a better job of understanding the academic socialization experiences of teacher candidates of color. Program specific insights gleaned from this study were brought to light only with an understanding of participant perspective; a word of caution to anyone trying to replicate ideas without such an understanding of the population they aim to serve. Professional development that focuses on the "overwhelming presence of Whiteness" (Sleeter, 2001); teacher educators and prospective teacher candidates need more awareness and understanding of how the predominantly White culture affects the learning environment in P-12 and college classrooms.

The state of Oregon's efforts to recruit, prepare and retain teachers of color who represent the ethnic and linguistic backgrounds of their students is admirable. As the population of diverse students increases, Oregon's colleges and universities will begin to see evidence that they are graduating a higher proportion of CLD students. Invested stakeholders should consider intentional recruitment efforts, at both the P-12 and higher 
education settings. To do so, I echo recommendations made in the 2016 Oregon Educator Equity Report, such as, (a) “expansion of cadet programs for future teachers at middle and high school levels"; (b) "a campaign to focus on the state's employment needs"; and (c) "provide seed funding to grow and expand partnership models."

Recruitment efforts need to include resources at all points along the educational pipeline. The TPP's unique approach of providing continuity of support, as students begin community college throughout the graduate education preparation, is worth consideration. Consistency and continuity described by participants, not only at the point of admissions or in transition from one educational institution to the next but throughout the entire journey to a career in teaching, exemplifies strong retention-focused advising. Resources would be well spent on support services available for students while they are in teacher preparation programs, and possibly to help maintain and sustain alumni involvement post-licensure. Reliance on faculty to provide teacher candidates of color all the support they need to be successful in a traditional preparation program may not be the best model. Professional advisors may be able better positioned to provide supplementary services with retention in mind.

Harper (2012) concluded that moving the agenda forward on college campuses is not easy and demands honest discussions about the realities of race on campus. "The responsibility for addressing toxic racial climates should not belong to the chief diversity officer, the office of multicultural affairs, or people of color-it must be owned by all units and every person on campus" (p. 23). In that vein, the responsibility for changing our nation's teacher workforce should not only be placed on our school districts and university partners. I recommend extending this responsibility to include community 
stakeholders, such as boards of education, professional associations, and policy makers, such as state departments of education.

More research is needed as well. Research agendas related to the recruitment, preparation and graduation of more teachers of color could include, prospective teacher experiences from different cultures, races and ethnicities - possibly enrolled (or not) in pipeline programs - and cross-cultural comparisons. As Harper (2012) stated, "Racism and racial stereotypes pose serious threats to one's sense of belonging, engagement, academic achievement, and persistence" (p. 22). Improving conditions for teachers of color must take into account experiences of teachers from different cultural and racial groups. Additionally, studies similar to this one, exploring the experiences of African Americans who are not enrolled in a teacher pipeline program and gaining a better understanding of recruitment and preparation from their perspective.

Research on the retention of African American teachers to consider challenges teachers of color face once they enter the profession. Along this same avenue of research, I think it would be interesting to learn more about the retention as it relates to the graduates of the TPP; following up with TPP alumni to learn more about their experiences in the field. I would also recommend further investigations focused specifically on the TPP, as effective practices such as those reported by participants in my study, may prove illuminating.

\section{Concluding Thoughts}

When I began this study, I wanted to gain a better understanding of African American teacher experiences in Oregon. I knew, from my former work at the university and being responsible for data reports, that extremely small numbers of African 
Americans were enrolled in, and completing, educator preparation programs in the state. In addition, I was acquainted with the Teacher Pipeline Program director and familiar with the success rate of the program's student population. I wanted to learn more about the African American students in TPP, hear their stories, and better understand what contributed to their success. As Lortie (2002) noted, "Any occupation which fails to recruit new members will not survive" (p. 25); critically needed new members, such as African American teachers in Oregon, have important and insightful information about their pathway into teaching.

I pursued a research agenda that instead of focusing on deficit assumptions, affirmed inclusivity and recognized excellence; research that aligned with what worked with less emphasis on what did not work. The findings of this study indicated that one of factors most contributing to the success of the participants was their sense of belonging and community, especially in association with the TPP. The TPP director was described as particularly influential, and served in a plethora of roles for the students - including academic advisor, teacher, counselor, and program-'mom'. I was not surprised to learn the significance that the director played in supporting the students, but I was taken back by the depth and familial-like relationship that existed between her and the participants. Clearly, strong bonds between the director and the participants had developed over time, which was not necessary a surprising realization; yet, I was somewhat awed by the profound trust, care, and cohesiveness that was evident.

It was their mission - their commitment to equity and the belief that together they would make positive change happen in their communities - that fueled their passion, sustaining community spirit and strength. All of the participants rallied around the notion 
of social justice and the importance of equity work to educator preparation. They were equally united in their criticism of the graduate educator preparation program for lacking in culturally relevant pedagogies. I was surprised to learn how negatively the participants viewed the program and their experiences. I wondered if the faculty in the educator preparation program were ill equipped to differentiate the instruction, or perhaps it was the curriculum was to blame, maybe both. I can only imagine the large continuum that must exist within a cohort of 20-25 graduate students of their understanding about race and privilege, and their level of comfort with conversations around racism and equity. I mention this, not to provide an excuse, but rather to point out the need for anti-bias training and professional development on White privilege for faculty and preservice students.

As mentioned, I aspire to increase awareness about the successes of African American teachers in Oregon. This research highlights the voices of four teachers and their success stories. From this research, it is evident that our increasingly diverse nation continues to breed racist ideology and the "overwhelming presence of Whiteness" (Sleeter, 2001) perpetuates systems, such as institutional racism, that continue to oppress people of color. The four participants inspire me, and I am confident that their passion for and commitment to equity will inspire others as well. 
References

Achinstein, B., \& Ogawa, R. T. (2011). Change(d) agents: New teachers of color in urban schools. New York, NY: Teachers College Press.

Achinstein, B., Ogawa, R. T., Sexton, D., \& Freitas, C. (2010). Retaining teachers of color: A pressing problem and a potential strategy for "hard-to-staff" schools. Review of Educational Research, 81(4), 71-107.

Ahmad, F. Z., \& Boser, U. (2014). America's leaky pipeline for teachers of color: Getting more teachers of color into the classroom. Washington, DC: Center for American Progress Report.

Allen, M. B. (2005). Eight questions on teacher recruitment and retention: What does the research say? Denver, CO: Education Commission of the States.

Allen, W. R. (1992). The color of success: African-American college student outcomes at predominantly White and historically Black public colleges and universities. Harvard Educational Review, 62(1), 26-45.

American Association of Colleges for Teacher Education. (1989). Recruiting minority teachers: A practical guide. Washington, DC: Author.

American Association of Colleges for Teacher Education. (2013). The changing teacher preparation profession. Washington, DC: Author.

Bandura, A. (1977). Self-efficacy: Toward a unifying theory of behavioral change. Psychological Review, 84(2), 191-215.

Bandura, A. (1986). Social foundations of thought and action: A social cognitive theory. Englewood Cliffs, NJ: Prentice- Hall Bandura, A. (1997a). Self-efficacy: The exercise of control. New York, NY: W.H. 
Freeman and Company.

Bandura, A. (1997b). Self-efficacy. Harvard Mental Health Letter, 13(9), 4.

Bandura, A. (2001). Social cognitive theory: An agentic perspective. Annual Review of Psychology, 52(1), 1-26.

Bandura, A. (2012). On the functional properties of perceived self-efficacy revisited. Journal of Management, 38(1), 9-44.

Banks, J. A. (2004). Multicultural education: Historical development, dimensions, and practice. In J. A. Banks \& C. A. M. Banks (Eds.), Handbook of research on multicultural education (2nd ed., pp. 3-29). San Francisco, CA: Jossey-Bass.

Baumeister, R. F., \& Leary, M. R. (1995). The need to belong: Desire for interpersonal attachments as a fundamental human motivation. Psychological Bulletin, 117(3), 497-529.

Baxter, P., \& Jack, S. (2008). Qualitative case study methodology: Study design and implementation for novice researchers. The Qualitative Report, 13(4), 544-559.

Bennett, C. I., McWhorter, L. M., \& Kuykendall, J. A. (2006). Will I ever teach? Latino and African American students' perspectives on PRAXIS I. American Educational Research Journal, 43(3), 531-575.

Bensimon, E. M. (2007). The underestimated significance of practitioner knowledge in the scholarship on student success. The Review of Higher Education, 30(4), 441469.

Bireda, S., \& Chait, R. (2011). Increasing teacher diversity: Strategies to improve the teacher workforce. Washington, DC: Center for American Progress.

Booker, K. C. (2007). Likeness, comfort, and tolerance: Examining African American 
adolescents' sense of school belonging. The Urban Review, 39(3), 301-317.

Boser, U. (2011). Teacher diversity matters: A state-by-state analysis of teachers of color. Washington, DC: Center for American Progress.

Boser, U. (2014). Teacher diversity revisited: A new state-by-state analysis. Washington, DC: Center for American Progress.

Bouwma-Gearhart, J. L., \& Hora, M. T. (2016). Supporting faculty in the era of accountability: How postsecondary leaders can facilitate the meaningful use of instructional data for continuous improvement. Journal of Higher Education Management, 31(1), 44-56.

Brown, K. D. (2014). Teaching in color: A critical race theory in education analysis of the literature on preservice teachers of color and teacher education in the US. Race Ethnicity and Education, 17(3), 326-345.

Brown v. Board of Education, 347 U.S. 483 (1954).

Bryan, N., \& Browder, J. K. (2013). “Are you sure you know what you are doing?”-The lived experiences of an African American male kindergarten teacher. Interdisciplinary Journal of Teaching \& Learning, 3(3), 142-158.

Case, C. W., Shive, R. J., Ingebretson, K., \& Spiegel, V. M. (1988). Minority teacher education: Minorities recruitment and retention methods. Journal of Teacher Education, 39(4), 54-57.

Chief Education Office. (2015). 2015 Oregon Educator Equity Report. Retrieved from http://education.oregon.gov/wpcontent/uploads/2015/11/Educator_EquityReport_CEdO_Nov_2015.pdf 
Chief Education Office. (2016). 2016 Oregon Educator Equity Report.

Retrieved from http:/education.oregon.gov/portfolio/2016-educator-equityreport/

Chung, J. Y., \& Harrison, L. M. (2015). Toward an ethnic studies critique for teacher education. Multicultural Perspectives, 17(1), 4-12.

Clewell, B. C., \& Villegas, A. M. (1998). Diversifying the teaching force to improve urban schools: Meeting the challenge. Introduction. Education and Urban Society, 31(1), 3-17.

Clewell, B. C., \& Villegas, A. M. (1999). Creating a nontraditional pipeline for urban teachers: The pathways to teaching careers model. Journal of Negro Education, $68(3), 306-317$.

Clewell, B. C., \& Villegas, A. M. (Eds.). (2001). Ahead of the class: A handbook for preparing new teachers from new sources. Washington, DC: The Urban Institute.

Cochran-Smith, M., \& Fries, K. (2005). The AERA panel on research and teacher education: Context and goals. In M. Cochran-Smith \& K. Zeichner (Eds.), Studying teacher education: The report of the AERA panel on research and teacher education (pp. 37-68). Mahwah, NJ: Erlbaum.

Conley, D. T. (2011). Redefining college readiness, Volume 5. Eugene, OR: Educational Policy Improvement Center.

Conley, D. T., \& McGaughy, C. (2012). College and career readiness: Same or different. Educational Leadership, 69(7), 28-34.

Creswell, J. W. (2005). Educational research: Planning, conducting, and evaluating quantitative and qualitative research. Upper Saddle River, NJ: Pearson. 
Darling-Hammond, L. (2007). Third annual Brown lecture in education research-The flat earth and education: How America's commitment to equity will determine our future. Educational Researcher, 36(6), 318-334.

Dee, T. S. (2004). Teachers, race, and student achievement in a randomized experiment. Review of Economics and Statistics, 86(1), 195-210.

Dillard, C. (1994). Beyond supply and demand: Critical pedagogy, ethnicity, and empowerment in recruiting teachers of color. Journal of Teacher Education, $45(1), 9-17$.

Dilworth, M. E. (1990). Reading between the lines: Teachers and their racial/ethnic cultures. (Teacher Education Monograph No. 11). Washington, DC: ERIC Clearinghouse on Teacher Education and American Association of Colleges for Teacher Education.

Dilworth, M. E., \& Coleman, M. J. (2014). Time for a change: Diversity in teaching revisited. Washington, DC: National Education Association Report.

Dweck, C. S. (2006). Mindset: The new psychology of success. New York, NY: Random House.

Dweck, C. S. (2008). Can personality be changed? The role of beliefs in personality and change. Current Directions in Psychological Science, 17(6), 391-394.

Dweck, C. S., Walton, G. M., \& Cohen, G. L. (2011). Academic tenacity: Mindsets and skills that promote long-term learning. Seattle, WA: Bill \& Melinda Gates Foundation.

Earley, P. C. (1994). Self or group? Cultural effects of training on self-efficacy and performance. Administrative Science Quarterly, 39, 89-117. 
Eddy, C. M., \& Easton-Brooks, D. (2011). Ethnic matching, school placement, and mathematics achievement of African American students from kindergarten through fifth grade. Urban Education 46(6), 1280-1299.

Elias, M. J., White, G., \& Stepney, C. (2014). Surmounting the challenges of improving academic performance: Closing the achievement gap through social-emotional and character development. Journal of Urban Learning, Teaching, and Research, $10,14-24$.

Elliott, W., Destin, M., \& Friedline, T. (2011). Taking stock of ten years of research on the relationship between assets and children's educational outcomes: Implications for theory, policy and intervention. Children and Youth Services Review, 33(11), $2312-2328$.

Ferguson, R. F. (2002). What doesn't meet the eye: Understanding and addressing racial disparities in high-achieving suburban schools. Oak Brook, IL: North Central Regional Educational Laboratory.

Flyvbjerg, B. (2006). Five misunderstandings about case-study research. Qualitative Inquiry, 12(2), 219-245.

Gay, G. (2010). Culturally responsive teaching: Theory, research, \& practice $\left(2^{\text {nd }} \mathrm{ed}\right)$. New York, NY: Teachers College Press.

Glenn, T. B. (Ed.). (2012). Finding our way back to first: Reclaiming world leadership by educating all America's children. Baltimore, MD: National Association for the Advancement of Colored People.

Good, J., Halpin, G., \& Halpin, G. (2007). Retaining black students in engineering: Do 
minority programs have a longitudinal impact? In A. Seidman (Ed.), Minority student retention: The best of the journal of college student retention: Research, theory, \& practice (pp. 45-58). Amityville, NY: Baywood.

Gordon, J. A. (2000). The color of teaching. New York, NY: Taylor \& Francis. Governor's Office of Education and Workforce Policy. (2001). Minority teacher report: A ten-year retrospective. Retrieved from http://education.oregon.gov/wpcontent/uploads/2015/09/History-of-Minority-Teacher-Act.pdf

Graham, A., \& Erwin, K. D. (2011). I don't think black men teach because how they get treated as students: High-achieving African American boys' perceptions of teaching as a career option. The Journal of Negro Education, 80(3), 398-416.

Grissom, J. A., Kern, E., \& Rodriguez, L. A. (2015, April). Teacher and principal diversity and the representation of students of color in gifted programs: Evidence from national data. Paper presented at the annual meeting of the American Educational Research Association, Chicago, IL.

Gushue, G. V., Clarke, C. P., Pantzer, K. M., \& Scanlan, K. R. (2006). Self-efficacy, perceptions of barriers, vocational identity, and the career exploration behavior of Latino/a high school students. The Career Development Quarterly, 54(4), 307317.

Haberman, M. (1988). Proposals for recruiting minority teachers: Promising practices and attractive detours. Journal of Teacher Education, 39(4), 38-44.

Hall, E. V., Phillips, K. W., \& Townsend, S. S. (2015). A rose by any other name?: The consequences of subtyping “African-Americans” from "Blacks.” Journal of Experimental Social Psychology, 56, 183-190. 
Harper, S. R. (2009). Race-conscious student engagement practices and the equitable distribution of enriching educational experiences. Liberal Education, 95(4), 3845.

Harper, S. R. (2010). An anti-deficit achievement framework for research on students of color in STEM. In S.R. Harper \& C. B. Newman (Eds.), Students of color in STEM: Engineering a new research agenda (pp. 63-74). San Francisco, CA: Jossey-Bass.

Harper, S. R. (2012). Black male student success in higher education: A report from the national Black male college achievement study. Philadelphia, PA: University of Pennsylvania, Center for the Study of Race and Equity in Education.

Harper, S. R., \& Davis, III, C. H. (2012). They (don't) care about education: A counternarrative on Black male students' responses to inequitable schooling. Educational Foundations, 26, 103-120.

Howard, T. C. (2013). How does it feel to be a problem? Black male students, schools, and learning in enhancing the knowledge base to disrupt deficit frameworks. Review of Research in Education, 37(1), 54-86.

Hudson, M. J., \& Holmes, B. J. (1994). Missing teachers, impaired communities: The unanticipated consequences of Brown v. Board of Education on the African American teaching force at the precollegiate level. Journal of Negro Education, 63(3), 388-393.

Humes, K., Jones, N., and Ramirez, R. (2011). Overview of race and Hispanic origin: 2010. Washington, DC: Census Bureau (Census 2010 Briefs, C2010BR-02). Hurtado, S., Milem, J. F., Clayton-Pedersen, A. R., \& Allen, W. R. (1998). Enhancing 
campus climates for racial/ethnic diversity: Educational policy and practice. The Review of Higher Education, 21(3), 279-302.

Ingersoll, R., \& May, H. (2011). Recruitment, retention, and the minority teacher shortage. Consortium for Policy Research in Education. CPRE Research Report \# RR-69.

Johnson, E., \& Williams, F. (2010). Desegregation and multiculturalism in the Portland public schools. Oregon Historical Quarterly, 111(1), 6-37.

King, S. H. (1993). The limited presence of African-American teachers. Review of Educational Research, 63(2), 115-149.

Klopfenstein, K. (2005). Beyond test scores: The impact of black teacher role models on rigorous math taking. Contemporary Economic Policy, 23(3), 416-428.

Kuh, G. D. (2007). What student engagement data tell us about college readiness. Peer Review, 9(1), 4-8.

Kuh, G. D. 2008. High-impact educational practices: What they are, who has access to them, and why they matter. Washington, DC: Association of American Colleges and Universities.

Kuh, G. D., Kinzie, J., Buckley, J. A., Bridges, B. K., \& Hayek, J. C. (2006). What matters to student success: A review of the literature commissioned report for the national symposium on postsecondary student success: Spearheading a dialog on student success. Washington DC: National Postsecondary Education Cooperative.

Kvale, S., \& Brinkmann, S. (2009). InterViews: Learning the craft of qualitative research interviewing ( $2^{\text {nd }}$ ed.). Thousand Oaks, CA: Sage.

Ladson-Billings, G. (2009). The dreamkeepers: Successful teachers of African American 
children (2nd ed.). San Francisco, CA: Jossey-Bass.

Land, A. L., Mixon, J. R., Butcher, J., \& Harris, S. (2014). Stories of six successful African American males high school students: A qualitative study. National Association of Secondary School Principals Bulletin, 98(2), 142-162.

Landsman, J. (2004). Confronting the racism of low expectations. Educational Leadership, 62, 28-33.

Lent, R. W., Brown, S. D., \& Hackett, G. (1994). Toward a unifying social cognitive theory of career and academic interest, choice, and performance. Journal of Vocational Behavior, 45, 79-123.

Lewis, C. W. (2006). African American male teachers in public schools: An examination of three urban school districts. Teachers College Record, 108(2), 224-245.

Lindley, L. D. (2006). The paradox of self-efficacy: Research with diverse populations. Journal of Career Assessment, 14(1), 143-160.

Lortie, D. C. (1975, 2002). Schoolteacher: A sociological study. Chicago, IL: University of Chicago Press.

Luzzo, D. A., \& McWhirter, E. H. (2001). Sex and ethnic differences in the perception of educational and career-related barriers and levels of coping efficacy. Journal of Counseling \& Development, 79, 61-67.

Mapes, B. (2011, August 4). The photo vault: The architects of Measure 5, Oregon's most powerful ballot measure. The Oregonian. Retrieved from http://blog.oregonlive.com/mapesonpolitics

Maxwell, J. A. (2005). Qualitative research design: An interactive approach $\left(2^{\text {nd }}\right.$ ed.) Thousand Oaks, CA: Sage. 
McCray, A.D., Sindelar, P.T., Kilgore, K.K., \& Neal, L. I. (2002). African-American women's decisions to become teachers: Sociocultural perspectives. Qualitative Studies in Education, 15(3), 269-290.

McDonald, M. (2007). The joint enterprise of social justice teacher education. Teachers College Record, 109(8), 2047-2081.

McMillan, D.W. \& Chavis, D.M. (1986). Sense of community: A definition and theory. Journal of Community Psychology, 14, 6-23.

Merriam, S.B. (2009). Qualitative research: A guide to design and implementation. San Francisco, CA: Jossey-Bass.

Nasir, S. N., McLaughlin, M. W., \& Jones, A. (2009). What does it mean to be African American? Constructions of race and academic identity in an urban public high school. American Educational Research Journal, 46(1), 73-114.

National Collaborative on Diversity in the Teaching Force. (2004). Assessment of diversity in America's teaching force: A call to action. Washington, DC: National Education Association.

National Center for Education Statistics [NCES]. (2015). Digest of education statistics, 2015. Table 209.10: Number and percentage distribution of teachers in public and private elementary and secondary schools, by selected teacher characteristics: Selected years, 1987-88 through 2011-12. Retrieved from https://nces.ed.gov/programs/digest/d15/tables/dt15_209.10.asp

National Education Association [NEA]. (2009). Strengthening and diversifying the teacher recruitment pipeline: Current efforts. Washington, DC: Author.

Noguera, P. A. (2003). The trouble with Black boys: The role and influence of 
environmental and cultural factors on the academic performance of African American males. Urban Education, 38(4), 431-459.

Oregon Department of Education [ODE]. (2016). Statewide report card 2015-2016: An annual report to the legislature on Oregon public schools. Retrieved from http://www.ode.state.or.us/data/annreportcard/rptcard2016.pdf

Oregon Education Investment Board [OEIB]. (2014). The 2014 Oregon minority teacher act status report. Retrieved from http://education.oregon.gov/wpcontent/uploads/2015/09/Minority_Teacher_Report_FNL1.pdf

Osterman, K. F. (2000). Students' need for belonging in the school community. Review of educational research, 70(3), 323-367.

Pascarella, E., \& Terenzini, P. (2005). How college affects students: A third decade of research. San Francisco, CA: Jossey-Bass.

Palmer, R. T., Wood, J. L., Dancy, T. E., \& Strayhorn, T. L. (2014). Black male collegians: Increasing access, retention, and persistence in higher education. Hoboken, NJ: Wiley.

Perna, L. W., \& Thomas, S. L. (2006). A framework for reducing the college success gap and promoting success for all. Washington, DC: National Postsecondary Education Cooperative.

Perna, L. W., \& Titus, M. A. (2005). The relationship between parental involvement as social capital and college enrollment: An examination of racial/ethnic group differences. Journal of Higher Education, 76(5), 485-518.

Ramirez, A. Y. (2010). Why teach? Ethnic minority college students' views on teaching. Multicultural Education, 17(3), 29-35. 
Reddick, R. J. (2013). From problem to prizewinners: Recalibrating perspectives on black student achievement. Texas Education Review, 1, 164-178.

Rendón, L. I. (2006). Reconceptualizing success for underserved students in higher education. Washington, DC: National Postsecondary Education Cooperative.

Rivkin, S. G., Hanushek, E. A., \& Kain, J. F. (2005). Teachers, schools, and academic achievement. Econometrica, 73(2), 417-458.

Robinson, J. J., Paccione, A., \& Rodrigue, F. (2003). A place where people care: A case study of recruitment and retention of minority-group teachers. Equity \& Excellence in Education, 36(3), 202-212.

Sawchuk, S. (2014, October 21). Steep drops seen in teacher-prep enrollment numbers. Education Week. Retrieved from http://www.edweek.org/ew/articles/2014/10/22/09enroll.h34.html

Schwartz, R. A., \& Washington, C. M. (2007). Predicting academic success and retention for African-American women in college. In A. Seidman, (Ed.), Minority student retention: The best of the journal of college student retention: Research, theory, \& practice (pp. 29-43). Amityville, NY: Baywood.

Seidman, I. (2013). Interviewing as qualitative research: A guide for researchers in education and the social sciences $\left(4^{\text {th }}\right.$ ed). New York, NY: Teachers College Press.

Sleeter, C. E. (2001). Preparing teachers for culturally diverse schools research and the overwhelming presence of whiteness. Journal of Teacher Education, 52(2), 94106.

Sleeter, C. (2008). Equity, democracy, and neoliberal assaults on teacher education. 
Teaching and Teacher Education, 24(8), 1947-1957.

Sleeter, C. E., \& Milner, H. R., IV. (2011). Researching successful efforts in teacher education to diversify teachers. In A. F. Ball \& C. A. Tyson (Eds.), Studying diversity in teacher education (pp. 81-104). New York, NY: Rowman \& Littlefield.

Stewart, D. L. (2015). Know your role: Black college students, racial identity, and performance. International Journal of Qualitative Studies in Education, 28(2), $238-258$.

Spellman, S. O. (1988). Recruitment of minority teachers: Issues, problems, facts, possible solutions. Journal of Teacher Education, 39(4), 58-63.

Taubman, P. M. (2010). Teaching by numbers: Deconstructing the discourse of standards and accountability in education. New York, NY: Routledge.

Tillman, L. C. (2004). (Un)intended consequences? The impact of the Brown v. Board of Education decision on the employment status of black educators. Education and Urban Society, 36(3), 280-303.

Torres, J., Santos, J., Peck, N. L., \& Cortes, L. (2004). Minority teacher recruitment, development, and retention. Providence, RI: Brown University, Educational Alliance.

U.S. Department of Education. (2015). Higher Education Act, Title II, State Report Card System: Academic Year 2013-14. Retrieved from https://title2.ed.gov/Public/DataTools/Tables.aspx

Villegas, A. M., \& Davis, D. E. (2007). Approaches to diversifying the teaching force: Attending to issues of recruitment, preparation, and retention. Teacher Education 
Quarterly, 34(4), 137-147.

Villegas, A. M., \& Irvine, J. J. (2010). Diversifying the teaching force: An examination of major arguments. The Urban Review, 42(3), 175-192.

Villegas, A. M., \& Lucas, T. (2004). Diversifying the teacher workforce: A retrospective and prospective analysis. In M. A. Smylie \& D. Miretzky (Eds.), Developing the teacher workforce: 103rd Yearbook of the National Society for the Study of Education (pp. 70-104). Chicago, IL: University of Chicago Press.

Villegas, A. M., Strom, K., \& Lucas, T. (2012). Closing the racial/ethnic gap between students of color and their teachers: An elusive goal. Equity \& Excellence in Education, 45(2), 283-301.

Wilder, M. (2000). Increasing African American teachers' presence in American schools: Voices of students who care. Urban Education, 35(2), 205-220.

Wilson, S., \& Youngs, P. (2005). Research on accountability processes in teacher education. In M. Cochran-Smith \& K. Zeichner (Eds.), Studying teacher education: The report of the AERA panel on research and teacher education (pp. 591-644). Mahwah, NJ: Erlbaum.

Wong, P. L., Murai, H., Bérta-Ávila, M., William-White, L., Baker, S., Arellano, A., \& Echandia, A. (2007). The M/M Center: Meeting the demand for multicultural, multilingual teacher preparation. Teacher Education Quarterly, 9-25.

Wood, J. L., \& Palmer, R. T. (2014). Academic achievement and the community college: Perspectives of Black male students on the importance of 'focus.' Journal of College Student Affairs, 32(1), 141-153.

Wood, J. L., \& Turner, C. S. V. (2011). Black males and the community college: Student 
perspectives on faculty and academic success. Community College Journal of Research \& Practice, 35, 135-151.

Yin, R. K. (2014). Case study research: Design and methods. Los Angeles, CA: Sage.

Zhan, M., \& Lanesskog, D. (2014). The impact of family assets and debt on college graduation. Children and Youth Services Review, 43, 67-74.

Zumwalt, K., \& Craig, E. (2005). Teacher characteristics: Research on demographic profile. In M. Cochran-Smith, \& K. M. Zeichner (Eds.), Studying teacher education: The report of the AERA panel on research and teacher education (pp.111-156). Washington, DC: American Education Research Association. 
Appendix A

Recruitment Documents

Flyer for Teacher Pipeline Alumni

African American Teacher Recruitment: A Case Study in Oregon

This research project is focused on obtaining a deeper understanding about the factors that contribute to the recruitment of African Americans into teaching as a career in Oregon.

Participation:

As a participant you will be asked to:

- Complete a brief pre-interview questionnaire,

- Participate in two digitally recorded interviews (60 minutes each) in a private setting, to be used solely by the researcher, and

- Review typed transcribed record of your interviews for accuracy.

In an attempt to protect your time, interviews will be scheduled at times and places (e.g., your school, local library) that are acceptable to you. Participation in these activities are voluntary.

What will be asked during the interview?

The interview questions will focus on learning more about:

What compelled you to become a teacher.

How you successfully navigated your way to and through higher education.

What you learned that could help improve achievement of other prospective African American teachers in

Oregon.

Proposed timeline:

September 2015 - January 2016: interviews

December 2015 - March 2016: participants review their transcribed interviews

Benefits:

The benefits of participating in this study may include helping to diversify the Oregon teacher workforce, specifically to increase African American representation, by providing insights into the motivations, supports, networking strategies, and optimal pathways that have led to success.

\section{Confidentiality:}

To safeguard the identity of participants, data will be kept in password protected and locked environments, and any information that is obtained in connection with this project will be kept strictly confidential. Typed transcribed texts from the audiotaped interviews will not include participant names or the names of other individuals, places, or schools. All recordings and typed transcripts will be will be destroyed within three years.

Who do I contact if I have questions about the case study?

If you are interested in participating or have questions about the case study, please contact Deborah Allen: dma@pdx.edu

503-225-1851 


\section{Email to Teacher Pipeline Alumni}

\section{Dear [Teacher Pipeline Program Alum],}

My name is Deb Allen and I am currently a student at PSU pursuing my doctoral degree. I am writing to you to see if you would be willing to participate in my research study. I have attached a flyer to this email with more detail about the study.

The overall goal of this project to is to provide a potential resource to assist the education community with the escalating need for more culturally and linguistically diverse teachers. More specifically, I would like to assist programs, like [Teacher pipeline Program], with the recruitment of more African Americans into teaching in Oregon.

\{Program Director's name] can confirm the current trend that less African Americans are enrolling in teacher education programs in Oregon, and I would like my study to provide information to help reverse that trend. I believe sharing your success story is essential to making that happen.

Please note that your participation would be confidential, your identity would remain completely protected. In addition, any information you disclose will be transcribed and you will have an opportunity to review/edit that transcription for accuracy (all names and information will be deleted or changed for privacy reasons). Please read the attached flyer for more information.

If you have any questions about my study or if you are interested in participating, please contact me: dma@pdx.edu / [phone number].

Thank you in advance for your consideration, Deb 
Appendix B

Informed Consent Form

Deborah M. Allen

Informed Consent Form

Submitted with IRB Application for Exempt Review

African American Teacher Recruitment: A Case Study in Oregon

You are invited to participate in a research study conducted by Deborah Allen, a doctoral student in the Curriculum and Instruction department in Portland State University's Graduate School of Education. As a result of the study, the researcher expects to learn about participants' aspirations, motivations, and strategies for success in pursuit of a career in teaching. The research will be used for inclusion in a dissertation and possibly shared in publications and presentations (e.g., conferences). If you decide to participate, the study includes a brief pre-interview questionnaire and two in-depth (e.g., approximately 60 minute) interviews; data from your participation will be analyzed for inclusion in the study.

Confidentiality: Any information that is obtained in connection with this study, and that can be identified with you, will remain confidential and will be disclosed only with your permission. To maintain confidentiality, pseudonyms will be used and any names of schools, employers, or other related entities will not be disclosed. Data will be kept secure on the researcher's computer, which is password protected; printed data will be kept secure in the researcher's locked home office.

Your participation is voluntary. If you decide to participate, you are free to withdraw your consent and discontinue participation at any time. If you have questions or concerns about your participation in this study, contact Deborah Allen at dma@pdx,edu, [phone number].

Your signature below indicates that you have read and understand the information provided above and that you agree to take part in this study. If you have any questions about your rights as a research participant, please contact the PSU Institutional Review Board, Office of Research Integrity, $1600 \mathrm{SW} 4^{\text {th }}$ Ave., Market Center Building Ste. 620, Portland, OR, 97201, 503-725-2227 or 1-877-480-4400.

Participant's Signature

Date

Name (please print) 
Appendix C

Pre-interview Questionnaire

In what community (city/state and neighborhood) were you born?

Where were you raised (city/state and neighborhood)?

What undergraduate institution(s) did you attend?

(Please list all, including community colleges.)

What institution(s) is your bachelor's degree(s) from?

Date of completion:

Did you have an Education Minor? Y/N

What institution(s) is your Master's degree(s) from?

Date of completion:

Where did you complete your teacher preparation program?

Date of completion (license earned):

Number of years of teaching experience (and/or administrative experience, please be specific):

How do you identify in terms of gender? 


\section{First Interview}

Appendix D

Interview Protocol

1. Tell me about your family while you were growing up. (Who did you live with? Siblings? Extended family? Role models?)

2. Tell me about your parents' (depending on questionnaire response) occupations and educational backgrounds.

3. Tell me a little about your experiences as a P-12 student. (Did you attend a lot of schools? Do you recall influential teachers?)

4. What conversations did you and your family members have about education and school?

5. What individuals, if any, played a key role in your success in P-12 school?

6. Tell me a little bit about your friendships growing up and their influence, if any, on your education or P-12 school experiences.

7. Please describe your experiences and interactions with teachers, counselors and administrators while going through elementary, middle and high school.

[Related to their expectations, trust, or cultural sensitivity?]

8. What was the school environment like during elementary, middle and high school? [Was it safe? Welcoming? How would you describe the school culture?]

9. Tell me about your involvement in extracurricular activities.

10. What types of careers did you consider while growing up?

11. What did you know about college before attending? What pre-college experiences, if any, did you have? [Early exposure to college? Bridge program?]

12. What conversations, if any, did you and your family have about paying for college?

13. How did you learned about PTP?

14. Please describe your experiences in PTP? [Finanical support? Academic support? Other types of supports? Experiences with personnel and services?]

15. What types of activities did you participate in while going to college? [Student government, Clubs, Extracurricular?] Did you work while going to college?

16. Tell me about your experiences with faculty while earning your bachelor's degree. 
17. How would you describe the undergraduate campus environments?

18. What else you would like to share about your undergraduate college experiences?

\section{Second Interview}

1. What motivated you to become a teacher?

2. Tell me about any conversations you had with others about your decision to become a teacher. For example, your family, friends, teachers, or colleagues (e.g., did they discourage you, were they supportive)?

3. Tell me about getting admitted to graduate school.

4. Please describe your experiences attending graduate school.

5. What role did the PTP play in the process of going to graduate school and earning your teaching license?

6. Please describe your experiences in preparing to become a teacher. For example, tell me about your experiences in graduate courses and your experiences as a student teacher.

7. Tell me about your experiences with faculty while earning your graduate degree.

8. What supports were most beneficial to you while you completed your graduate degree and the requirements for the teaching license? [Test prep? Academic?

Peer/Family/Community support?]

9. What else would you like to add about your experiences in graduate school and preparing to become a teacher?

10. First, why do you think there are so few African Americans in Oregon interested in teaching as a career?

11. What are your suggestions or ideas for attracting and recruiting more African American teachers in Oregon?

12. What else would you like to share with me about becoming a teacher in Oregon? 
Appendix E

Codes Families, Codes, and Subsets

(Alphabetical Order)

Code Families

Childhood / Pre-college / P-12 School

Graduate School

Undergraduate

Teaching/Career Experience

Teacher Pipeline Program

Codes and Subsets

Academic Support

Accountability

Admissions

Advising

Alumni

Campus Climate

Career Plans

Classroom Experiences

Change Agent

Colleagues

College Plans

Commitment to Student Success

Community / Relationships

Community College

Cultural Comp/Cult Relevant Pedagogy

Curriculum

Decision to Teach

Elementary/Primary

Employment/Hiring

Experiences with Youth

Extracurricular Activities

Faculty

Family/Relatives

Family Involvement

Family SES

Finances

High School

Hobbies/Activities

Like-mindedness

Mentoring
Middle School

Moving / Transitions

Neighborhood

Only one of few AA/students of color

Oregon history

P-12 Achievement

P-12 School Experiences (+/-)

P-12 Teachers (+/-)

Parents (Mother/Father)

Peers/Friendships

Perseverance

Pre-college tour/experiences

Race/Racism

Racial Identity

Resilience

Role Models

School Climate (P12)

School District

Siblings

Stigma (TPP)

Student Teaching

Student Support Services

Social Justice

Teacher Exams/Test Preparation

Union (Teaching)

Upbringing / Growing Up / Maturity

White Culture/Presence of/Privilege

White Teachers

Wraparound Approach

Work (non-teaching) 